\title{
Identit(ies) and Agency: College Students' Navigations of Sexuality and Gender in Complex Figured Worlds
}

\author{
Melissa M. Chesanko \\ West Virginia University
}

Follow this and additional works at: https://researchrepository.wvu.edu/etd

\section{Recommended Citation}

Chesanko, Melissa M., "Identit(ies) and Agency: College Students' Navigations of Sexuality and Gender in Complex Figured Worlds" (2014). Graduate Theses, Dissertations, and Problem Reports. 610.

This Dissertation is protected by copyright and/or related rights. It has been brought to you by the The Research Repository @ WVU with permission from the rights-holder(s). You are free to use this Dissertation in any way that is permitted by the copyright and related rights legislation that applies to your use. For other uses you must obtain permission from the rights-holder(s) directly, unless additional rights are indicated by a Creative Commons license in the record and/ or on the work itself. This Dissertation has been accepted for inclusion in WVU Graduate Theses, Dissertations, and Problem Reports collection by an authorized administrator of The Research Repository @ WVU.

For more information, please contact researchrepository@mail.wvu.edu. 


\title{
Identit(ies) and Agency: College Students' Navigations of Sexuality and Gender in Complex Figured Worlds
}

\author{
Melissa M. Chesanko
}

\author{
Dissertation submitted \\ to the College of Education and Human Services \\ at West Virginia University \\ Doctor of Education in \\ Curriculum \& Instruction
}

\author{
Melissa Sherfinski, Ph.D., Chair \\ Sharon Hayes, Ph.D. \\ Samuel Leizear, MSW \\ Charline Barnes Rowland, Ed.D. \\ Audra Slocum, Ph.D. \\ Department of Curriculum \& Instruction
}

\section{Morgantown, West Virginia}

2014

Keywords: Gender, sexuality, sexual orientation, gender identity, LGBTQ, identity, pansexual, bisexual, figured worlds, campus climate, queer

Copyright 2014 [Melissa Chesanko] 


\section{ABSTRACT \\ Identit(ies) and Agency: College Students' Navigations of Sexuality and Gender in Complex Figured Worlds}

\section{Melissa M. Chesanko}

In this study I conducted individual and focus group interviews in order to understand the ways in which students who identify as lesbian, gay, bisexual, transgender, and queer (LGBTQ) perceive the campus climate at West Virginia University and in what ways their experiences are shaped by that climate. Campus climate is defined as "the cumulative attitudes, behaviors, and standards of employees and students concerning access for, inclusion of, and level of respect for individual and group needs, abilities, and potential" (Rankin, 2006, p. 7).

The campus climate for students who identify as lesbian, gay, bisexual, transgender, and queer (LGBTQ) at a university is shaped not only by individual interactions, but through inclusion in curriculum, existence of LGBTQ-specific support, domestic partner benefits, policies on non-discrimination, equal opportunity, and housing, among other factors. By taking an intersectional approach that considers the ways in which sexuality, race, gender, class, and other identity markers come together, this research uses a framework that draws especially from identity and agency in cultural worlds (Holland, 1998), from which to understand the ways in which individual student experiences are shaped, influenced, created, reflected, and/or formed in relation to the climate that they perceive. Rather than viewing identity through a singular lens, the term identit(ies) shows the ways in which multiple aspects of one's identity comes together to form one's complete identity, expressing simultaneously the components and the whole.

There was much to be learned from this study, in the categories of curriculum findings, figured world findings, and identity findings. This study found that the collective lens of curriculum is greater than the individual lens and the role of a single person in improving curricular inclusion. It also found that students self-author in figured worlds and that the figured world of gender non-conforming students is substandard. Finally, the study found that nonmonosexual students occupy position identities and that agency is dependent on intersectional access.

The study carries implications that are divided into three categories, that of conceptual implications, methodological implications, and practical implications. The conceptual implications of this study include: language implications, climate influences whole person identity, exclusion from curriculum is political, and that dialogue is capable of generating critical thinking. The methodological implications include participant advertising and selection, structured post focus group feedback, researcher identity and interaction implications. The practical implications include: supporting trans* and gender non-conforming students, supporting the cultural worlds of panels, providing spaces for reflection, and supporting a whole person identity. 
IDENTIT(IES) \& AGENCY iii

\section{Dedication}

To everyone who was willing to share their stories for this study. Thank you for your openness in sharing your life with me and the reader. This is also dedicated to those whose stories are not told within this research, especially to those whose stories still remain untold to anyone.

"The fact that we are here and that I speak these words is an attempt to break that silence and bridge some of those differences between us, for it is not difference which immobilizes us, but silence. And there are so many silences to be broken." - Audre Lorde 


\section{Acknowledgements}

I would like to first acknowledge my advisors, who have helped me through this journey sharing their knowledge at varying points along the path. To my chair, Dr. Melissa Sherfinski, thank you for believing in my study, my abilities and my work. You trusted me and allowed me to thrive within that trust. To the rest of my committee, Dr. Charline Barnes Rowland, Dr. Sharon Hayes, Dr. Audra Slocum, and Mr. Samuel Leizear, you have provided support and feedback. I'd also like to thank the instructors I've had along the way and those who have worked with me on my research through my time here at West Virginia University. Specifically, I'd like to thank Dr. Donna Breault for your assistance in drafting my prospectus and Dr. Adriane Williams for getting me to this point and for giving so much of yourself while you were here at WVU and even long after. I will continue to carry the lessons you taught me.

I would most certainly not be here without the support of my family. I would like to thank my grandmother, Rosalie Price, for being my inspiration to move to Morgantown and how fortunate I was to spend time with her, as well as my Uncle Teener (Norman Claudio) before they each passed away. All of my family instilled in me a love for West Virginia and an appreciation for hard work, whether it is in coal mines, grocery stores, or classrooms. I'd like to thank my Aunt Betty and Uncle Connie Mantini and Uncle Carl and Aunt Barbara for all they've done for me and all the support they've provided to our family. I'd like to thank Betty Chittum all the training and conferences I've been able to attend; I couldn't have done without your uncompromising care of Greta. And last, but certainly not least, I'd like to thank my mom, Janice Price, who has always said she was my biggest fan and has always been there to support me. She could see the end goal even when I lost track of them and believed in me even when I was uncertain. 
I owe a debt of thanks to those who have helped me gain invaluable experience in higher education while I completed this work. Thank you to Mr. David Fryson and everyone at the Division of Diversity, Equity and Inclusion for all of the opportunities within that office. Thank you to everyone at the Center for Women's and Gender Studies. That first opportunity to teach seven years ago is what inspired all of this work and the autonomy and pedagogical authority given by the department allowed me to shape my own instructor identity. Special thanks to Dr. Kasi Jackson and to Cathy Jasper for all that you gave over my time at WVU. Thank you to the School of Social Work for the opportunity to teach one of the best classes ever, Human Sexuality and Social Work Practice.

I'd like to acknowledge everyone at WVU working towards justice for gender and sexuality as part of, but even more so, above and beyond the roles of their jobs. Most notably I'd like to thank Dr. Brian Jara for all your work and personal support since you have been at WVU. Brian, your arrival at WVU was the stuff of legends, like Dorothy to Oz, and I have certainly felt a greater sense of community doing this work since you've been here. I'd also like to thank T. Anne Hawkins for everything that you continue to do and for reminding me to breathe. Thank you to the original Vagina Warrior Ruth Kershner for unconquerable fortitude and for your solid dissertation-writing advice. Thank you Deb Beazley for all your work with Safe Zone. Additionally, I'd like to thank everyone who has worked to improve the campus climate through the following organizations: the LGBT Alumni Group, the WVU Commission for LGBTQ Equity the Gender Equality Movement, and Spectrum. To all of those who participated within the educational panels, thank you for sharing your stories and your experiences and for opening dialogue on campus. 
I have been lucky and privileged to meet and work with many others doing work to support LGBTQ students, faculty and staff across the country. I'd like to acknowledge all of the wonderful folks that I have met through Campus Pride, the Consortium for Higher Education LGBT Resource Professionals, and the Creating Change Conference. The professionals and the students I met all inspire me in ways simple and profound on a daily basis and your work encourages me to keep going as well. A special thank you to Grace Nichols for your beautiful spirit and for being an inspiration, both personally and professionally.

My academic journey began with much of the strong foundation that I gained from my academics and activism during my undergraduate degree. I would like to thank Dr. Suey Spivey for her inspiration and strong structural foundation in understanding justice. I would like to thank Becca Martin for being there from the beginning of our activist roots at Harmony meetings, our participation in educational panels, potlucks, protests, planning and so much constructing and (de)constructing of our own identit(ies). Thank you for always being there for me - right down to the very end, helping with edits and clarity of vision even from halfway around the world. Very few people would give real-time feedback from Hong Kong to West Virginia and I owe you a debt of gratitude. All my love to you and Joy and your families.

A huge thank you to all of my friends for listening, supporting, and encouraging me through this process. Special thanks to Allison Pack. You always know how to break it down and keep me grounded. To everyone who has supported me in small and large ways, thank you to Elizabeth, Hannah, Allyson, Raymond, Kombe, Ellen, among others; and to everyone who supported me through social media, cups of coffee, lunches, events, meetings, emails, and other little moments of encouragement: thank you. All of these added up and kept me going. To my classmates who have gone before me or alongside me in their journeys and inspired me, thank 
you; Gaby, Wu, Brandi, Saya, and Sera, among others. Sera, I credit this topic to that one conversation we had over coffee two years ago. Thank you for your support. To those who helped me in the naming of this dissertation and working through the concept of identit(ies) you gave me plenty to consider and certainly kept it entertaining, thank you, especially to Jesse and Faye!

I would not have made it through this process without the following: copious amounts of coffee, my dog Greta, and Netflix. Finally, in the words of Ani Difranco, "I've got more than one membership to more than one club and I owe my life to the people that I love." I also recognize that while this paper is complete, the actual work of life is not done - in the classic words of Ice Cube, "Life ain't a track meet, it's a marathon." 


\section{Table of Contents}

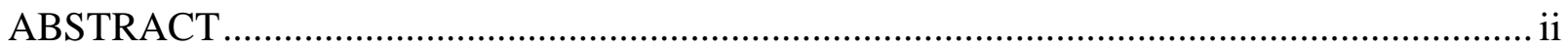

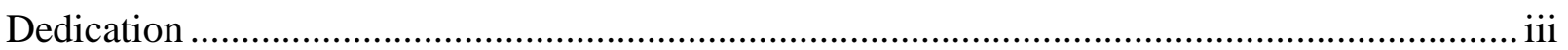

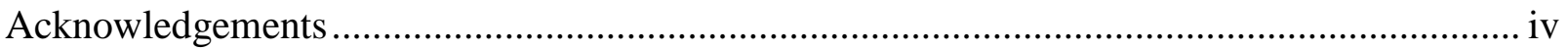

Table of Contents

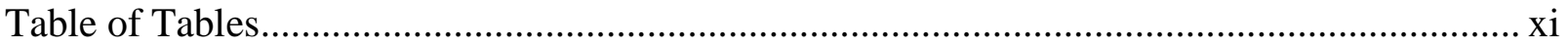

Table of Figures

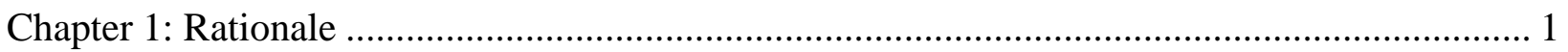

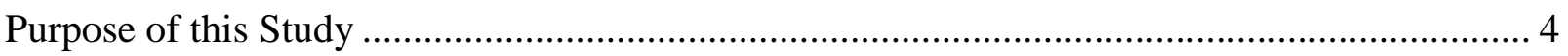

Context of Language in the Study ............................................................................ 4

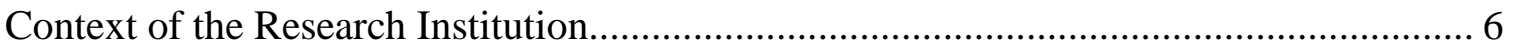

Campus Climate

LGBT Policy Inclusion and Institutional Commitment............................................... 13

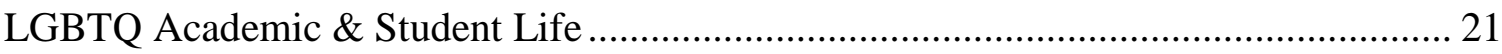

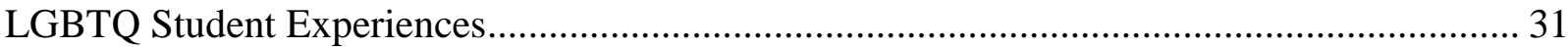

LGBTQ Youth \& Adolescent Experiences..................................................................... 34

LGBTQ Student Vulnerabilities and Resiliencies ........................................................ 35

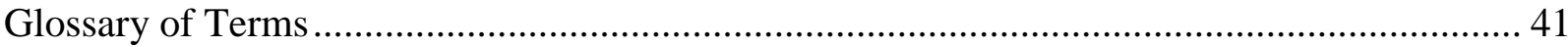

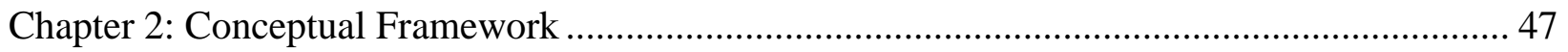

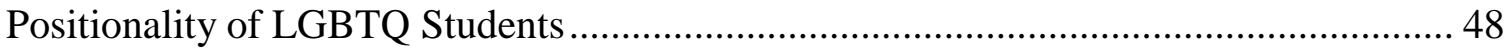

Identity and Agency in Cultural Worlds ................................................................... 50

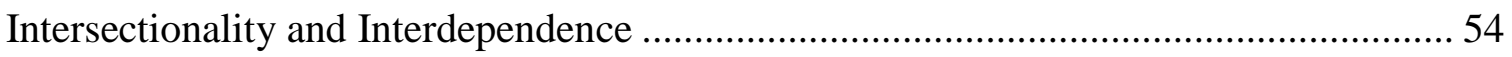

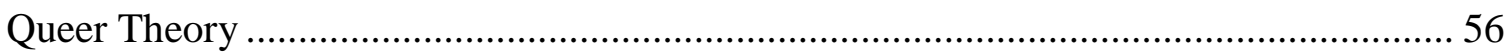

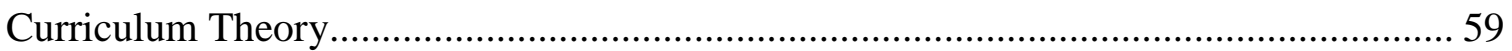

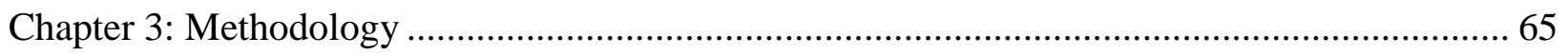

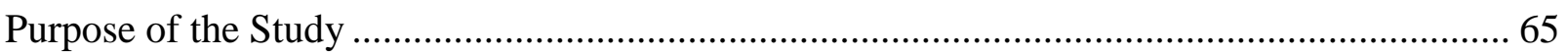

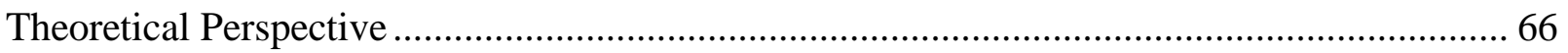

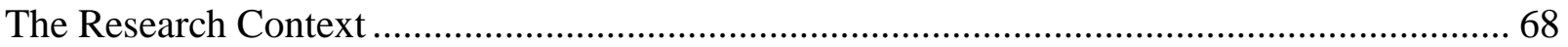

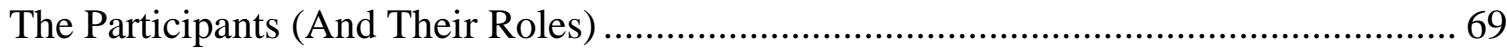

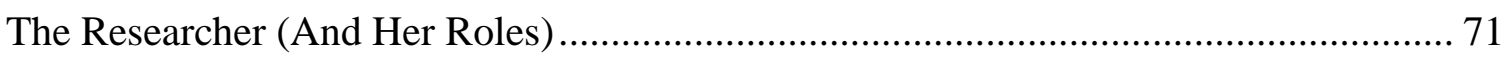

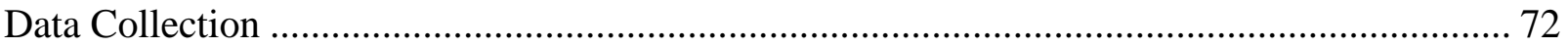

Data Sources: Individual Interviews ...................................................................... 76

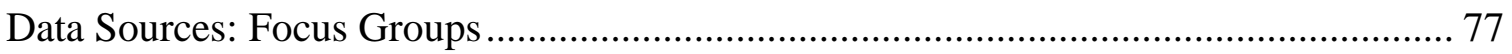

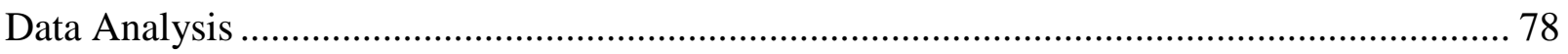




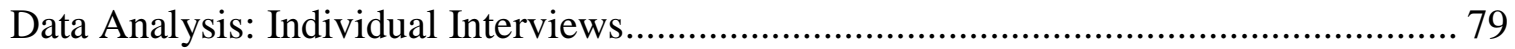

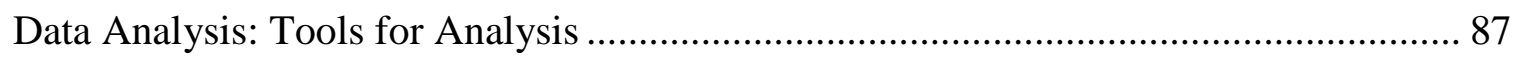

Analyzing the Researcher's Roles through Analysis Tools............................................ 92

Monitoring for Subjectivity ............................................................................... 100

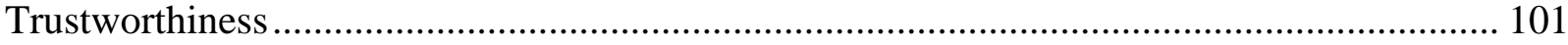

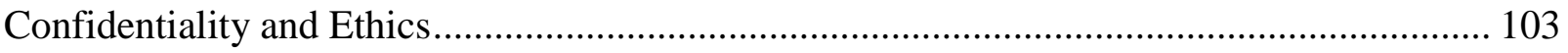

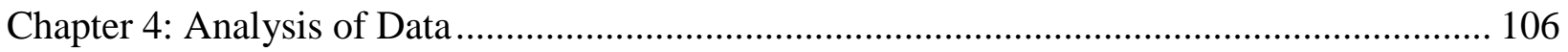

Participant Identity (De)Construction .................................................................................... 107

The Figured Worlds of Campus Climate and Curriculum .................................................. 110

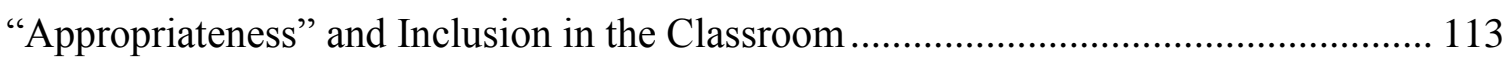

Figural Identities: The Role of One Person ................................................................ 116

Gender Identity and the Figured World ................................................................ 119

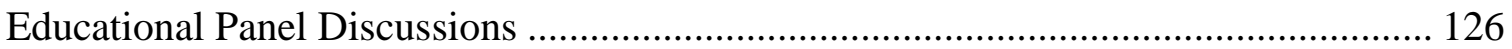

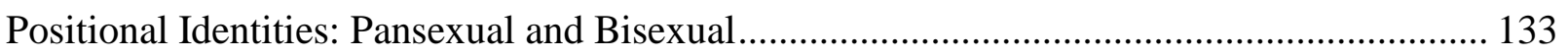

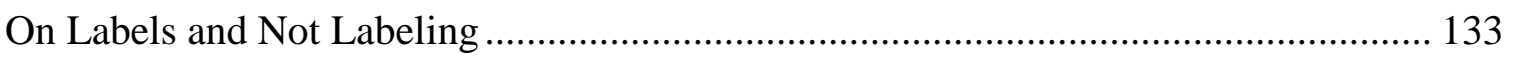

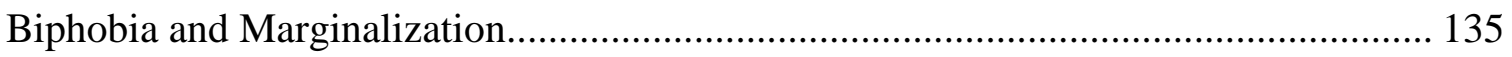

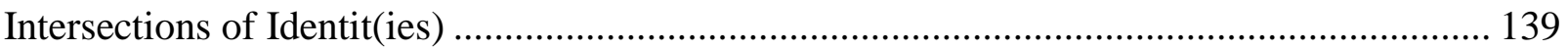

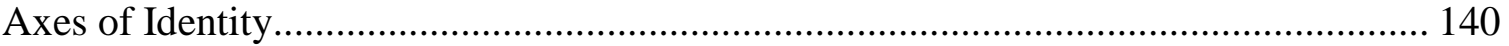

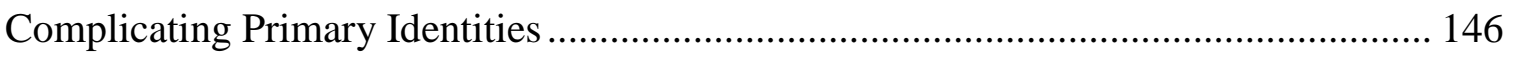

Chapter 5: Discussion of the Findings, Implications, and Conclusions ..................................... 151

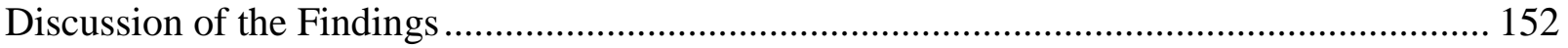

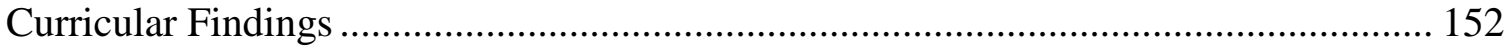

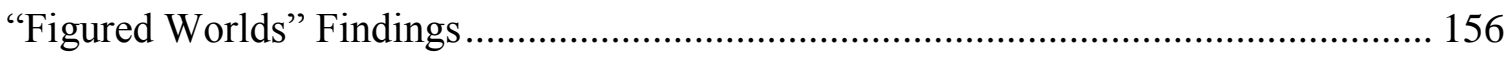

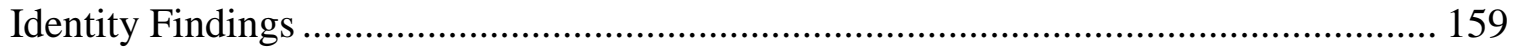

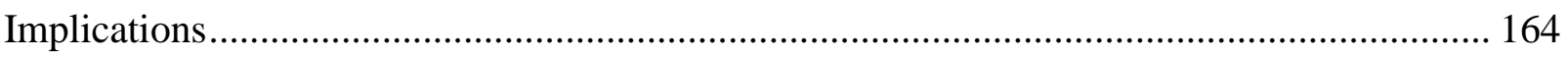

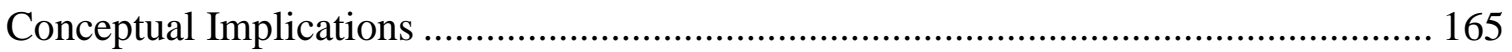

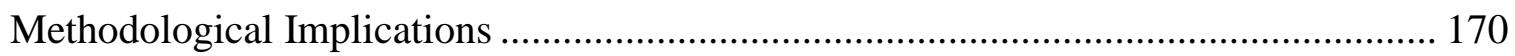

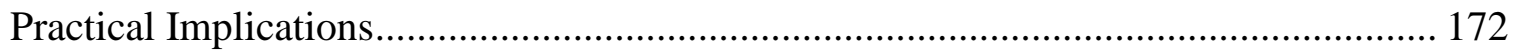

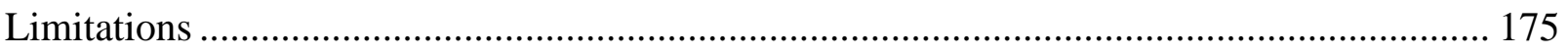

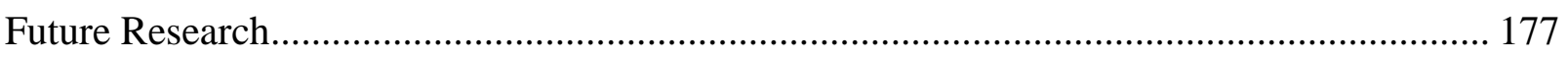

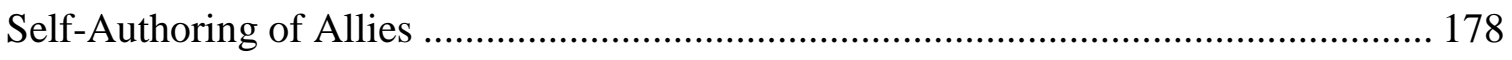

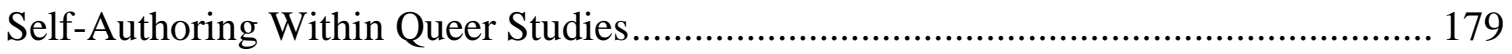

Gender Non-Conforming Student Experiences ......................................................... 179

Meeting the Needs of 'Invisible' Identities ................................................................ 180

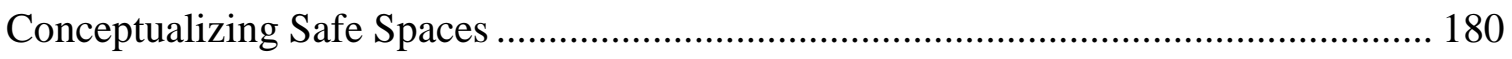

Full Campus Climate Assessment ………………….............................................. 182 


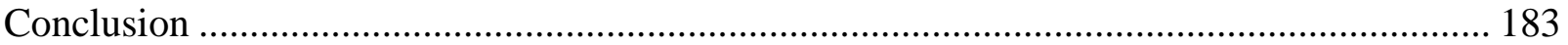

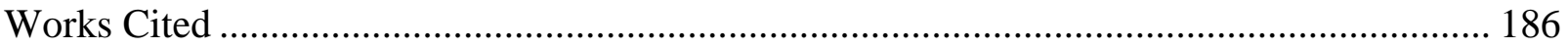

Appendix A: Demographic Questionnaire .................................................................... 200

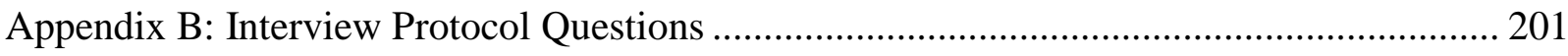

Appendix C: Focus Group General Protocol Questions ......................................................... 203

Appendix D: Focus Group A Protocol Questions.................................................................. 205

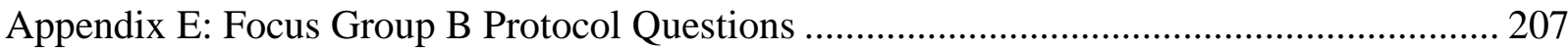

Appendix F: IRB-Approved Advertisement ...................................................................... 209

Appendix G: IRB-Approved Consent Form ……………............................................. 210

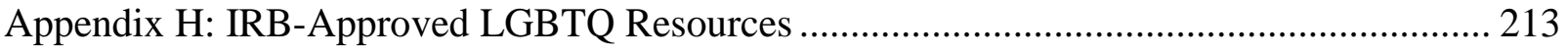

Appendix I: D'Augelli's Model of Identity Development....................................................... 214 
IDENTIT(IES) \& AGENCY xi

\section{Table of Tables}

Table 1: Participant Selection and Focus Group Participation ..............................86

Table 2: Gee's Identity as a Lens for Discourse Analysis Tool.........................91

Table 3: Participant Identit(ies) and Focus Group Participation........................... 108 


\section{Table of Figures}

Figure 1: Conceptual Framework....................................................... 47

Figure 2: Identity and Agency in Figured Worlds......................................53

Figure 3: Identit(ies) and Agency in Figured Worlds.................................... 87

Figure 4: Figured World Understandings.............................................112 


\section{Chapter 1: Rationale}

On November 2, 2011 the Student Government Association (SGA) at West Virginia University (WVU) passed Resolution 2011-06 to voice their support on adding gender identity to all of the University's social justice policies, encourage administrative participation in campus climate surveys on lesbian, gay, bisexual, transgender, and queer (LGBTQ) issues and begin investigating the feasibility of establishing an LGBTQ advocacy office or administrator (Chesanko, 2011b). I was in attendance at the meeting for the proposal of Resolution 2011-06 and, while much support was given from the audience, there was opposition within the SGA with many university governors expressing concern about the cost of the proposal and one governor saying, "an office separate from the WVU Queer Student Union was an unnecessary expense" (Clark, 2011). The WVU Queer Student Union (QSU) is a student organization, run for and by students. The opposition to a paid, professional position to work with LGBTQ students was based on the idea that this is something that students can and should do for themselves. At another point in the meeting, a governor stated that they "could see that gay students care about this and showed up," gesturing to a particular area within the room, showing a certain level of assumption of who identifies as LGBTQ and, perhaps, not seeing others.

The lack of institutional support for gender and sexuality issues at West Virginia University is not based solely on the lack of existence of an LGBTQ center or professional. By looking at past inclusion or omission of identities within diversity events, it is clear that some LGBTQ students have felt silenced and ignored. One student wrote a column within the student newspaper about an administratively-sponsored event on campus to promote diversity, that "rather than raise awareness of pivotal social justice issues and instigate change, the [stated] goal was to make people feel happy and calm," which she called a "patronizing pat on the head for 
people who truly seek to make a difference" (Prentice, 2012). She went on to say that "as a member of the LGBTQ community, (she) felt marginalized and ignored rather than celebrated and understood." She further stated: “As a woman, I was offended and angered by the patriarchal tone of the story that was chosen as entertainment" (Prentice, 2012). Prentice concluded that, "though the organizers claimed to be honoring people who strive for progress, in reality the event itself pointed out just how far behind our campus is in recognizing, celebrating, and understanding diversity." While these are just a few examples of students making their voices heard within the avenues available to them, there has not been a venue from which students can consistently voice their experiences on campus. The power rests with dominant identities and institutionalized power, leaving students relatively powerless against the larger campus climate.

I want to understand the impact on students who identify as LGBTQ and other nonmajority identities based on sexual orientation and gender identity of this imposed role of students as the professional resource on campus, the lack of institutional support, and the simultaneous invisibility of some identities and individuals while assuming the LGBTQ identity of others. A variety of factors come together to create the climate of the campus in which students live and learn. This climate is then perceived and experienced differently by students based on their own position and personal identity within the campus. Campus climate affects all students, but it has a distinctive impact on lesbian, gay, bisexual, transgender, and queer (LGBTQ) students. It is important to the success of students and the overall success of the institution that educators understand the ways in which the campus climate impacts the lives of the students at the institution.

Campus climate exists on a macro level and consists of many factors that are determined 
on an institutional level. While these factors affect people on a very real individual level, the climate itself is seen to be much more systemic. There are no consistent definitions of campus climate and most research on campus climate has been conducted based on racial and ethnic minorities (Hart \& Fellabaum, 2008). Within recent years though, more research has been done on college campus climates in relation to LGBTQ students at individual institutions and at universities in the United States at large (Blumenfeld, 2012; Brown, Clark, \& Gortmaker, et al., 2004; Brown \& Gortmaker, 2009; Messinger, 2009; Poynter \& Washington, 2005; Rankin, 2006; Rankin, Weber, \& Blumenfeld, et al., 2010). The campus climate affects not only LGBTQ students, but also the entire student, faculty, and staff populations. Much of this research focuses on student experiences across an entire campus or uses data from multiple institutions within the same study. Any single institution of higher education can often be quite large in terms of the physical space, but also in the ways in which students' experiences can be fragmented based on the microclimates of the campus or university to which they are the most connected and exposed and their roles within the campus (Vaccaro, 2012). Many studies have been conducted on the experiences of students who identify as LGBTQ within higher education (Beemyn, Curtis, \& Davis, et al., 2005; D’Augelli, 2006; Gortmaker \& Brown, 2006; Harley, Nowak, \& Gassaway, et al., 2002; Joyce, 2007). Research has been conducted on the strategies and best practices to most improve the LGBTQ student experience and on improving the overall campus climate. However, there is little research assessing the ways in which students view and perceive their experience within the context of the overall campus climate (Campus Pride, 2013; Rankin, 2006; and Rankin et al., 2010). The way in which these experiences are situated is shaped by many factors, including the context of the university at which this study is being conducted and the overall political and policy implications that affect all of these. 


\section{Purpose of this Study}

In this study I asked, "How do students who openly identify as lesbian, gay, bisexual, transgender, and/or queer (LGBTQ) perceive the campus climate at this university and in what ways are their experiences shaped by that climate?" Within this study I wanted to understand the ways in which individual LGBTQ student experiences were shaped, influenced, created, reflected, and/or formed in relation to the climate as they perceived it. This study focused on sexuality and the ways in which the visibility/invisibility or intentional exposure/erasure of sexual orientation and gender identity on a college campus have, or have not, affected LGBTQ students. I especially tried to understand the ways in which students perceive they have altered their behaviors in order to compensate for their perception of the campus climate and the ways in which their perceptions have been shaped not only by their own experiences, but also by their perceptions of the experiences of other LGBTQ individuals. This study was not a full campus climate assessment, but one focused on students' perceptions of campus climate to more fully understand their experiences. As "very little research exists on how LGB students perceive their broader college experience" (Longerbeam, Johnson, \& Inkelas, et al., 2007, p. 215) and because it is particularly important to connect the experiences of LGBT students to their environment, this study was designed to add to that literature.

\section{Context of Language in the Study}

The language used when discussing sexual orientation and gender identity in a college context is constantly shifting. I chose for the purposes of this study to use the acronym LGBTQ, which is inclusive of lesbian, gay, bisexual, transgender and queer (or sometimes termed questioning) identities. I recognize that this particular verbiage may become dated as our collective consciousness surrounding sexual orientation and gender identity expands and 
matures. However, at the time of this study, within this particular context, this is the acronym that best seemed to work with the population. The choice of LGBTQ reflected the language used by students at this particular institution. Within the past few years, the student organization adopted this acronym. It is therefore a reflection of the environment and student experience. Acronyms and additional terms that are used throughout the study are listed in a glossary at the end of chapter one.

Within this study, I wanted study to be inclusive of all students who identify in any way as a non-heterosexual and/or non-cisgender identity, including but not limited to lesbian, gay, bisexual, transgender, transsexual, queer, pansexual, and/or same-gender loving. Therefore, in the presentation of the study to the student population for recruitment purposes I chose to use this more specific and inclusive language. For the purposes of the literature review and to allow easier discussion within the rational, the acronym LGBTQ was used because it encompasses, for the most part, the context of experiences of individuals based on sexual orientation (gay, lesbian, or bisexual), gender identity (transgender) and the fluidity among and within both of these (queer). In studies that only looked at a smaller portion of the acronym, such as lesbian, gay and bisexual individuals, the acronym may be changed to reflect that, such as LGB. All acronyms used for various studies are defined in the glossary at the end of chapter one. It should be noted that although the acronym LGBTQ has often been used in studies to inclusively discuss the experiences of students with minority sexual orientation or gender identity status, there is often a lack of visibility given to bisexual and transgender persons and they are often excluded within segments of gay and lesbian communities (Harley et al., 2002). Therefore, even when the LGBTQ acronym is used, it was important to pay attention to the ways in which the experiences of all segments of the population were or were not fully understood. I wanted to be conscious of 
this common blanketing of identities that can leave out the experiences of segments of people within an already marginalized population.

Overgeneralizations among populations have been reported frequently in research looking at LGBTQ students' experiences. Dugan and Yurman (2011) found that within research on LGBTQ student experiences found that there were more nuanced within-group differences, but that for the purposes of quantitative research there can be a "foundational rationale for the appropriateness of collapsing LGB students into a single category in quantitative analysis" ( $\mathrm{p}$. 212). They did, however, suggest for future research it is worthwhile to begin investigations by looking for within-group differences and that further research should be conducted that look at the interactions between sexual identity development and the college campus environment (Dugan \& Yurman, 2011). Since this research was qualitative in nature, the appropriateness of collapsing students' experiences was not present. Therefore, while I will often use an acronym to refer to the group, I was mindful of the individual experiences within the group and, in fact, integrated this into the methods. I was also consistently aware of the ways in which gender, gender identity, sexual orientation, development level, and salience of identities play into these experiences. While this is the acronym and language primarily used within the literature review of the study, the language used within the analysis and findings of this study is expanded to be representative and reflective of the expressed identities of the participants of the study.

\section{Context of the Research Institution}

This study was conducted at West Virginia University (WVU) and the context of the research institution and the state in which it is situated is important to understand for the purposes of the study. Research has shown that the areas that are more likely to adopt antidiscrimination laws on sexual orientation are those that are more educated, less religious, and 
more urban (Klawitter, 2011). West Virginia is situated as an area that does not fit within any of these demographics. Further, the geographical areas which support adopting policies most favorable to anti-discrimination are those where these laws have public relevance, the scope of the debate is broad, interest groups have resources, policy entrepreneurs take an active role, and the issue is framed in a practical way (Klawitter, 2011).

Most of these considerations are arguably not present around the institution in question, making it among those areas that are less likely to adopt anti-discrimination laws. The state is overall less educated, more religious and more rural, has fewer resources, and is often swayed by the powerful resources of the coal industry. The state is less educated, as according to the U.S. Census Bureau (2013), West Virginia had a high school graduation rate of $82.6 \%$, which was less than the U.S. average of $85.4 \%$ and the bachelor degree completion rate was an even greater contrast with West Virginia at $17.6 \%$ and the U.S. average at $28.2 \%$. Basing education not just on attainment, but on quality as measured by scores and the priority put on education, the state was among the lowest in the nation when comparing K-12 education. West Virginia ranked $47^{\text {th }}$ in the nation for teacher pay with a salary of $\$ 44,260$ for $2010-2011$, which was at $80.6 \%$ of the national average (NEA, 2012). The state is more religious than average. In a poll conducted by the Pew Forum on Religion \& Public Life in 2009, West Virginia was ranked $15^{\text {th }}$ of all states in importance of religion in their lives based on self-report of worship attendance, frequency of prayer, and belief in God. Of West Virginia's total population, 75\% align themselves with one of the following three religious traditions: Evangelical Protestant, 36\%; Mainline Protestant, 32\%; and Catholic, 7\% (Pew Forum, 2010).

Robinson and Spivey (2010) argue that the "ways in which partisan politics and state regulation impact policymaking governance $[s i c]$ on campuses have not been a significant focus 
in explaining the chilly climate for LGBTQ people in higher education" (p. 1309) but that these should be considered. Carnoy (1989) said that at American public institutions there can often be a struggle between the changing structure of the labor market and the various social movements seeking greater equality. These political pressures can be present in the role of interest groups, and many universities have themselves opened Washington offices to lobby for their own interests (Smith et al., 2008). One difference between higher education and its commercial counterparts is that "higher education rarely can reach a common position when confronted with disputes among its diverse members and thus higher education usually fails to take action on contested issues" (Smith et al., 2008, p. 109). This slowness to act at an institutional level was seen at the research site during data collection. The struggle for equity among LGBTQ students, faculty, and staff had been active among key players for at least the past decade. Two recognized organizations exist on campus, one for LGBTQ students and one for LGBTQ faculty, staff, and doctoral students. In 2013, the student organization changed its name from Queer Student Union (QSU) to Spectrum. It had undergone a name change in 2011 from BiGLTM (Bisexual, Gay, Lesbian, and Transgender Mountaineers) to QSU. The student organization focuses on social needs, support, and, to a lesser degree, political activism. A new student organization was established in the spring of 2013 called Mountaineers for Equality to work "toward equality for all individuals, regardless of sexual orientation and gender identity" (Merithew, 2013). WVU's faculty group is named Common Ground and is geared mainly towards university policy and issues that directly affect those employed by the institution. Along with non-affiliated members of the campus community, these groups have argued that policies are not meeting the social justice needs of the campus and have worked towards changes in these over the past few years. These include benefits for domestic partners and inclusion in the social justice policies on non- 
discrimination and equal opportunity.

There are many ways in which individual motivation and collective action interact within policy and a theoretical and conceptual background can help to frame these interactions. Wildavsky (1997) explains that motives may be based on self-interest. Some of the attempts to further LGBTQ social and political equality at West Virginia University have been the result of an individual's experiences with inequity, or self-interest (Brewster, 2011; Prentice, 2012). Further, morality depends not on the motivation, but on the social interaction between motivation and individual actions and that collective objectives are not set, but rather are by-products of the individual interactions; meaning, then, that public objectives are the "collective consequences of private acts" (Wildavsky, 1997, p. 26). While some of the private acts executed as an attempt to change public policy on campus at WVU are published, such as opinion articles, many more remain unknown to the general public, such as meetings, conversations, and personal communications. While not always visible, the impact of these behind the scenes interactions must not be understated. When it comes to LGBTQ social issues especially, "political preferences are personal" (p. 31) and these belong to individuals or a group thereof and are continually undergoing change (Wildavsky, 1997). This is also further complicated by the distinctly personal nature of an individual's views on sexuality. One possible cause behind the difficulty in discussing LGBTQ issues at a university level is the idea that many individuals within and outside of the LGBTQ community may hold the belief that "one's (LGBT) sexual orientation is a private matter not to be discussed in a public venue" (Joyce, 2007). Indeed within workplace cultures of diversity, silencing of sexual orientation is among one of the aspects of diversity which is still seen as acceptable to silence (Bell, Ozbilgin, \& Beuregard, et al., 2011). There are several types of silencing, such as quiescent silence, which is based on fear; 
acquiescent silence, which is based on resignation; pro-social silence, which is based on altruism or cooperative motives; and a culture of silence, which means that there are "widely shared perceptions among employees that speaking up is not worth the effort or is downright dangerous" (Bell et al., 2011, p. 135). To put this another way, for LGBT employees, the "ability to be 'out' at work and to have the same rights, benefits, and privileges of everyone else is a key aspect of voice" (Bell et al., 2011, p. 136).

\section{Campus Climate}

The climate students experience consists of many components. Rankin (2006) defines campus climate as "the cumulative attitudes, behaviors, and standards of employees and students concerning access for, inclusion of, and level of respect for individual and group needs, abilities, and potential" (p. 7). In the case of this study, the climate is referring specifically to the cumulative attitudes, behaviors, and standards related to access, inclusion of, and level of respect for lesbian, gay, bisexual, transgender and queer individual and group needs, abilities, and potential. Individuals encounter unique challenges due to their sexual orientation, gender identity, or gender expression that often prevents them from achieving their full academic potential or participating fully in the campus community (Rankin, 2006). The need for resources directed specifically towards LGBTQ students has been recognized more and more over the past several decades and in 2002 Campus Pride was established. Its primary objective is "to develop necessary resources, programs and services to support LGBT and ally students on college campuses across the United States" (2013). Combining the networking ability of the national Campus Pride organization and the research capacity of the Q Research Institute for Higher Education resulted in the comprehensive document "2010 state of higher education for lesbian, gay, bisexual, and transgender people," a review of college campus climate surveys, one of the 
most extensive ways of understanding the state of higher education for LBTQ students (Rankin, et al., 2010). This assessment found that LGBTQ respondents experienced significantly greater harassment and discrimination based on their sexual orientation or gender identity, respectively, and were more likely than non-LGBTQ identified respondents to have negative perceptions of campus climate. Individuals who identified as a minority based on multiple aspects of their identity, such as LGBTQ students of color, were found to encounter multiple forms of oppression and were at a higher risk for having negative perceptions of campus climate than those who identified as a minority in one or no aspects of their identity, such as white heterosexual students.

Further, LGBTQ individuals demonstrated more behaviors that were in response to the campus climate, such as considering leaving the school, avoiding certain locations, and avoiding disclosure, and LGBTQ individuals were more likely to disagree with the institution's policies, procedures, programs and curriculum than non-LGBTQ identified individuals. Interestingly, in comparing the experiences of LGBTQ students, faculty, and staff, the "analysis indicated that students were at the highest risk for experiencing conduct that interferes with their ability to live and learn on campus" (p. 11). However, it was found that LGBQ faculty members had "more negative perceptions of campus climate than their LGBQ student and staff counterparts" and were more likely to consider leaving the institution (p. 14). The fact that students experience the most interference in their lives, but faculty members were more likely to have negative perceptions and consider leaving raises many questions about perception, resources, and position within the campus structure. For instance, do students have the impression that this is just the nature of the campus climate and they must deal with it as it is? Do faculty members have more power to change their own lives in response to campus climate, whereas students do not have the 
power to make major life changes based solely on the campus climate? Or, what other explanations are there for this distinction? If students are experiencing conduct that interferes with their ability to live and learn, but they are not leaving, then how are they coping with this? Does one's concept of 'permanence' versus only being at an institution a given amount of time influence this perception? How are members of the faculty and the administration helping students to cope — and are they? How do identity and individual positionality relate to all of these experiences?

Campus Pride (2013) has an LGBT Friendly Campus Climate Index National Assessment Tool which can be completed by an approved campus administrator to determine the university's ranking in the following areas: LGBT policy inclusion, LGBT support and institution commitment, LGBT student life, LGBT academic life, LGBT housing, LGBT campus safety, LGBT counseling and health, and LGBT recruitment and retention efforts. This would be one way in which the university could improve its efforts towards outreach to LGBTQ students, faculty and staff, as well as begin to understand the areas in which improvements could be made. While many of these measurements are not within the scope of possibility for this study and are generally assessed by individuals within the system, specifically administrators, it is worth noting the lack of any institutional campus climate studies at the institution to the point of this study. Since these are the main categories used by many college campuses in assessing the climate, I considered them important to understand from the perspective of the subjects of this study. In balancing these categories with the scope of this study, a few of these categories were considered in greater depth. Because this study focused on individual students' experiences and the context of the campus climate, research on LGBTQ policy inclusion and institutional commitment, LGBT academic and student life, and the correlation of attitudes regarding sexual 
orientation and gender identity are all important to understand within this context.

\section{LGBT Policy Inclusion and Institutional Commitment}

Creating policies that are inclusive of LGBTQ students, faculty, and staff is important for cultivating a safe and positive campus climate and experience for LGBTQ individuals (Joyce, 2007; Klawitter, 2011; Rankin et al., 2010; Robinson \& Spivey, 2010; Widlavsky, 1997; Zemsky \& Sanlo, 2005). The inclusion of sexual orientation and gender identity into policies encourages discussion about these issues in a variety of settings within the university and can lend an air of importance to the issues that individuals face (Zemsky \& Sanlo, 2005). The Campus Pride study on the "2010 State of Higher Education for Lesbian, Gay, Bisexual, and Transgender People," used the findings on student, faculty, and staff experiences in correlation with the resources available on campuses to determine the best practices in providing LGBTQ individuals with positive experiences (Rankin et al., 2010). The first recommendation is that institutions develop inclusive policies so that individuals feel more comfortable knowing they are supported by their institutions and are able to be more satisfied and productive because they are not hiding their identity. Non-discrimination policies, equal opportunity policies, and domestic partner benefits are most directly linked to legal and structural consequences and are affected by inclusion or non-inclusion of sexual orientation and gender identity. While not as directly tied to university policy adoption, the inclusion (or lack thereof) of sexual orientation and gender identity has direct effect on LGBTQ students in more subtle ways such as within statements on diversity, inclusion and/or social justice, the language used on university websites, statements on syllabi, and other official university documentation. Campus Pride also recommends that universities demonstrate institutional commitment by using inclusive language on documents and responding procedurally to acts of intolerance (Rankin et al., 2010). 
LGBT policy inclusion and institutional commitment can be seen as a part of a larger goal of diversity and equity within higher education. West Virginia University has developed a 2020 Strategic Plan for the Future, which states as its mission:

As a land-grant institution in the 21 st century, West Virginia University will deliver highquality education, excel in discovery and innovation, model a culture of diversity and inclusion, promote health and vitality, and build pathways for the exchange of knowledge and opportunity between the state, the nation, and the world (West Virginia University, 2013d).

The third goal in meeting this mission is to foster a diverse and inclusive environment (West Virginia University, 2013d). This goal states that the university will "become a model institution for the attraction and inclusion of diverse groups," and will "integrate diversity broadly into the curriculum," and will "create an integrated administrative infrastructure to promote diversity, inclusion, equality, and intercultural and intercommunity outreach" (West Virginia University, 2013d). The 2020 Strategic Plan for the Future was unanimously endorsed by the WVU Board of Governors in February of 2011 (University Relations, 2011). The relevance of the WVU Strategic Plan for the Future to LGBTQ institutional commitment can be seen specifically within non-discrimination policies, equal opportunity policies and domestic partner benefits, as can these be applied to a broader perspective of LGBTQ student experiences within a university context.

Non-discrimination/equal opportunity policies. Colleges and universities create their own statements of non-discrimination and equal opportunity. For public universities, these must include the minimum guidelines set by the Federal Government, but schools can choose to make their statements more inclusive. Based on self-report through the employer database of the 
Human Rights Campaign, 567 colleges and universities offer protection against discrimination based on sexual orientation and 96 also include gender identity (Messenger, 2009). However, a more extensive listing with the Transgender Policy Center shows that there are at least 632 colleges and universities within the United States that include gender identity in their nondiscrimination statements (2013). LGBTQ faculty and staff respondents in the Campus Pride study stated that they more often experienced discriminatory employment policies, as opposed to non-LGBT faculty and staff respondents (Rankin et al., 2010).

West Virginia University includes sexual orientation, but not gender identity, within its non-discrimination policy. The policy includes "race, sex, age, disability, veteran status, religion, sexual orientation, color, or national origin in the administration of any of its educational programs, activities, or with respect to admission or employment" (West Virginia University, 2012a). Inclusion in non-discrimination and equal opportunity policies are not the same as affirmative action policies, as simply providing a discrimination-free workplace does not mean that there are any quotas or direct penalties enacted for not meeting percentage-based goals (Zemsky \& Sanlo, 2005). To be clear, inclusion in non-discrimination is about ensuring a workplace free of discrimination, not about meeting quotas. Sexual orientation, but not gender identity, is also included in the Affirmative Action and Equal Opportunity policy, listed in full as:

Recruit, hire, train, promote, retain, tenure, and compensate persons in all applicable administrative, classified, faculty, unclassified, and student job titles without regard to age, ethnicity, disability status, national origin, race, religion, sex, sexual orientation or veteran status unless otherwise prohibited by applicable law; Base decisions of employment to further the principles of affirmative action and equal employment opportunity; Ensure that 
promotion, reappointment and tenure decisions are in accordance with the principles of affirmative action and equal employment opportunity by imposing only valid requirements for promotional, reappointment and tenure opportunities; Ensure that all personnel action including compensation, benefits, lay off, return from lay off, training, education/tuition assistance, social and recreational programs will be administered without regard to age, ethnicity, disability status, national origin, race, religion, sex, sexual orientation or veteran status unless otherwise prohibited by applicable law (West Virginia University, 2013a, emphasis added).

In the past few years, students, faculty, and staff have advocated for the inclusion of gender identity into WVU's non-discrimination and equal opportunity policies. In order to show the student body support for this, the SGA passed a resolution stating support for gender identity policy inclusion and the creation of an LGBTQ center, as well as a resolution detailing the LGBTQ center plan (Clark, 2011; and Palmer, 2012b). Several opinion pieces have been written for the student newspaper, The Daily Athenaeum, advocating for LGBTQ students, faculty, and staff on campus and within the state of West Virginia (Brewster, 2011; Chesanko, 2011a; Chesanko, 2011b; Prentice, 2012; Staff, 2012; and Staff, 2013). There have been no opinion pieces written in opposition, though there were some negative anonymous comments made on the online links to the support opinion pieces.

The state in which the university is located does not include sexual orientation or gender identity in its anti-discrimination policies. The state context is also important when considering non-discrimination and equal-opportunity policies. Universities cannot rely on local, state, or federal regulations to protect their constituents, but at times they may find themselves at odds with these institutions. As Joyce (2007) states, it is not unusual for universities attempting to add 
legal protections for LGBTQ individuals to receive little or no support from the courts and state legislatures. In 2012, the West Virginia Department of Education added sexual orientation and gender identity to their non-discrimination and anti-bullying policies. Students who complete their K-12 education within the same state as this university are therefore more protected than they are once they get to college. The policy states:

Acts of harassment, intimidation, or bullying that are reasonably perceived as being motivated by any actual or perceived differentiating characteristic, or by association with a person who has or is perceived to have one or more of these characteristics, shall be reported using the following list: race; color; religion; ancestry; national origin; gender; socioeconomic status; academic status; gender identity or expression; physical appearance; sexual orientation; mental/physical/developmental/sensory disability; or other characteristic (West Virginia Department of Education, 2013).

There are currently no federal laws regarding gender identity or sexual orientation, as Title VII of the Civil Rights Act of 1964 has been repeatedly held by federal appeals courts to not have intended these identities under the term "sex" that is included (Human Rights Campaign Foundation, 2009). State laws protect individuals' overall safety and equality, not just inside the workplace, but in other aspects of life, as well. Twelve states and the District of Columbia, at the time of this paper, had laws against hate crimes based on sexual orientation or gender identity and an additional nineteen have laws against hate crimes based on sexual orientation alone (Human Rights Campaign, 2009). Specific to the education of students from elementary to high school status, sixteen states and the District of Columbia have laws addressing discrimination, harassment, and/or bullying based on sexual orientation or gender identity and an additional two states include laws related only to sexual orientation (Human Rights Campaign, 2011a). LGBT 
individuals can experience discrimination in housing and sixteen states and the District of Columbia have laws addressing this for sexual orientation and gender identity, as well as an additional four states that address only sexual orientation (Human Rights Campaign, 2011b). Due to the inconsistent coverage of gender identity and sexual orientation in the United States, there are 172 million (of the 281 million citizens in the U.S.) who live in jurisdictions that do not provide these protections; which accounts for more than sixty percent of all U.S. citizens. According to the Human Rights Campaign Foundation (2009):

In states where discrimination based on sexual orientation is prohibited under state employment law, five out of every 10,000 lesbian, gay and bisexual workers file complaints - the same rate as sex discrimination complaints, and less than race discrimination complaints. At the same time, the average annual number of sexual orientation complaints for all states is just over 1,200—compared with race and sex complaints at 11,500 and 13,800, respectively. (p. 2)

While it is possible that fewer complaints do equate with less discrimination, it is more likely, given the general cultural climate, that many individuals do not have the avenues in which to voice discrimination complaints even though discrimination is happening. Currently sixteen states and the District of Columbia have laws in place regarding discrimination based on sexual orientation and gender identity and an additional five states have laws on only sexual orientation (Human Rights Campaign, 2012).

Domestic partner benefits. Domestic partner benefits are "benefits that an employer chooses to offer to an employee's unmarried partner, whether of the same or opposite sex," though employees do sometimes choose to offer these only to opposite sex couples (Employee Benefit Research Institute, 2009). Companies choose to include domestic partner benefits 
mainly as a means to make them more competitive to a diverse workforce, but also to ensure fairness within their compensation practices (Employee Benefit Research Institute, 2009). Conceptually speaking, if a company is to include sexual orientation within their nondiscrimination policy, yet does not offer health insurance or retirement benefits to the spouses of same-sex partners, they are in some ways violating their own policies by unjustly benefiting their heterosexually-partnered employees. Based on self-report through the employer database of the Human Rights Campaign, 309 colleges and universities provide healthcare to same-sex domestic partners; however, this makes up less than eight percent of the United States' four thousand accredited institutions of higher education (Messenger, 2009). Private sector businesses are not prohibited by any laws in creating domestic partner benefits, however federal and state laws can affect taxation of benefits and the creation of these in the public sector (HRC, 2013). The private sector has been quicker to increase their commitment to domestic partner benefits than colleges and universities. Many private companies adopt domestic partner benefits, as well as the inclusion of sexual orientation and gender identity in their non-discrimination statements, as demonstrated by the percentage increase in these as companies are higher ranked within the Fortune 500 listings (Human Rights Campaign, 2012b). According to HRC's 2011 calculations, $40 \%$ of Fortune 1000 companies offered domestic partner benefits, $58 \%$ of the Fortune 500 offered them, and $83 \%$ of the Fortune 100 companies offered domestic partner benefits (Human Rights Campaign, 2012b).

West Virginia University does not specify that its dual-career services are exclusive to heterosexual couples and include "spouses/partners" in finding jobs within the surrounding community, also including enriching WVU's “commitment to diversity, inclusion and talent retention" in its mission (West Virginia University, 2013b). The institution approved 'soft 
benefits' for same-sex partners in 2011, which gave partners access to WVU's Child Learning Center, employee wellness activities, access to University Libraries and the Rec Center, and eligibility to enroll in the Faculty and Staff Assistance Programs (Young, 2011). However, the struggle for 'hard benefits,' particularly health insurance, remains contentious. Because the benefits of the institution in this study are tied into state funds, the government is a complicating force within this decision. This was learned after the chairs of the PEIA Finance Board, who include the Chancellor for Health Sciences and the Provost \& Vice President for Academic Affairs, requested the matter be discussed at the March 21, 2013 PEIA/RHBT Finance Board Meeting (PEIA, 2013). The request was made based on finding that "most of our peers offer health insurance benefits to domestic partner(s)" and that they "increasingly find that in order to recruit and retain high quality faculty we must provide this benefit in order to be competitive at the national level where we recruit most of our faculty" (PEIA, 2013, p. 34).

Institutions of higher education are affected by their decisions to not provide domestic partner benefits, as well as by their inclusion or omission of sexual orientation and gender identity from all other policies and statements. The administration has allowed for anonymous comments on the plan (West Virginia University, 2013c). One commenter stated that it "is unacceptable for a university to even claim to value a goal of diversity and inclusion when it continues to discriminate by not offering full domestic partner benefits" (West Virginia University, 2013c). Offering domestic partner benefits will increase diversity and draw from a field of the most qualified candidates. Not including domestic partner benefits does impact the pool of qualified candidates at West Virginia University, as evidenced by a comment on the 2020 Strategic Plan: "I currently am at an institution that does provide domestic partner benefits. Accepting the WVU offer and transitioning here would present a significant and on-going 
additional financial burden" (West Virginia University, 2013c). It is not just for financial reasons that applicants may make this decision, as this same commenter said:

To be clear, my concerns regarding partner benefits are not solely personally and financially motivated. It is important for me to be as vocal as possible here that a lack of full domestic partner benefits is a lack of equity, and that joining an institution that continues to discriminate gives me serious pause. (West Virginia University, 2013c)

\section{LGBTQ Academic \& Student Life}

LGBTQ academic life consists of more than what happens in the classroom. In understanding academic life related to sexual orientation and gender identity, it is important to understand how inclusive curriculum is incorporated inside and outside the classroom. Campus Pride recommended that universities improve LGBTQ college students' experiences by integrating LGBTQ issues and concerns in curricular and co-curricular education, which can then provide a space in which all individuals on campus are able to challenge heterosexist beliefs and respond appropriately to anti-LGBTQ incidents and bias (Rankin et al., 2010). Indeed, LGBTQ students and faculty were less likely than non-LGBTQ students and faculty to agree that their institution's general education and departmental curriculum was inclusive and representative of LGBT contributions (Rankin et al., 2010). Academic efforts at institutions can include the formation of LGBTQ studies programs, identifying the institution as LGBTQfriendly, encouraging positive relationships and experiences with faculty and staff, and creating LGBTQ mentoring programs, among other LGBTQ academic services. Zemsky \& Sanlo (2005) argue that nondiscrimination policies on campuses do impact the experiences of LGBT students, faculty and staff and show that $100 \%$ of campuses that have LGBT centers have nondiscrimination policies in place regarding sexual orientation. 
From an LGBTQ academic life perspective, West Virginia University did approve the addition of an LGBT Studies minor in 2013. This was developed within the already existing Women's \& Gender Studies Program and was a simple institutional change that brought together all, or most, of the courses related to sexual orientation and gender identity that were already being taught within the institution, roughly 15 courses (B. Jara, personal communication, May 15, 2013). The university does not have a center for LGBTQ students, faculty, and staff or anyone within the university who is paid to work at addressing the needs of this population. Over the past few years a few external LGBTQ-related speakers have been brought onto the campus, though this was often initiated by students or faculty and not conceived from an administrative level (Eberly News, 2012; Festival of Ideas, 2013; Palmer, 2012a; WVU College of Law, 2013). The social justice statement that was recommended for staff to include on their syllabus up until the fall of 2013 included sexual orientation, but did not include gender identity or expression and read as follows:

West Virginia University is committed to social justice. I concur with that commitment and expect to maintain a positive learning environment based upon open communication, mutual respect, and non-discrimination. Our University does not discriminate on the basis of race, sex, age, disability, veterans [sic] status, religion, sexual orientation, color or national origin. Any suggestions as to how to further such a positive and open environment in this class will be appreciated and given serious consideration. If you are a person with a disability and anticipate needing any type of accommodation in order to participate in this class, please advise me and make appropriate arrangements with the Office of Disability Services (293-6700). (West Virginia University, 2012b) 
With the restructuring of the Office of Social Justice to become the Division of Diversity, Equity and Inclusion, this statement was updated for the fall of 2013. The introduction to the statement says that the "Student Instruction Committee of the Faculty Senate with the support of the Office of the Provost recommends that faculty, on a voluntary basis, consider including a social justice statement in each course syllabus" (West Virginia University, 2014). The statement was reformatted so as to not include any identity groups, thereby not expressly leaving out any particular group. It reads as follows:

The West Virginia University community is committed to creating and fostering a positive learning and working environment based on open communication, mutual respect, and inclusion. If you are a person with a disability and anticipate needing any type of accommodation in order to participate in this class, please advise me and make appropriate arrangements with the Office of Accessibility Services (293-6700). For more information on West Virginia University's Diversity, Equity, and Inclusion initiatives, please see http://diversity.wvu.edu. (West Virginia University, 2014)

Giving a suggestion for a statement does not mean that faculty, staff, and instructors will necessarily include the statement or know what it means to execute the statement. They may wish to maintain a positive learning environment that is socially just, but may not understand how to go about this task. Because it is not required to include the statement, the onus is therefore entirely on faculty and staff to take the initiative to create a classroom that is inclusive and equitable towards students regardless of sexual orientation and gender identity.

Roles of faculty and staff. LGBTQ students' relationships with faculty and staff can impact their experiences on campus both inside and outside of the classroom. One study found that LGB students reported significantly higher rates of satisfaction with faculty and staff 
interactions than heterosexual students, though the identity of faculty and staff in these interactions was not known, with bisexual students' satisfaction being the highest (Garvey \& Inkelas, 2012). Mentoring can be a valuable resource for LGBTQ students. Within a mentoring relationship where the student or mentee identifies as LGBTQ, it is important to manage the possible stigma and additional stress that may be associated with coming out within the institution's context; subtle forms of sexual bias that may exist within the mentoring relationship; and the cohort and/or identity differences that may exist between the mentor and mentee (Russell \& Horne, 2009). While a mentoring relationship and paying specific attention to the needs of LGBTQ students within this relationship can be invaluable, it is not to be seen as a substitute for institutional and policy change on a campus to improve the status of LGBTQ students and free up the demands of the mentoring relationship for personal, academic, and professional growth (Russell \& Horne, 2009). Therefore, while it is important to incorporate faculty and staff involvement in LGBTQ students' lives, this should be as a complement to a full perspective of LGBTQ-friendly policies and practices. Incorporating concepts of sexual orientation and gender identity into classrooms is an important role for instructors to take on. It is important to recognize that sexuality also includes heterosexuality and, by virtue of such, more instructors are likely already incorporating (heteronormative) sexuality into their classes without being aware (Skelton, 1997). Instructors incorporating sexuality in such a way that one is simultaneously supporting LGBTQ students, while also disrupting students' notions of sexuality and calling attention to compulsive heterosexuality can be difficult. The concept of comfort is often raised in the teaching of sexuality, related to both faculty and students. Skelton (1997) states that "the teaching of sexuality seems to trigger more anxiety in relation to teaching than any other subject," and mostly for reasons that are personal (p. 424). Alexander (2011) argues 
that it is the corporate model of higher education that leads to the affective experience of students as being the penultimate goal, with instructors concerned about their evaluations if they were to leave students feeling uncomfortable or frustrated rather than satisfied. This brings up the reality that "despite the gains of queer theory in academia, and the initial gains of queer activism in the 1990s, contemporary mass-media discourses about sexuality are often part of the queer studies classroom" (Alexander, 2011, p. 61). This brings about a disjuncture of queer studies simultaneously disrupting notions of sexuality while creating a safe space for LGBTQ students. For instance, when LGBTQ students look to queer studies as a place for community, yet they meet critical queer perspectives that disrupt the "truths" that they hold about their own identities, it becomes important to "reconsider the queer pedagogical methods necessary to foster, rather than alienate, students' active engagement with sexuality studies" (Alexander, 2011, p. 61).

Comfort must also be situated within a context of power and privilege. Instructors must deal with considerations of political climate of their department, classroom, and self-presentation when making decisions about curriculum inclusion. Their level of privilege is situated within this political climate and context (Skelton, 1997). Discomfort does not have to be either positive or negative. If understood within the broader framework of privilege, discomfort can serve a purpose. By incorporating discomfort into a pedagogical use, it "suggests that queer pedagogies have the potential to inspire readings and attachments that are surprising, pushing students to foster worldviews that are complicatedly considered, as ambivalent as they are insightful, and as critical as they are compassionate" (Alexander, 2011, p. 69). Curriculum can be a tool to create change in attitudes, but when courses are optional, the students who are likely to enroll in the courses may already be the ones who are willing to expand their views (Engberg, Hurtado, \& 
Smith 2007). When first-year students became investigators in an ethnographic study of the environment for lesbian, gay, bisexual, and transgender students, it influenced their perceptions, self-awareness, and behavior, which supports and extends theories of sexual identity development, attitude change, and social justice ally development (Evans \& Herriott, 2004). If faculty and staff are not supported at an administrative level, there is less freedom to make these kinds of pedagogical choices. By providing faculty with the autonomy and institutional support to challenge students to deeper ways of understanding identity, including sexuality, students will grow in profound ways.

Role of institution and administration. The role of student affairs in incorporating diversity into higher education has changed significantly over the years. Despite student affairs playing a large role in incorporating multicultural issues into higher education, the research on these efforts has been scant (Pope, Mueller, \& Reynolds, 2009). Student affairs scholarship emerged in the 1970s and the early populations of interest were Black students and women, but emphasis has since shifted to include "veterans, students with disabilities, adult learners, Latino/a students, Asian American students, gay and lesbian students, students of various religious affiliations, and international students" (Pope et al., 2009, p. 643) with a more recent emphasis on gay and lesbian students. In addition to who is being studied, a shift was made from understanding demographics and structural diversity to creating environmental conditions on campuses that grow and support diversity while confronting and dismantling systems of privilege and oppression (Pope et al., 2009).

The concept of providing space for LGBTQ students is important. Often this is done through the creation of an LGBTQ center. The first LGBT Campus Resource Center was founded at the University of Michigan in 1971, with many more opening in the 1980s and the 
majority founded in the 1990s, though centers continue to open at universities every year (Sanlo, 2000). Most often these centers are formed after a university creates a task force to explore campus climate and thus a proposal, needs assessment, and space and budgetary assessment is created (Sanlo, 2000). While some universities have provided LGBT spaces, Stewart (2007) argues that this quantifiable increase in queer visibility actually came through "quasiinstitutionalization," and that this assimilation is at the same time halting the qualitative improvement of queer studies. This means that we should consider that what is seen on the surface does not always represent the desired outcome and raising questions about whether and to what degree the disjuncture is intentional. For instance, as with queer studies, courses may be offered on a campus, but they may be in various departments and difficult for students to find, or, as with policies, which may have be implemented by administrators but were done in a very private way so as not to bring 'unnecessary' attention to the issue (Stewart, 2007). The same space that has allowed for the growth of queer studies could cause the undoing and concealing of identities and curriculum. Stewart argues for the use of more "organic" spaces while admitting the difficulties in finding these spaces and then in the fluid nature of these, meaning if queer spaces are not set aside for such a purpose, they may not last (2007).

While LGBTQ students do make their decisions on universities based first on quality of education and the good reputation of the university, they are also concerned with student organizations, a gay-friendly campus, and diversity on campus (Burleson, 2010). Many students consider the campus climate when making their decision between colleges and campuses do give potential students about the level of support LGBTQ students can expect to find, such as through organizations, resource centers, special-interest housing, and other options (Burleson, 2010). Some U.S. universities have been planning and implementing programs to actively recruit gay 
college applicants, as well as conducting college fairs run by the gay advocacy group Campus Pride, often using the increasing number of gay-straight alliances in secondary schools as a way to provide outreach services to potential students (Lipka, 2011). It is not as clear that universities are reaching out to potential bisexual and transgender students in the same ways, or if their efforts remain singularly-focused in language that addresses lesbian and gay students. One survey by Einhaus, Viento, \& Croteau (2004) found that $95 \%$ of the surveyed universities did not participate in LGBT recruitment; however the authors noted that the admissions department at their own campus did participate in recruitment and marketing initiatives.

The current role of institutions in meeting the needs of LGBTQ students, faculty and staff is not promising. In the Campus Pride study, LGBTQ respondents were less likely to agree that their institutions provided adequate resources on LGBTQ issues and concerns, positively responded to harassment incidents or provided adequate support to LGBTQ employees and their partners (Rankin et al., 2010). Research shows that "getting campus leaders to attend to and act on meeting the learning and development needs of LGBT students, as illuminated in a campus climate study, particularly in a politically conservative environment, is not easy" (Brown \& Gortmaker, p. 129). Brauer (2012) described the difficulty of administrative change by saying: That is the nature of social and institutional change: they take time, gathering energy from symbolic acts; gaining momentum from every voice, connection, and action; churning toward transformation with the erratic power of an ocean wave. Every campus will build that energy and momentum differently, but when they do, their collective efforts will combine in a surge of greater LGBTQ inclusion across higher education. (p. 9)

It is for this reason that looking at the individual experiences of students can give a 
different perspective on the overall system and the role of administrative change. The collective impact of each of these experiences comes together to form something much larger. Students' experiences on campus can be framed not just with the role played by faculty and staff, the role of the institution and administration, but also the many and various attitudes on the college campus that correlate, shape and interact with attitudes on sexual orientation and gender identity.

\section{Attitudes on Sexual Orientation and Gender Identity}

The overall campus climate affects everyone; LGBTQ students, faculty, and staff, as well as non-LGBTQ individuals. While it is not completely possible to predict the factors that create a negative or hostile campus climate for LGBTQ individuals, some research has been done that assesses the correlates to these beliefs and the interventions that can help to improve the campus climate on an individual and systemic level. It can be worthwhile to understand overall attitudes on campus that may correlate with anti-LGBTQ attitudes and work to improve these as a whole.

Attitude correlation with other forms of oppression. One study that considered the experiences of undergraduate students found that they were significantly more likely to report greater discomfort with and more negative attitudes toward LGB individuals than toward the specified ethnic/racial groups and looked at whether the respondents' gender, ethnic/racial, sexual orientation, and religious differences were correlated with attitudes and comfort (Holley, Larson, \& Adelman, et al., 2008). The researchers found that men and Christians, denomination unspecified, had more negative attitudes towards LGB people, but there was no difference among various ethnic groups in attitudes toward LGB people (Holley et al., 2008). Rankin (2006) shows how there will be differences in perceptions of campus policies and climate based on social group membership_-for instance African Americans may rate the campus racial climate as more negative or men may not perceive sexual harassment on campus. Engberg, 
Hurtado, and Smith (2007) found that attitudes of acceptance towards LGB peers can be cultivated when undergraduate students interact across race, interact with LGB peers, or enroll in diversity courses (and that their entering LGB attitudes directly influenced their enrollment in diversity courses). There are, however, no significant differences reported based on sexual orientation for the appreciation of racial and ethnic diversity or concept of the campus racial climate (Longerbeam et al., 2007).

Attitude correlation with education level. There is some evidence that higher education levels lead to an increase in tolerance and one study found that juniors and seniors had significantly more positive attitudes towards gays and lesbians than did freshmen and sophomores (Lamber, Ventura, \& Hall, et al., 2006). Early normalizing experiences in childhood, meeting LGB peers in high school or college and experiences of empathy based on LGB peers' struggles and successes have been shown to be key factors in positive attitude formation to LGB individuals (Stotzer, 2009). D'Augelli (2006) found specifically that there are personal and professional challenges faced by students, faculty, and community members in a rural university setting. In a rural community it can be even more difficult to develop informal helping resources for local LGB people or to foster institutional and policy changes to make the university a safer place for LGBT faculty, staff and students (D'Augelli, 2006). In one study, researchers found that heterosexual students held generally supportive attitudes, but felt public pressure to hide their support for LGB civil rights and to tone down and hold private antagonistic religious views (Jurgens, Schwitzer, \& Middleton, 2004). Notably, the participants presented as more knowledgeable than they actually were about LGB issues, overestimating their understanding of LGB matters (Jurgens et al., 2004). All of these factors contribute on an individual and systemic level to the overall campus climate and are worth considering when 
researching the impact on LGBTQ students in higher education.

\section{LGBTQ Student Experiences}

The campus climate is a broader concept that affects individuals in unique ways. The ways in which all types of discrimination and oppression intersect with one another and are interdependent will be further illustrated through the conceptual framework in Chapter 2. All populations are made vulnerable when homophobia and heterosexism are allowed to thrive on a college campus. However, it is important to simultaneously understand the ways in which different aspects of identity intersect, as well as view a more tangible observation of the LGBTQ population's particular vulnerabilities in order to understand the ways in which representation and resources impact a university campus.

There are some specific considerations that can be made regarding LGBTQ student populations. Fine (2011) found that many LGB college students make meaning of the heterosexism and homophobia that they encounter in their daily lives by minimizing incidences of heterosexism and homophobia. This minimizing comes through a desire on the part of many respondents to develop an identity apart from, rather than integrated with, sexual identity; suggesting that heterosexism and homophobia can be countered by the participants' resistance to it, leading to a view of the campus climate that is generally positive (Fine, 2011). When looking at the experiences of LGB students, it may be necessary to understand how "out" they are on campus because, as Gortmaker and Brown (2006) found, there are some differences in experiences, such as in the need to hide their identity, perceived unfair treatment, perceptions of a homophobic campus, understanding of lesbian and gay issues, involvement and activity levels, and the presence of a lesbian and gay student network.

For many populations within education, the administration at universities uses student 
outcomes to gauge students' engagement and productivity on campus and compared to their peers. Due in large part to data collection resources, this type of information is generally not available on LGBTQ students. However, a few studies have been done examining LGBTQ student outcomes. Understanding LGBTQ students' outcomes is most often done within the context of a larger quantitative study that happens to ask questions based on sexual orientation and/or gender identity. These are increasingly difficult to find due in large part to conservative political attacks influencing the removal of questions based on sexual orientation and gender identity from large surveys, such as with the Youth Risk Behavior Survey (Strauss, 2005). One such study was the Harvard College Alcohol Study (CAS), which is one of the only large, nationally representative studies to include a question on same-sex sexual experiences (Carpenter, 2009). In order to understand LGB students' experiences, Carpenter (2009) considered the following outcomes: academic, satisfaction, economic, social capital, and time use.

Individuals will experience the campus climate differently based on their role on campus and their social identity (Vaccaro, 2012). For undergraduate students, the perception of campus climate is based more so on their perceptions regarding their overall campus experience whereas for graduate students, their perception may be based more on department-specific engagement and professional identity (Vaccaro, 2012). Student who engaged in LGBTQ campus activism sometimes experience negative backlash from this engagement, sending messages that they are not accepted (Vaccaro, 2012). LGBTQ student involvement in activist organizations connects their identity in visible ways that identity is not necessarily connected when students are involved in organizations focused on other social activism (Renn, 2007). Being involved in LGBTQ student activist organizing changed some students' academic lives and careers goals, 
influencing them to align their studies more with LGBTQ and queer studies, but also in some cases causing difficulty in balancing their co-curricular and academic responsibilities (Renn, 2007). Students come to LGBTQ activism and leadership positions with different levels of engagement and these can be seen through their progression through and identification with the six stages of the Leadership Identity Development Model (Renn \& Bilodeau, 2005). These stages include: awareness, exploration/engagement, leadership identified, leadership differentiated, generativity, and internalization/synthesis, all of which manifest within LGBTQ student leaders in various ways (Renn \& Bilodeau, 2005).

From the research that has been conducted on LGBTQ student experiences and outcomes, a few demographic considerations can be made. Gay male students had higher grade point averages, saw their academic work as more important, and were connected closely to a faculty member or administrator, and participated in more activities than their heterosexual male counterparts (Carpenter, 2009). Gay men were more likely to discuss their academic work and career goals (Longerbeam et al., 2007). Socially, gay men were more likely to drink to fit in and feel comfortable in social situation and were less likely to socialize with friends from home than heterosexual men (Longerbeam et al., 2007). Both male and female sexual minority students found participation in arts and politics more important heterosexual students (Carpenter, 2009; Longerbeam et al., 2007). LGB students were also more likely to discuss sociocultural issues, such as human rights, multiculturalism, and politics with their peers (Longerbream et al., 2007). LGB students were less likely to have a religious affiliation than their heterosexual peers, and were most likely to report increased growth in critical thinking and liberal learning, or openness to broad perspectives and an appreciation of a wide range of intellectual topics (Longerbeam et al., 2007). 


\section{LGBTQ Youth \& Adolescent Experiences}

Students not only experience the college campus in very different ways, but they arrive in higher education with a variety of experiences behind them, which could impact their experience within and perception of the campus climate. College students may expect to find an environment that is welcoming of diversity including sexual orientation when they come to college, but this is not always the climate into which they arrive. Sanlo (2006) stated that "more students are coming to college already open about their sexual and gender identities and already expecting a campus that will support them" (p. 1). LGBTQ students in particular may have very different background circumstances related to their families and high schools and varying experiences in higher education. While more and more high school students are 'coming out' today than ever before, for many people college is the first time that they identify and/or label their sexual orientation not only to others, but often to themselves (Savins-Williams, 2005). There is no one path for individuals who identify as sexual minorities. According to a study by Savin-Williams and Diamond (2000), the average first age of same-sex sexual attraction is between seven years old and nine years old while the average age of first self-labeling is between ages 16 and 17 years and the average age of first same-sex sexual contact is between 14 and 16 years. Additionally, it's important to note that this is not always a sequenced development, but rather a trajectory that some young people see differences in their experiences that are sometimes based on their gender.

According to the Gay, Lesbian, and Straight Education Network (2010), LGBT-related resources and supports in high schools have increased over time; specifically Gay-Straight Alliances, school staff who were supportive of LGBT students, and LGBT-related materials in school libraries. Positive images and visibility in media and popular culture have also increased, 
but young people still see many examples of bias and discrimination against individuals who identify as lesbian, gay, bisexual, or transgender. However, this does not mean that LGBTQ students have entirely positive experiences related to their identity. Nearly 9 out of 10 LGBT students experienced harassment and two-thirds felt unsafe at some point based on their sexual orientation (GLSEN, 2010). Bullying has received increased attention in primary and secondary schools and often the basis of this bullying is the perceived or actual sexual orientation of a student, and identifying as LGBTQ in high school can often put students in hostile situations (GLSEN, 2010). Bullying also indicates a power differential, which is reinforced within the system of academia (Misawa, 2007).

\section{LGBTQ Student Vulnerabilities and Resiliencies}

Too often the experiences of LGBTQ students are measured from a deficit model. Within the past, research efforts, laws, and policies have tended to focus on the role played by victimization in the lives of LGBTQ youth within schools, and it is important for researchers to seek a clear picture of LGBTQ experiences (Strauss, 2005). I want to be clear in my choice of terms here when I use the term vulnerability. It is not about the weaknesses or strengths of a given population, but on our ability as humans to connect and communicate. I mean this more in line with Brown (2010), that "vulnerability is the birthplace of creativity, innovation, and change." Brown (2006) discusses resilience within the context of shame, stating that there are four components to resilience; empathy, connection, power, and freedom. Shame resilience includes an ability to recognize and accept personal vulnerability, which also means that recognizing the universality of our most private struggles often leads to a second important benefit of reaching out to others (Brown, 2006). Vulnerability is about authentically seeing one another and struggling through the difficult and uncomfortable spots. It means that things may 
get messy, but that messiness is an opportunity. My choice of the term vulnerability therefore, not only reflects the susceptibility to harm from outside forces of the LGBTQ youth population, but also the possibility that the participants' experiences represent for resilience and connection. Within the specific intersections of identities there are strengths from which to gain understanding.

Bisexual student experiences. Bisexual students may have different experiences from their lesbian and gay peers. Bisexual students' experiences often remain invisible and are collapsed into the experiences of lesbian and gay students. An analysis of several studies showed that overall bisexual students have significantly less favorable perceptions of the campus climate and often encounter ostracism, discrimination, and oppression from both the heterosexual and gay communities (Dugan \& Yurman, 2011). Bisexual students report better relationships with faculty and staff than heterosexual or homosexual students (Garvey \& Inkelas, 2012). This may be because bisexual students can benefit and suffer from heteronormative practices in college and, due to the lack of validation for bisexual identity, may seek support and guidance from faculty and staff (Garvey \& Inkelas, 2012). A study that looked specifically at bisexual students, found that general social support from family and friends was most predictive of depression and life satisfaction, whereas sexuality-specific support was most predictive of internalized binegativity (Sheets \& Mohr, 2009). Therefore, if students are receiving generalized support, they will overall have a stronger sense of life satisfaction and lower incidence of depression, but a feeling of support regarding sexual orientation comes from sexuality-specific support from family and friends. Carpenter (2009) found that bisexual females were much more dissatisfied with their education and academic work, spent less time studying and had fewer friends than heterosexual females, but that they were active in more campus activities. 
There are clearly complex and mixed results regarding bisexual students' experiences and much more understanding is needed on the ways in which these experiences differ based on gender and identity. It is also important to understand the ways in which behavior and identity may or may not correlate for bisexual individuals. The response may be different for bisexual individuals based upon how the question on identity is asked. The ways in which bisexual students' personal and academic experiences tie together is unclear and there are some mixed messages within the findings on bisexual students, such as the closer relationship to faculty and staff while also feeling more dissatisfied with education and academics.

Transgender student experiences. Beemyn (2005) discussed the following as obstacles that challenge transgender college students: health care, residence halls, bathrooms, locker rooms, records and documents, public inclusion, and programming, training, and support. Beemyn (2005) looked at some best-case policies, such as health and counseling training, providing health services to transitioning students, such as endocrine tests, offering "all gender" housing on campus, having gender-free bathrooms, and broadening identification-card policies to include transgender and transitioning transsexual students. Beemyn (2005) devoted a section to bathrooms and the move to "aid transgender people in being able to "pee in peace," as well as to gender-neutral locker rooms. Beemyn and colleagues (2005) outlined the ways in which colleges and universities are beginning to consider the needs of transgender students, as well as defining terms surrounding the population. They discuss how few campuses understand how to offer support to this segment of the community. The needs of transgender students are broken down into the following topics: services, educational services, support services, inclusive policies, campus housing, bathrooms and lockers rooms, counseling and health care, college records and documents. 
These findings are similar to the needs of transgender individuals on a societal level, in which the dramatic differences of experience can be seen though the statistical results of the “Injustice at Every Turn” survey (Grant, Mottet, and Tanis, 2011). While discrimination was pervasive throughout the sample, transgender people of color fared much worse, with those identifying as African American having the worst situations in most of the areas surveyed. Grant et al. (2011) found that $41 \%$ of transgender individuals had attempted suicide, $55 \%$ had lost a job due to bias, $51 \%$ were bullied in school, and $61 \%$ and $64 \%$ were the victims of physical and sexual assault, respectively. Of additional concern was receiving quality medical care and obtaining identity documents. The support and acceptance of family helped significantly with many of the threats that individuals faced. It should also be noted that the respondents showed great resilience in the face of cumulative discrimination (Grant et al., 2011).

Multiple minority identities and experiences. Students who identify as LGBTQ and also identify as a minority within another aspect of their identity, whether related to race, ethnicity, ability or another axis of identity, have unique positions within the campus climate and their experience of that climate. It is important to recognize the balance between students needing to have a homogenous group for comfort and support and the role that student affairs administrators can and should play in connecting privileged and oppressed groups across the campus (Poynter \& Washington, 2005). A very important point raised by Rankin (2005) is that while individual programs, policies, and centers are important and demonstrate institutional support, there is a "paradigm shift" which also must happen and this demands that those who are in systems of power do not silence LGBT voices on campus and that they work to disrupt heterosexism and homophobia, creating new assumptions of diverse sexualities and relationships. It is also important to understand the implications of understanding the experiences 
of oppressed individuals within the context of dominance. For instance, LGBTQ college students with disabilities have been relegated to a status of invisibility; little is known about the experiences of LGBT students with disabilities, those working with individuals have little training or knowledge and the identities are often dealt with as separate entities within the university (Harley et al., 2002).

The perspectives of students who identify as LGBTQ and as racial or ethnic minorities will reflect the campus context in relation to their specific identity. Campus Pride found that there was an increased risk for negative perceptions of campus climate when individuals were at the intersection of multiple cultural and social identities (Rankin et al., 2010). Students of color were 10 times more likely to indicate racial profiling as a form of harassment than white people, with a $20 \%$ rate and $2 \%$ rate, respectively. In terms of feeling comfortable or very comfortable in their classes, LGBT students of color were significantly less likely, at $60 \%$, than White students, at $65 \%$ (Rankin et al., 2010). While respondents of color were more likely to perceive harassment related to racial identity, the primary basis for observed harassment was sexual orientation according to both respondents of color, at 75\%, and White respondents, at $76 \%$ (Rankin et al., 2010). As illustrated through the personal story of Misawa (2007), bullying in adulthood is often a manifestation towards intersecting identities, such as racism and homophobia in his case. Misawa (2007) was a graduate student who experienced bullying from a faculty on his campus. When the faculty found out that the research Misawa was conducting discussed the intersections of sexuality and ethnicity, rather than just "culture," he refused to work with him further stating “we don't talk about those things in our daily conversations. We talk about culture. I don't want to talk about it. We should not meet again” (Misawa, 2007). This meeting escalated when the faculty member sent out an email to a listserv for students of color 
stating that there is a graduate student researching race and sexual orientation and no students should respond to this student (Misawa, 2007).

While there are differences in experiences based on race and ethnicity of LGBTQ students, research has found that there is not a significant difference in identity formation related to sexual identity, sexual orientation and recent sexual activity among Black, Latino and White youth (Rosario, Scrhimshaw, \& Hunter, 2004). While there is no notable difference in identity formation based on race, there are some differences noted with regard to identity integration, noting that Black youths participated in less gay-related activities, were less comfortable with the coming out process, and endorsed fewer positive attitudes on sexual orientation; however, they also experienced the greatest increase in positive attitudes (Rosario et al., 2004). The purposes or intent behind harassment or negative campus climate as experienced by students cannot always be clear. It is also difficult to completely understand how an individual's complex identity shapes their perception of these experiences. Just as one's identity cannot be parsed out into components, often these experiences are based on the complex intersections of identities.

These concrete experiences relate specifically to the framework guiding this study. Martinez (2003) examines the contributions of lesbians of color to the developmental relationship between queer theory and qualitative research methodology, stating that the contributions of lesbians of color in this context have been overlooked despite being featuredan oversight that is explained through an examination of theoretical perspectives that dominate our current understanding of the relationship between queer theory and qualitative research. Though much writing has been done spotlighting individual experiences of lesbians of color, there is the tendency on the part of the reader to essentialize these experiences. Martinez states that when someone reads text which "implicates us all in the perpetuation of racisms and their 
violences in the concrete everyday lives we live-and (we) are faced with a choice: confront our own place in the perpetuation of racisms and their violences, or don't" (p. 119). It is when we do not confront our own place within this that we have the tendency to essentialize that person's experience; that being a theorist or doing theorizing does not "inoculate one against our culturally based preferences for liberalism and individualism as they are carried in the concrete practices of our habitual lives" (Martinez, p. 119).

While my work has been grounded in a conceptual framework, as detailed in the next chapter, this does not exclude me from carrying the biases of my environment into my work. It also does not exclude the reader from carrying their biases. I have therefore made all efforts to call attention to the ways in which these individual experiences are situated within a broader context of privilege and dominance and to do my part to call attention to those parts that, as Martinez stated, implicate us. In crafting my conceptual framework and methods, I wanted to ensure that I (and the reader) did not have the choice to avoid confronting my (and our) own place within that perpetuation of racism and all other isms.

\section{Glossary of Terms}

I recognize there are many terms related to sexual orientation and gender identity that may be unfamiliar to readers. I have included a list of terms within this document that may need further explanation. These definitions represent my usage. This includes concepts that may also come up within data collection. As these terms are used by participants within the study, the meaning ascribed to the terms by the participant will be sought out through the methods and analysis. I recognize that these terms change and vary due to context, culture, time, and individual understanding. 
- Ally: someone who advocates for members of a community other than their own; one who confronts heterosexism, homophobia, heterosexual privilege in themselves and others

- Asexual: broadly, a lack of sexual attraction, interest, or orientation

- Bisexual: person with the potential to feel sexually attracted to and to engage in sensual or sexual relationships with people of either sex though not necessarily at the same time or to the same extent

- Biphobia: the fear, hatred, or aversion towards bisexuals; often based on stereotypes or erasure of visibility

- Bullying: unwanted aggressive behavior that is repeated (or has the potential to be repeated) and involves a real or perceived power imbalance

- Cisgender: a gender expression aligned with gender identity, also meaning that one's gender identity aligns with the gender assignment one was given at birth

- Closeted/in the closet: keeping one's sexual orientation, and/or gender or sex a secret

- Coming out: the process of disclosing one's sexual orientation; this is not a 'one-time' event

- Domestic partner benefits: benefits conferred on non-legally-married, cohabitating couples; within the context of higher education, health insurance is an example of a hard benefit, while library \& recreation center use are soft benefits

- Equal opportunity/non-discrimination policies: these include policies applied to recruitment, hiring, training, promotion, tenure, etc., in order to protect minority students faculty and staff from discrimination

- Gay: often refers to someone who is male-identified who is sexually, romantically, and emotionally attracted to other men, though gay may be a gender-neutral way of describing someone who is attracted to another person/persons of the same gender 
- Gender: the social construction of how one 'should' act based on their sex; described as feminine or masculine

- Gender identity/expression: the way in which an individual identifies which a gender category; may be woman, man, or neither; gender identity does not cause or correlate with sexual orientation and should be understood as a separate component of identity

- Gender non-conforming: a term for individuals whose gender expression is different from societal expectations related to gender.

- Gender queer: a term used to describe someone who does not subscribe to traditional or expected gender norms

- Gender stratification: ranking of one gender/gender identity over others

- Hate crime: a bias-motivated crime, victim is targeted due to actual or perceived membership in a social group, often resulting in more strict penalties for the crime

- Heterosexual: someone who is attracted to the 'opposite' sex

- Heterosexism: the assumption that everyone is and/or should be heterosexual; can be individual or institutional

- Homophobia: the irrational fear, hatred, or aversion of homosexual people or homosexual feelings; manifests as harassment, discrimination, and violence

- Hormone Replacement Therapy (HRT): therapy for transgender and transsexual individuals that balances hormones in the body, in order to allow the body to enhance characteristics matching the gender identity of the individual

- Identit(ies): the use of the parenthesis shows the ways in which multiple aspects of one's identity, or identities, come together to form one's complete identity. Identit(ies) is thus simultaneously that complete identity and the components of identities. 
- Internalized homophobia/biphobia/transphobia: negative understandings and assumptions an LGBTQ person may carry about oneself, often without realizing, due the culture's messages

- Intersex: variety of conditions in which a person is born with a combination of sexual or reproductive anatomy that doesn't fit the typical definitions of female/male

- Lesbian: someone female-identified who is sexually, romantically and emotionally attracted to women

- LGB: stands for Lesbian, Gay, and Bisexual

- LGBQ: stands for Lesbian, Gay, Bisexual and Questioning

- LGBT: stands for Lesbian, Gay, Bisexual, and Transgender

- LGBTQ: stands for Lesbian, Gay, Bisexual, Transgender, and Queer (or sometimes questioning)

- LGBTQAI: stands for Lesbian, Gay, Bisexual, Transgender, Queer, Asexual, \& Intersex

- Non-monosexual sexual identities: identities in which, similarly to bisexuality or pansexuality, a person is attracted to and engages in sensual or sexual relationships with people of either sex though not necessarily at the same time or to the same extent, however this term is inclusive of all gender identities and sexual expressions. This term is used to be inclusive of those who identify as bisexual, pansexual or do not label their identity.

- Pansexual: similar to bisexuality in that the person has the potential to feel sexually attracted to and to engage in sensual or sexual relationships with people of either sex though not necessarily at the same time or to the same extent, however it is inclusive of all gender identities and sexual expressions 
- Pink triangle: reclaimed as a gay pride symbol; originally it was used right side up as a Nazi concentration camp badge for gay men, was turned upside down for the reclaiming and is used as a symbol on the institution's Safe Zone program insignia

- Queer: an umbrella term for anyone who is a sexual minority or is non-heteronormative or opposing of a gender binary; controversial due to being re-appropriated from slang anti-gay speech

- Rainbow flag: the six colors represent the diversity of the LGBT community; the most common gay pride symbol

- Reparative therapy: tries to 'cure'/convert homosexuality; often religiously-based, traumatizing; counselors/psychiatrists see as ineffective

- Sex: one's 'biological' female/male identifier; usually determined by genitals, but can also include chromosomes, hormones, etc.

- Sexual orientation/identity: one's emotional, romantic, and/or sexual attractions to the sex/genders accompanying; these terms are used and NOT "sexual preference" as it implies choice where none exists

- Sodomy laws: laws that define certain sexual acts as crimes, including oral and anal sex; rarely enforced on heterosexual people and still seen as targeting and pathologizing gay and lesbian individuals

- Trans*: the use of the asterisk is to indicate that the term is meant to be inclusive of all identities and is seen as more inclusive than "trans," such as transgender, transsexual, genderqueer, non-binary, genderfluid, genderfuck, intersex, third gender, cross-dresser, bigender, trans man, trans women, agender 
- Transgender: an umbrella term used to describe anyone who eschews traditional gender roles or the binary of sex \& gender

- Transphobia: the irrational fear, hatred, or aversion to transgender people; often manifests as harassment, discrimination, and violence

- Transsexual: describes a person whose 'biological' sex does/did not align with the cultural expectation of their gender; they may or may not have surgery, take hormones, and transition to target gender 


\section{Chapter 2: Conceptual Framework}

The conceptual framework used in this study situates LGBTQ student experiences within micro and macro locations of institution and discourse. Holland et al.'s (1998) germinal blended theorizing from critical, socio-cultural, and social constructivist perspectives in Identity and Agency in Cultural Worlds informs an understanding of how students co-construct meanings. Queer Theory is an excellent lens for examining the extremely personal and individual, especially related to conceptions of sexual orientation and gender identity, and viewing it within a broader context of social structure and power. Curriculum theory is used to situate both the inclass and out-of-class curriculum elements. The entire framework is situated within the concepts of intersectionality and interdependence as these affect both individual identities and overall power and oppression within a system.

Figure 1.

Conceptual Framework.

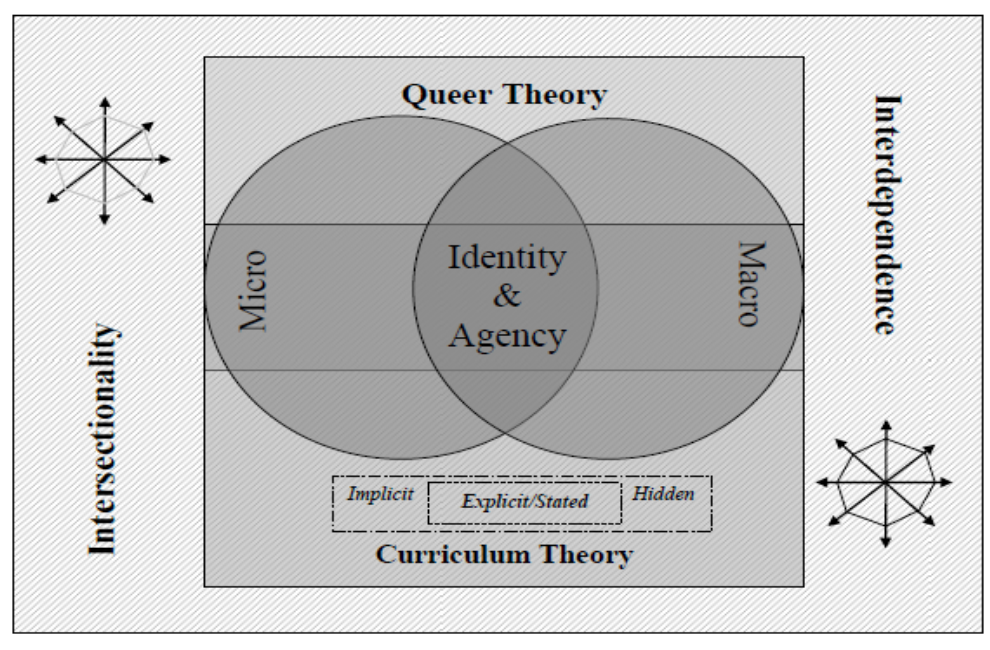

The study is situated within a framework of intersectionality and interdependence. The overlapping circles represent the micro/individual and macro/structural components that come together to create the students' experiences. These experiences can be understood using 
Holland's "Identity and Agency in Cultural Worlds." Queer Theory and Curriculum Theory guide the understanding of these relationships.

\section{Positionality of LGBTQ Students}

This framework centers the experiences of LGBTQ students within individual (micro) and institutional (macro) levels. As this study is designed to make sense of individual experiences and how these relate to the overall campus climate, it follows that the framework addresses the position of both of these within the system. Seen as two overlapping circles, the micro level of students' individual experiences overlaps with the macro level of the institutional structure, which includes policies, practices, and other larger scale concepts. LGBTQ student experiences, both individually and collectively, lie in the center of the daily and ongoing individual and small group interactions they have which reinforce their understanding of themselves and others within the social context and the larger institutional context. The micro and macro social structures are mutually reinforcing, as well as at times in conflict with one another. For instance students may receive one message, such as of support, within a one-on-one interaction, but may receive a different message on an institutional level, such as lack of inclusion in policies. There is no underlying assumption about the direction of these messages, whether they are positive, negative, or neutral, and in what way they are delivered. The only assumption is that students' lives are shaped by all of these in ways that they may or may not perceive. Therefore, at the core of this theoretical framework, it is important to always come back to student experiences as the focal point. Additionally, it is imperative that this be considered within the particular context in which this study was conducted. While this framework could be applied to other environments, the constructed micro and macro levels are meaningless without attention to context. 
From a micro level perspective, this sphere of the framework represents individual students' interpersonal experiences. These could include, but certainly are not limited to, interactions with other students, interactions with faculty and staff, and interactions with the administration. Seeing as how the context of this study is limited to a particular university, the micro level for student experiences will generally be limited as such. However, this limited viewpoint is not without an extended context. Students do not and have not lived their entire lives within this exclusive environment of the university setting. They bring with them background experiences and interactions that influence their current interactions and certainly shape their perceptions of their current environment. Additionally, they do not operate within a bubble of the university. They are connected to outside individuals and groups that may not be in any way affiliated with the university context.

The macro sphere of the diagram represents the institution of the university. While I recognize that the university is situated within other, larger macro systems and that these systems influence and direct the course of university policy and culture, for the sake of this framework, the institution of the university is itself the main macro entity of which I will be referring. The university structure is a complex system and included in this macro perspective are the policies, procedures, physical construction, customs, norms, and financial aspects, among other things. The macro level perspective is based on this particular time and space, however it has been crafted over time and is influenced greatly in perception and action by those who have been connected previously. Because this is a public land-grant institution, the state context matters considerably in understanding the macro context of the university. Individuals with power operate at not only a micro level in students' lives, but also at a macro level as a part of the 
institutionalization of their power. It is a complex interplay between personal and political. It is at the crux of this interplay that LGBTQ student experiences can be understood.

\section{Identity and Agency in Cultural Worlds}

Identity and agency within the context of the conceptual framework lies in the center of the micro and macro spheres. The identity and agency framework was originally conceptualized by the anthropologist Dorothy Holland and her colleagues in 1998 and has since become wellused among scholars in education and the social sciences. In this theory identity, or selfunderstanding, forms within major structural features of society, such as race, ethnicity, nationality, gender or sexual orientation. Agency, the capacity for action in society, also forms within these structural features. The concepts of identity and agency do not stand alone, but rather inform one another, as I will describe in detail in this section.

In this framework it is possible to focus on the development of identity and agency specific to activities situated within socially constructed and historically contextualized cultural "worlds." I diverge slightly, however, from Holland (1998) and choose to use "identit(ies)" rather than identity as features of cultural worlds. I have chosen to do this because the inclusion of the plural identities within the parenthetical shows the ways in which our singular identity consists of complexities of identities that are ever-present and work together to create a whole person embodiment. I generally use the term identit(ies) from this point forward. "Worlds" frame various aspects of social life, such as romance, academics, or local politics; and in the case of this study, I use the worlds metaphor to frame being an LGBTQ student on a university campus. This, however, may be further contextualized as the experiences of all LGBTQ students are likely not the same and the worlds will look different depending on identit(ies) and agency. 
The theory is informed by three major concepts: the figured world, identit(ies) in figured worlds, and self-authoring.

Figured worlds. The worlds that Holland and her colleagues described are created in part through language, particularly figurative language such as metaphor. The figured world is defined as "a socially and culturally constructed realm of interpretation in which particular characters and actors are recognized, significance is assigned to certain acts, and particular outcomes are valued over others" (Holland et al., 1998, p. 52). The concepts of who gets to name, interpret and value certain acts and outcomes over others is discussed further by the concepts within Queer Theory later in this chapter. Figured worlds are historical phenomena and social encounters in which participants' positions matter, are socially organized and reproduced, and distribute "us," giving the landscape human voice and tone (Holland et al., 1998). According to Holland (1998), the "relationships of the practices and activities that instance figured worlds with larger, institutionalized 'structures' of power confer a depth to figured landscapes that extends beyond the immediate order of interaction" (p. 57). Understanding the figured world can therefore help us to understand not only the individual within that moment, but also their position within a structure of privilege or oppression. This position within a structure of privilege or oppression is further explored within the next section of the conceptual framework, intersectionality and interdependence. It is not enough just to recognize these positions, but it is necessary to look at the ways in which they work together as intersecting and interdependent systems on all levels. These systems are a part of creating the figured world and the individual's position within the system creates identities within that figured world. These systems create the trajectories of the figured world and are a part of moving individuals along those trajectories. 
Identit(ies) in figured worlds. There are two types of identit(ies) constructed in figured worlds. First, figural (or narrative) identit(ies) are those that speak to the events, actions, and characters of the figured world and are a part of the general story line (Holland et al., 1998). Second are positional identit(ies). Positional identities "have to do with behavior as indexical of claims to social relationships with others, how one identifies one's position relative to others, mediated through the ways one feels comfortable or constrained" (Holland et al., 1998, p. 127). These positional identities relate to one's power, status, and relative privilege within the figured world; lending to how one socially identifies with others and one's sense of social place and entitlement (Holland et al., 1998). They can mean many things, but within this study they encompass sexuality, class, race, culture, ability, status and position within the university, and any other positionality that is relevant for the participants.

Self-authoring. Self-authoring is the meaning that we make to ourselves and that is invisible to itself. Self-authoring moves from an inner speech into social speech. According to Holland, the space of authoring is "a broad venue, where social languages meet, generally and accentually, semantically and indexically, freighted with the valences of power, position, and privilege" (p. 203). The authoring self is invisible to itself and this self-authoring happens within a space of authoring, which can be seen as a zone of proximal development, meaning that the individual can do more within the context of the support of others (Holland et al., 1998). Holland states that the authoring "comes from the I, but the words come from collective experience" (1998, p. 171). It is in this space, I argue, that LGBTQ students' identities and experiences interact and are shaped by the campus climate. By using Holland's framework to understand students' particular experiences, it is possible to see the ways in which they are shaped by the environment and the ways in which students are shaping that environment with their authoring. 
There is a constant movement during which identit(ies) and agency is created, or rather during which one's self-control and ability to exert control over one's own position within the figured world is created or is not created. This movement takes place within the space of authoring and the movement is driven by self-authoring. However, people are not able to freely self-author without structural constraints. Their positional identities within that figured world, such as class, gender, sexuality, intersect in ways that influence the trajectories of their experience. Even in understanding the realms of gender and sexuality, the ways in which these inequities manifest are quite complex and interact within the figured worlds in ways that unfold differently for each individual.

This study seeks to understand the ways in which positional identities influence these trajectories and how these trajectories are adjusted and sustained through relations, such as between participants and other students or with faculty or administration, as well as among and between groups, such as within the LGBTQ community and across different axes of identit(ies). Identit(ies) and agency is the way in which these all come together within a particular context at a particular time. There are historical and situational determinants to a person's present position and these shape the level of agency, or self-control, that the person can exert over their selfauthoring. However, even in the face of powerful situational determinants, there are ways in which individuals find ways to afford self-control and agency, but this is especially true when supported by others of like perspective (Holland, 1998). The way in which these tie together for this conceptual framework is illustrated in Figure 2.

Figure 2.

Identit(ies) and Agency in Figured Worlds. 


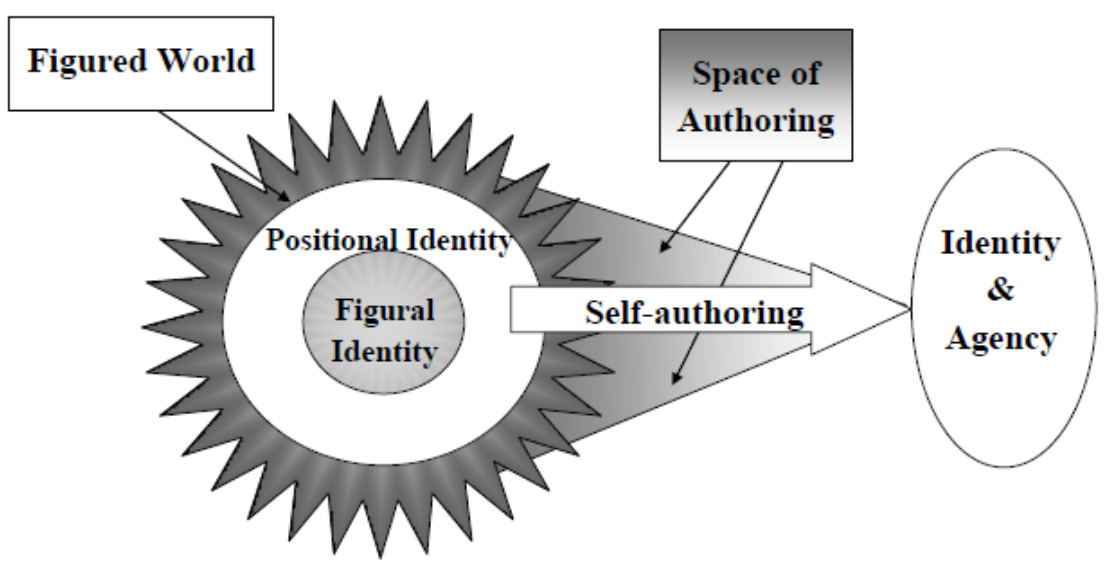

Figure 2: Visual representation of identit(ies) and agency formation. Identit(ies) and agency is developed out of a self-authoring. This self-authoring takes place within a space of authoring, which comes from the larger concept of one's positional identit(ies) and figural identit(ies) within the figured world. These stories may then lead to different life outcomes based on both individual agency and the specific contexts in which the individual is placed.

\section{Intersectionality and Interdependence}

A theoretical framework that includes conflict theory, queer theory, and certain curricular theories guide this study in understanding student experiences. LGBTQ students' experiences are shaped not only by their sexual orientation, but also by other aspects of their identities and how these interact with their surrounding environments, as well as the ways in which their identities have fit within the context of their experiences prior to the higher education setting.

Intersectionality is an approach that takes into account the ways in which sexuality, race, gender, class, and other identity markers come together at societal and individual levels to reinforce privilege and oppression. As Weber (2010) states "race, class, gender and sexuality are systems of oppression. Oppression exists when one group has historically gained power and control over 
societally valued assets by exploiting the labor and lives of other groups and using these assets to secure its position of power into the future" (p. 17).

This framework considers that oppression exists at the level of higher education and that certain groups have power over others in this system. The ways in which these structural inequalities manifest within any specific context cannot be assumed. The intersections of sexuality, race, gender, and class vary depending on historical and geographic location, as well as the individuals involved. Therefore, it is important to consider all of these components in understanding sexuality with regard to identity in a specific location and context. There are many models of LGBTQ identity development, but those that are most in line with my conceptual framework are the feminist, postmodern, and queer theory perspectives. These most take into account LGBTQ identities within the context of "the system" and with regard to gender identity; they view that it is "not necessarily linked to biological sex assignment at birth, but is created through complex social interactions and influenced by the dynamics of institutionalized power inequalities (Bilodeau \& Renn, 2005). LGBTQ identity development must be considered alongside all other aspects of an individual's identity. It is important to recognize that "the meanings of race, class, gender, and sexuality are not fixed, immutable, or universal but arise instead out of historically and geographically specific group struggles over socially valued resources, self-determination, and self-valuation” (Weber, 2010, p. 18). On an individual level "multiple-identity LGBT people have to contend with racism and religious intolerance from within the LGBT community and from homophobia within the various heterosexual minority and religious communities" (Poynter \& Washington, 2005, p. 44). Therefore, it is important to have a conceptual framework from which to view this study that guides an understanding of complex identities within a complex system. 
While intersectionality is a useful conceptual tool, it can perhaps be taken to an even deeper level by considering the concept of interdependence. Hackman (2012) offers an interdependent framework for teaching LGBTQI (lesbian, gay, bisexual, transgender, queer, and intersex) issues in higher education, stating that "different forms of oppression are not discreet entities that merely intersect, but are in fact deeply dependent for their survival" (p. 3). This means that there can be no LGBTQI liberation without also dismantling gender binaries, racism, and white privilege. This makes it a matter of moving beyond thinking of identities and oppression as parallel and similar to really digging into the ways in which these are constructed and reinforced in our society. According to Hackman, to counter interdependent oppression, educators must move beyond the concepts of "safe spaces" and "embracing diversity" and stop understanding social justice issues within a single-issue approach in order to understand the ways in which all forms of oppression serves to "reinforce, legitimize, and support all other forms of oppression" (p. 3).

\section{Queer Theory}

Currently and historically, LGBTQ individuals have had labels imposed onto them from society. These have gradually been reframed, renamed, and reclaimed. One of the most noteworthy reclamations is the term "queer," which has become used as an inclusive identity label and a disruptive theoretical perspective. Initially, the phrase "queer theory" was coined by Teresa de Lauretis to jokingly serve as the title of a conference in 1990 at UC, Santa Cruz (Halperin, 2003). By pairing the term 'queer,' a label that had been reclaimed by activists and street kids with the term 'theory,' which was an 'academic holy word,' Lauretis effectively disrupted the status quo. Queer theory caught on quickly and was seen as an "advanced, postmodern identity" that "superseded both feminism and lesbian/gay studies" (Jagose, 1996, p. 
340) and brought about queer scholarship in the academy and academic respect for queer work. Because there was not sufficient development on queer theory at this point, it was essentially created as a response to the academic demand. It is admittedly difficult to pin down a definition of queer theory because doing so contradicts the premise of queer theory as being nonnormative. Creating a school of thought surrounding queer theory is to "risk domesticating it, and fixing it in ways that queer theory resists fixing itself' (Jagose, 1996, p. 2). While this may be a risk, it is still necessary in creating a conceptual framework to determine, albeit broadly, what is meant by queer theory and by the term queer. Jagose (1996) defines queer as "those gestures or analytical models which dramatize incoherencies in the allegedly stable relations between chromosomal sex, gender, and sexual desire" and that "queer focuses on mismatches between sex, gender, and desire" (p. 3). The term queer serves to de-naturalize and to contextualize the history inherent in heterosexual and homosexual identities.

Pinar (2003) discusses using queer theory in academics and calls for a stance of homosexual positionality that is critical and grounded in theory in order to reject the "lure of Anglo-American patriarchy, of homosociality, of misogyny and racism, of 'power'” (p. 358). A strong critique on hegemonic white male subjectivity is at the heart of Pinar's discussion of queer theory. Pinar asserts that hegemonic white male subjectivity must have a radical restructuring, be dismantled and even brought to ruin in order for a democratic American society to proceed. A major consideration of this hegemonic white heterosexual male perspective is the understanding of difference. Hegemony depends on a "traumatic privileging of difference" ( $p$. 358). This difference is racialized and gendered, and then sexualized according to both of these constructs. Pinar suggests that a queer framework would cause one to see difference in sameness and sameness in difference, thus undermining the creation of privilege; difference still remains, 
but is expressed and perceived through self-differentiated difference. There is a democratic and horizontal distribution of difference relative to race, class, and gender.

What really needs to be done, and what queer theory can be useful in facilitating, is seeing the second half of Pinar's point: the difference within sameness. Loutzenheizer and MacIntosh (2003) point to multicultural policies in classrooms such as 'can't we all just get along' and 'foods and festivals,' as being similar to the use of tokenized gay historical figures in classrooms. These are the types of ideas that students are bringing with them from their education as they enter a higher education setting. However, seeing more differences within the sameness points to an idea that recognizes that the mythical norm of white male heterosexuality is just that, mythical. It also makes the distinction between equality (all things being the same) and equity (recognizing and seeking to dismantle the systemic, individual, and political inequities that are present on various axes of power).

The concept of heteroglossia can help to frame an understanding of sexual orientation. Heteroglossia is by definition the inclusion of all conflicting voices (Pinar et al., 2008). Whitson's conception of heteroglossia states that when one assimilates new knowledge to prior knowledge, nothing gets changed, but when one enters into the "otherness" in a way that prior experience and knowledge offer little help in understanding the new, then in this space of "otherness" dialogue can be authentic and students can come to a new understanding (Pinar et al., 2008). While heteroglossia may include a simultaneity of different languages, it also comes with "their associated values and presuppositions," as a rule in social life (Holland, 1998, p. 170). By including all conflicting voices and dismantling the mythical norm, queer theory provides an opportunity to address the concept of "the other" in policy, curriculum and student experiences. It is still important, however, to realize that even the conflicting voices carry with 
them the power and privilege assigned by the structure of the social context. The term "queer" itself, when used, "as opposed to gay, lesbian, or bisexual, purposefully disrupts the notion that identity is fixed or immutable. It includes a move to highlight the existence of and interrupt silent assumptions about heterosexuality as normal and homosexuality as 'Other' (Loutzenheiser \& Macintosh, 2003, p. 152). Queer theory can provide an opportunity to ask the question: could it be that everyone is queer, which is very different from the concept seen above that essentially asks "aren't we all the same?" Ahmed (2006) states that "we learn the habits of gender and sexuality, become gendered and sexed subjects long before we develop any capacity for critical reflection on or resistance to habits" (p. 102). The queering of heterosexuality can bring to light the ways in which heterosexuality is privileged, rather than just looking for the ways in which LGBTQ students lack privilege.

\section{Curriculum Theory}

Curriculum within higher education includes more than just text and that which is studied within courses and listed on syllabi. Curriculum also includes the priorities that an institution sets

on research, funding, course and major directions, guest lecturers, and many other factors outside of class that affect students directly and indirectly. Besides the distinction between the curriculum that is distinctly in-class and that, which is distinctly out-of-class, there is an overlap between what is learned inside and outside of the classroom and students' coursework. In many cases the out-of-class curriculum operates on a macro or institutional level and in-class curriculum is on a micro or mezzo level. However, this is not always the case, nor would it always be possible to distinguish easily between whether an element of curriculum is operating on a micro or macro level. Many elements of institutional power could come into play with decisions made about individual courses, and therefore the expression of curriculum may not be 
entirely micro in nature. All of these have elements of explicit, or stated, curriculum and implicit, or hidden, curriculum. Curriculum theory can help us to understand the ways in which these intersections of in-class and out-of class curriculum and implicit/explicit curriculum intersect, as well as the ways in which curriculum is at its core is political, institutionalized, and racialized/sexualized/gendered. It is not new to call on education to draw attention to the ways in which curriculum supports or denies justice. Anyon (2005) stated that "education already has a strong tradition of critical pedagogy and social justice activism to call upon" (p. 5). While activists and educators have made significant strides in LGBTQ inclusion within curriculum, there is still work to do. This work includes integrating our understanding of sexuality and gender identity into our conception of educational theories and frameworks. Simultaneously we must execute that understanding in our daily work within the educational system. Educators still have a responsibility as laid out by Sears (1987) to promote human dignity and to support the struggle for equality through education, which he described as:

Providing a learning environment which is free from physical and psychological abuse, portraying honestly the richness and diversity of humanity, fostering an understanding of human sexuality, integrating homosexual themes and issues in the curriculum, counseling young people who have or may have a different sexual orientation, and supporting gay and lesbian teachers. (p. 79)

While educators as individuals may see themselves as impartial and independent, it is now clear from a conceptual standpoint that education does not stand separate and neutral from power structures within society. Pinar and his colleagues (2008) explain that, despite the beliefs contained in literature prior to the 1970's that curriculum and schools in general were politically neutral, there is little to no argument in the theoretical literature now that 
curriculum can be read as a political text (p. 244). Indeed the American public education system has historically been used to play an important role in "founding political legitimacy and economic development policy on incorporating heterogenous waves of immigration into a mass national 'culture"' (Carnoy, 1989, p. 3). Curriculum can be understood as institutionalized text by understanding how it functions bureaucratically and how it is linked to the everyday functioning of the institution (Pinar et al., 2008). The subtle ways in which curriculum is politicized and institutionalized can be understood through one definition of hidden curriculum that comes from McLaren (1989) who explained:

The hidden curriculum deals with the tacit ways in which knowledge and behavior get constructed, outside the usual course materials and formally scheduled lessons. It is part of the bureaucratic and managerial 'press' of the school - the combined forces by which students are induced to comply with the dominant ideologies and social practices related to authority, behavior and morality. (Pinar et al., 2008, p. 248)

Cornbleth, in 1991, critiqued political scholarship as overlooking the setting when analyzing the sociocultural dynamics, such as gender and economic elements, saying "contextual elements were multidimensional, fluid, and intersecting" (p. 256). Pinar and his colleagues (2008) discussed that Cornbleth recommended that, rather than labeling "hidden curriculum," it was more useful to examine "the constraints and opportunities as well as the seemingly contradictory messages that are communicated by curriculum practices and the school milieu" and how students mediate these in order to emphasize the relational nature of social reality (p. 256). Inherent in this social reality are the lived experiences of students. Giroux states that in order to conceptualize the cultural politics of education, it is necessary to analyze "how social power organizes the basic categories of class, race, gender, and ethnicity as a set of ideologies 
and practices that constitute specific configurations of power and politics" (p. 147).

Understanding students' lived experiences in a way that takes into account the complexity of human behavior within a system is a necessary component of this. According to Giroux and McLaren (1989):

Schools need to be reconstructed [sic] around a cultural politics and pedagogy that demonstrate a strong commitment to engaging the views and problems that deeply concern students in their everyday lives. Equally important is the need for schools to cultivate a spirit of critique and a respect for human dignity that is capable of linking personal and social issues to the pedagogical project of helping students to become critical and active citizens. (p. 250)

Apple (1989) looked at the impermanent and constantly shifting relationship of political and educational concepts, discussing the ways in which these "ideological conflicts work themselves out" by saying that education "is one of the major sites in which different groups with distinct political, economic, and cultural visions attempt to define what the socially legitimate means and what the ends of a society are to be" (p. 34). However, in reality the honest dialog about these ideological conflicts is often stifled. Smith et al. (2008) looked at the ways in which there is not an open discussion on politically-charged issues and also found that college and university administrators are "much more likely to be timorous and to see only the dangers and the downside of fostering genuine political debate on their campus" (p. 136).

Educators have access to the tools necessary to create change, but in order to do that, they must first become aware of the existing power structures, how their pedagogical practices play into these and take steps to change this. In the book Teaching to Transgress, hooks (1994) describes feminist classrooms as spaces where professors tried to create "participatory spaces for 
creating knowledge" when she began teaching in the 1970s (p. 15), but that there has since been a shift away from this. hooks also stated that instructors who cannot communicate well are not able to teach students to do so and that those professors who are critical of "confessional narrative in the classroom or of digressive discussion, where students are doing a lot of the talking, are critical because they lack the skill needed to facilitate dialogue" (p. 151). While theory alone cannot create skill, having a theoretical stance that includes students' voices can provide educators with a foundation upon which they can confidently open up their teaching and research for shared knowledge creation.

Freire (2010) stated in Pedagogy of the Oppressed, "Only dialogue, which requires critical thinking, is also capable of generating critical thinking” (p. 150). For this dialogue to happen, Freire indicated that love, humility, faith in man, mutual trust, and hope must all exist. This indicates the importance of relationship-building between instructor and student in establishing critical thinking and open-mindedness. Freire cautioned that revolutionary leaders (and this could be applied to 'revolutionary' academics) cannot fall for a top-down approach of content planning and, rather, must fight alongside the oppressed for mutual liberation. Teachers must find ways to allow for the authentic speaking of non-dominant voices within the classroom. By challenging the status quo and hegemonic assumptions about education, teachers can end the false distinction of transmission of knowledge from "expert" to "novice" and can create the participatory learning environment discussed by hooks (1994). As Freire (2010) stated, 'authentic education is not carried on by ' $\mathrm{A}$ ' for ' $\mathrm{B}$ ' or by 'A' about ' $\mathrm{B}$,' but rather by 'A' with 'B,' mediated by the world"' (p. 93).

Students all bring their own unique worlds into the classroom. By creating an environment in which they can share these perspectives, instructors are breaking down that 
divide. bell hooks (1994) stressed the need for both analytical and experiential ways of knowing, that all students come to us with the "authority of experience" (p. 89), and that teachers should welcome this knowledge and grow from it. hooks (1994) made an analogy comparing experience to flour where she stated that if making a recipe for bread that called for flour and we had all of the ingredients but the flour, suddenly this becomes the most important ingredient, despite being insufficient alone (p.92). This is the same as experience. Experience is insufficient as a sole ingredient in rich critical discussions, but it can take us as educators and students that extra step farther in our understanding. We can create an environment that is equitable, conscious, and reciprocal, thus allowing for true learning to take place; empowering students to openly discuss and critically reflect on issues that are at once personal, political, and academic, as with difficult discussions related to identity. It is for this reason that student experiences are centered within this study — they are the "flour" in this recipe of understanding LGBTQ students within the context of one institution of higher education. 


\section{Chapter 3: Methodology}

When planning a research design that includes attitudes about and towards lesbian, gay, bisexual, and transgender individuals on a college campus, there are many methodological, political, and contextual issues to take into account. Brown and Gortmaker (2009) give methodological implications about conducting campus climate studies for LGBT students. They state specific drawbacks and benefits of using quantitative versus qualitative studies, as well as considerations to take into account. While quantitative studies can allow comparisons among and within college populations and settings, drawbacks include that they are limited in that there is no insight into the reasoning behind the responses. Further, a large sample is needed, and there is little opportunity to revise the study once it is begun. A qualitative method on the other hand allows an opportunity for exploring the responses in-depth, allows for follow-up and gives a better understanding of the participants. As said by Brown and Gortmaker (2009), a major strength of qualitative methods in regards to LGBT student experiences is "the richness of the findings, as they capture the voices of the respondents. Reporting stories of real life experiences can be particularly revealing and have a strong impact on the study's audience" (p. 121).

\section{Purpose of the Study}

As noted in chapter one, the purpose of this study was to address the research question "How do students who openly identify as lesbian, gay, bisexual, transgender, and/or queer (LGBTQ) perceive the campus climate at this university and in what ways are their experiences shaped by that climate?" This study was designed to hone in on those student perceptions of experience and to look at identity and agency as situated within those experiences. Within this study I wanted to understand the ways in which LGBTQ student experiences were shaped, influenced, created, reflected, and/or formed in relation to the climate as they perceived it. The 
study was not a comprehensive campus climate assessment, but rather was intended to understand more focused students' perceptions of campus climate to fully expand upon their experiences and how these relate to identity and agency. While the study asked specifically about LGBTQ student experiences, it was the goal to more broadly explore sexual orientation and gender identity related to identity and agency in the context of campus climate and experiences. Towards that purpose, the study was not made exclusive to those who identified as lesbian, gay, bisexual, transgender, or queer, but rather was opened to any student who identified as noncisgender or non-heterosexual.

\section{Theoretical Perspective}

The conceptual framework that centers student experience is not just at the heart of the theoretical perspective of this study, but also at the center of the methods of the study, shaping the decisions made in concrete ways. This study was guided by four major conceptual perspectives: identity and agency in cultural worlds, intersectionality/interdependency, queer theory, and curriculum theory. All four of the concepts guided the methods of the study in major ways, including the structure of the methods, the questions asked of the participants, and the analysis of the data. While these were not limited to particular aspects, some did shape specific areas in greater and more relevant ways than others.

My understanding of intersectionality and interdependence are woven through the conceptual framework visually and conceptually and this followed into the methods. Intersectionality and interdependence shaped my attempts to reach a broad range of identities not just in sexual orientation and gender identity, but also in race, ethnicity, national origin, class, background, ability, student status, and many identities. These concepts also shaped the questions that I asked in the Demographic Questionnaire (see Appendix A), such as how do you 
identify your race and ethnicity? Understanding the complexities associated with intersectionality and interdependency led me to making all of the questions open-ended on the demographic questionnaire and to closing it with the question "what else do you feel is important in your life and related to your identity that you would like to share?" I also added many questions into the individual and focus group interviews that would allow participants to discuss topics from an intersectional perspective, such as asking about belonging or isolation based on other aspects of identity, involvement in specific organizations, times when they felt especially aware of specific aspects of their identity (see Appendix B: Interview Protocol Questions).

Queer Theory was another key concept of the conceptual framework of this study. I remained constantly vigilant to try to center marginalized voices and to attempt to hear all of the differing perspectives, which is reflective of queer theory. Because I understand LGBTQ students' identity development from a feminist/queer perspective, it was important to me to consider the social construction of these identities within the systems of power on campus (Bilodeau \& Renn, 2005). Some considerations that helped to drive this understanding included examining how the university's context influence students' comfort level at being "out" and what that means to them. A queer theory perspective also drove the decision to add the language "or other non-cisgender/non-heterosexual identified" to the IRB-Approved Advertisement (see Appendix F), as this opened up the call for identities to more than just the LGBTQ acronym.

Keeping curriculum theory within the perspective of this study shaped decisions within the participant selection process, recognizing that academic learning takes place both inside and outside of the classroom and using both of these mechanisms as tools of recruitment. Curriculum theory also guided the questions asked in individual and focus group interviews, with questions on both explicit and implicit curriculum. 
Identity and agency in cultural worlds had the largest impact in shaping the data analysis of the study. As detailed at great length later in this chapter, the Figured Worlds Tool is a direct reflection of Holland's concept of Identity and Agency and was one of the major tools that I used to analyze the individual and focus group interview data. All of these were equally important in coming together to form the full context of the theoretical framework and thus the tapestry of the methods from the initial design all the way to the data analysis and drawing up of the findings.

\section{The Research Context}

This research was conducted at the land-grant institution of West Virginia University. The main WVU campus was the context and setting of the figured world that the participants experienced, but there were innumerable figured worlds embedded within this context. As stated

in chapter one, WVU includes sexual orientation in its non-discrimination and equal opportunity policies, but it does not include gender identity. WVU has 'soft benefits' for same-gender partners, which include usage of the library and recreation center, but it does not have health benefits for same-gender partners, nor does its student health insurance provide benefits for gender reassignment surgery or hormone replacement therapy. Compared to the rest of the United State, the institution is located within a state that is more religious than average, less educated than average, with a more rural population, less resources, and often swayed by a powerful coal industry.

Related more specifically to students, the university has multiple student organizations, but no center or office dedicated to LGBTQ outreach. Notably, during the course of this study, the university did fund a graduate assistant to provide part-time LGBTQ outreach and the researcher of this study was recruited for this role, as discussed in researcher's roles. While there were courses throughout many colleges within the university related to gender, sexuality and 
gender identity, the Center for Women's and Gender Studies had only within the past year of this study established an LGBTQ Studies minor. It is important to understand the broader research context of the institution to recognize the ways in which LGBTQ students were likely to have been accepted or respected within this campus climate, and this would likely depend on the students' contexts within the university. For many students who had access to these resources, they may see the university as progressing rapidly due to the steady changes over the past few years. However, for others who did not have access or who were in departments that were isolated from the resources, they may not have been aware of the progress. Due to the lack of certain policies, full-time staff, and a center/office, it would not have been as evident to students what did or did not exist on the campus. For those reasons as well, the context of the research institution are even more salient within the context of this study.

\section{The Participants (And Their Roles)}

I began the participant selection by directly contacting the leadership of the LGBTQ student organization, Spectrum, to pass the information about the study. I have worked with the organization in many contexts over the past three years and have established a rapport with many members. I also contacted individuals who were previously leaders of the organization directly. I solicited involvement by attending meetings and by posting directly to the social networking media that the members use, such as Facebook. I also posted the advertisement to other groups on Facebook that were known to be supportive of LGBTQ students, rights and activism efforts, such as the Young Democrats, the Gender Equality Movement, and the Secular Student Alliance. I provided contact information through all correspondence on how I can be reached privately and encouraged that type of contact over publicly posting, so that potential participants would remain anonymous. If anyone commented on a post on social media, I deleted it and let them know why. 
I provided enough information about the study so that it could easily be passed along to peers who may be interested in being involved, as can be seen in the Social Media Advertisement that was approved by the IRB and is seen in Addendum F. This allowed for some snowball sampling. In selecting the sample,

As listed on the advertisements in order to participate in the study, I required that students met the following criteria:

- Currently enrolled or have been enrolled in the university within the past year

- Identified as lesbian, gay, bisexual, transgender, transsexual, queer, pansexual, samegender loving or other non-heterosexual and/or non-cisgender identity

- Have been at WVU for at least one year

After they expressed interest in participating and I scheduled a time to meet with them, at the individual interview, participants first signed an IRB consent form in order to be involved with the study. This consent form also made them aware that they can drop out at any time that they so choose, see Consent Form in Appendix G. Participants were made aware of the expectations of involvement in the study. These included one individual interview lasting about one hour and two possible focus group sessions lasting one hour each, for which the topics would be determined based on the content of the individual interviews.

I ran two sets of focus groups with between 4-5 members in each group. I had allowed for the groups to be between 4-7 participants and the end size was based on those whose schedules would allow them to make the meetings that I had coordinated through email, at the time when the largest number of participants were available. Since 9 individuals in total were involved in the focus groups, but could have been more based on the allowed size, I tried to oversample for the interview portion to ensure that I was able to select enough individuals to 
create the two groups. As it is recommended that one over-recruit by about $20 \%$ to account for follow-through (Morgan, 1997), I initially conducted individual interviews with 15 students. This was enough to allow over-recruitment for participation in the two focus groups after the individual interviews. In order to hold two focus groups with between 4-7 individuals in each, I wanted to recruit additional participants to allow for the coordination of these focus groups. The sample size of 15 also allowed for a variety of identities in terms of sexuality, gender, gender identity, and student status of undergraduate or graduate.

\section{The Researcher (And Her Roles)}

As mentioned within the context of the research institution, one important role that I held as the researcher at the time of the study was the distinction of being the first person on campus to be paid specifically to perform LGBTQ-outreach work. While this work was part-time as a graduate assistant, it was still a more institutionalized role than the university had hosted prior. Additionally, this study was in progress at the time that I was offered the position. I had been at the university for eight years at the time of the study in the roles of graduate student, instructor, and graduate assistant. I considered myself a teacher and an activist on campus and I was often known by others for my affiliation with the Center for Women's and Gender Studies, though my graduate assistantship with that center had ended over a year prior to the start of the study.

As a student, I was enrolled throughout my time at the university in classes in school counseling, counseling, women's and gender studies, and education and received a Master's Degree in Counseling. As an activist most of my work focused on issues of equity related to gender and sexuality, though it often broadened out to issues of social justice more broadly speaking. Through this work, I had forged connections to many student organizations and had served in leadership positions in the Gender Equality Movement, which is the campus feminist 
organization, and Spectrum, which is the campus LGBTQ organization, prior to the study. While there could be drawbacks to both the institutional roles and the activist roles interfering with the researcher role, this helped to establish rapport with the organizations and instructors as I spread the word about the study and gave credibility to my intentions and knowledge behind the research.

\section{Data Collection}

Based on all of these research considerations, I conducted a qualitative study to answer the research question. A qualitative study allowed me to best capture the voices of students' experiences, which was to remain the focus of this research. Before any data was collected, the institutional review board (IRB) for West Virginia University approved all participant advertisements, consent forms, protocol questions, demographic questionnaire, and data collection methods. The IRB-approved forms with an attached watermark were used throughout the course of the study.

I conducted both individual and focus group interviews. This particular combination was to allow for a full picture of the students' experiences. The individual interview was to give an initial glimpse into the students' lives from an individual perspective, as the "qualitative research interview has a unique potential for obtaining access to describing the lived everyday world" (Kvale \& Brinkman, 2009, p. 29). By asking students on a one-on-one basis for more information about their world within the context of the university and how it relates to their sexual orientation and gender identity, I hoped to be able to probe deeper for a more nuanced understanding. Kvale \& Brinkmann (2009) said that "interviewing is an active process where interviewer and interviewee through their relationship produce knowledge" (p. 17). Through this active co-construction of knowledge, I wanted to get depth on certain aspects of their 
experiences.

All of the information collected from participants was collected using open-ended questions. The overall structure of this data collection began even with the Demographic Surveys distributed to the individual prior to their individual interview, as seen in Appendix A. I conducted these individual interviews first over the course of about a month. After initial coding of this data and pulling themes about which to direct the focus groups, I then ran two separate focus groups. The questions for the individual and focus group interviews are listed in Appendix B and Appendix C, respectively. The additional questions specific to the focus groups on participating in panels in the classroom and on bisexual, pansexual, and fluid sexual identities are in Appendix D and Appendix E, respectively. Conducting the interviews first was to allow me to choose from these particular areas expressed by the individuals to bring out ideas in the focus groups. This choice of order was also to help limit, or at least call attention to, group-think. The recommendations for ordering of individual interviews and focus groups is based on the purpose of the study, but the work of one researcher can offer some insight on the ways in which this order can affect the dynamic of the responses (Morgan, 1997). One example given of this dynamic is a study in which the researcher asked adolescent males about their relations with the opposite sex and found that when the boys were asked first in focus groups, they answered with a "macho" and bragging response, which they continued in their subsequent individual interviews, however when the order was reversed the boys displayed sensitivity in their individual interviews, but still displayed the "macho" responses in the group (Morgan, 1997). While the population and expected tonal outcomes are different from my subjects, the implications from this study reinforce the idea that it may be possible to extract more personal 
information from students by having conducted the individual interviews first. If I were to conduct the focus groups first, there was the possibility that the dominant ideas of the group could have, consciously or unconsciously, influenced the follow-up responses of the entire group.

Focus groups offered two major benefits to this study. First, in moderating a focus group, I could ensure that the participants paid special attention to the aspects of the research question and second, the data collected was reliant on the group members' interactions (Morgan, 1997). Because I was looking at students' lived experiences, it was helpful for them to have interactions with others who have similar lived experiences. There were topics that emerged that individuals did not think of on their own, but that resonated strongly once they considered it. While their own sexual orientation or gender identity may be something to which they've given plenty of thought, it is likely that their day-to-day experiences related to that are something that was not as transparent. As Morgan (1997) stated, "focus groups may have an advantage for topics that are either habit-ridden or not thought out in detail" (p. 11).

Just as the interaction of the set of students strengthened the focus group and a reason that I choose to use this method for this research, so did it come with some drawbacks. I was selecting participants from a relatively small and close-knit population and so I wanted to use as many approaches as possible to ensure that not all individuals knew one another or were in similar social locations. Within both focus groups there were some students who seemed to know one another and there were others who did not. They may have therefore brought preexisting social dynamics into the focus group, which could have served to preference certain individuals' experiences over others. I ran the risk of the dominant voices drowning out those whose experiences may already be silenced, thus contributing to a dynamic that I would also 
then be unable to learn about. However, within both focus groups, it seemed that all participants did feel comfortable speaking openly and all were equal participants in the discussion.

Additionally, there could have been "assumptions among acquaintances (that) include invisible boundaries around the subjects that they have tacitly agreed not to discuss" (Morgan, 1997, p. 38). In order to minimize group social dynamics from obscuring the content of the focus groups, I had several checks in place for authenticity. Besides the framing of the individual interview before the focus groups, I also allowed time at the end of each focus group for students to journal any closing thoughts that they did not get to say during the group. The journal prompt was open-ended and served to bring attention to the silences that would have otherwise gone unnoticed. I provided participants with the option to handwrite their responses on lined paper notepads, on blank paper. Since artistic expression and poetry had come up in some of the individual interviews, I also told the participants that they could draw, illustrate, create a poem, or use other creative means to express themselves. I brought pens, pencils, markers and colored pencils for them to use. However, at both of the focus groups, all of the participants stated that they felt that they were able to express everything that they wanted orally within the context of the group. No one chose to use the journaling or artistic options to share anything additional. Morgan (1997) stated, "the problem with having only one group is that it is impossible to tell when the discussion reflects either the unusual composition of that group or the dynamics of that unique set of participants" (p. 44) and no matter how detailed the analysis, there still exists the possibility that "the substantive content of the discussion may have been due to that one group's unique composition or dynamics" (p. 59). While this qualitative research is not intended to be generalizable, it was important that I minimize sampling bias. As seen in the discussion on population vulnerability, the voices of transgender and bisexual students are especially at risk for 
being silenced and overshadowed by the experiences of lesbian and gay students (Beemyn, 2005; Beemyn et al., 2005; Grant et al., 2011; Harley et al., 2002). It was therefore worth considering segmenting the groups into more homogeneous samples, such as based on sexual orientation or gender identity, in order to allow for a true dialogue. This may be logistically difficult and, due to the fluid nature of sexuality and gender, it is somewhat contra-indicated. The decision to have a focus group that was based on a set of identities, that of the bisexual, pansexual, and fluid sexual identities, was due to the themes that came out of the individual interviews. This decision was not made as an attempt to separate students based on their identities in order to minimize the dynamics that could inhibit group sharing. As the moderator, I tried to take the possibility of within-group bias into account and do my best to minimize the harm that could be done by this and at the very least I took these factors into account in the data analysis.

\section{Data Sources: Individual Interviews}

After completing the IRB consent form, participants filled out the Demographic Questionnaire listed in Appendix A. Individual interviews lasted between 35 minutes and 90 minutes, as needed. I conducted the interviews in a setting that allows for privacy yet is also within a public venue to allow for a feeling of safety and accessibility, such as a room within the downtown library. After the participant and I set a time that worked for us both, I arranged for a private study room and confirmed the reservation with them. When it was more convenient for the participant, I conducted the interviews in a private conference room in my office. I gave participants the options of multiple campus locations depending on the time and day of the interview. For most of the individual interviews, I brought the participant a bottle of water as I found that they sometimes would get thirsty during this process and it made them more comfortable. All of the interviews were recorded on a digital handheld device, which I then 
securely saved onto a jump drive and stored in a locked location. I transcribed all relevant content within the interviews, changing the individuals' names and any identifying information in order to ensure confidentiality. It took me approximately one month to conduct and concurrently transcribe the interviews before I was able to begin planning the focus groups. I used the questions listed in the Interview Protocol Questions in Appendix B. I completed, transcribed and preliminarily analyzed all interview content prior to conducting the focus groups, as these were intended to influence the content and flow of the focus groups.

\section{Data Sources: Focus Groups}

I conducted the focus groups in a similar setting to the interviews. The room was large enough to accommodate all 4-5 participants, sitting around an oblong table. The content of the focus group interviews was clustered into no more than three categories in order to have no more than three group interview sessions. Based on the content of the individual interviews, I pulled out some major themes on which to base the focus groups. I ran each focus group with a "funnel" format, meaning I presented the group with a broad topic at the beginning and allowed them to have open discussion on this, but probed for more specific issues as the discussion progresses. This allowed me to hear the participants' perspectives early on, while also meeting my research needs (Morgan, 1997).

I began the group with a discussion question and asked each person to answer. This set the tone for hearing from each participant and discouraged any one individual from dominating. I began with the questions listed in the Focus Group Protocol Questions in Appendix C, but modified these to include the questions listed in Appendices $\mathrm{G}$ and $\mathrm{H}$ to include specific questions about the focus group topic, as pulled from the individual interviews. I encouraged participants to jot notes on what they wanted to say so that they would not forget their thoughts 
as their turn to speak approached, however no one chose to utilize this method. During the focus groups I took notes on the relations among the participants, such as interrupting, gestures, look, emphasis, and side remarks that may have given additional meaning to the content of the discussion. At the end of each focus group, I allowed time for individuals to journal or create anything that they were not able to within the full group, but as mentioned previously none of them chose to do so. Focus groups ran between 70 minutes and 85 minutes. I tried to wrap up the discussion after about 50 minutes, asking individuals to give one last thought on what stood out to them the most from today's conversation, but in both cases after this point the discussion took another direction and the participants kept talking for at least another 15 minutes. Keeping the size of the focus groups small, only 4 people in one case and 5 in the other, allowed for more time for each person to speak. The smaller group size also minimized side conversations and maximized cohesiveness.

\section{Data Analysis}

The analysis began with coding the individual interviews. Further analysis of the data focused on two major discourse analysis tools: the Figured Worlds Tool (Gee, 2011) and identity as a lens of analysis (Gee, 2001). Identity as a lens of analysis can be situated within the Figured Worlds Tool and, when looked at together, these two tools come together to pull out the central focus of the conceptual framework: identity and agency. In order to use these tools, which will be further expanded upon, I first transcribed the individual and focus group interviews, omitting in transcription only those parts that were deemed irrelevant to the data analysis, which in most cases of omission were only those pleasantries exchanged at the beginning or end of the interview. I abbreviated some of that which I asked when reading verbatim from the questionnaire, as I could tell from that abbreviated form what I had said. I transcribed the 
participants' words verbatim, including stuttering, joining words, such as "um" and "like," but when these words were just a part of the participant's normal speech pattern and did not indicate something particular regarding their meaning in that sentence, they were removed for ease of reading in the quotations within the analysis and research discussion. In transcribing, I paid attention to the gaps and pauses in between utterances and the emphasis that was placed on words. I used the following conventions (Kvale \& Brinkman, 2009):

[ ] brackets to show overlap of statements

(.) dots in parenthesis to show gaps

:: colons to indicate prolonged sounds

Italicizing to indicate stressing on a word

( ) empty parenthesis to show inability to hear what was said

(( )) double parenthesis to indicate my own descriptions rather than a transcription

The use of the discourse symbols was important in my coding in order to capture the participants' full meanings. According to Mazzei (2007), there is no binary of spoken text and silence. It was important to me to look not only what was said, but also what remained unsaid. Participants are not always silent because they cannot find the right words or have nothing to say, but, rather, sometimes the silences exist because participants have everything to say and words are not sufficient, words cannot say enough—or hide enough (Mazzei, 2007). These silences can be a key in understanding the assumptions that compose the figured worlds.

\section{Data Analysis: Individual Interviews}

I created an organizational structure of the data through coding, using both inductive and deductive coding. The process of conducting all of the individual interviews took about two months. I transcribed these as I went, but it took a few weeks after completion to catch up on all 
of the final transcriptions. Listening to the interviews for a second time during the transcription process was the first process of analysis. I then used initial coding to begin assessing the data for meaning. This was an open-ended approach, during which I was looking for what data was recurring in order to decide what additional data was needed in order to support emerging theories (Saldaña, 2013). It was important to me to draw meaning from the participants' own words and therefore I inductively coded their statements based on the themes that emerged in vivo. In vivo coding is especially useful for studies that aim to "prioritize and honor the participant's voice" (Saldaña, 2013, p. 91) as it uses the participants' own words in order to maintain the perspectives and worldviews of marginalized groups.

After this first cycle of coding for the individual interviews, there were a number of themes that emerged. The major themes - in the general order of the time and intensity devoted to participants' discussion of them — was as follows: identities and understanding of labels; hearing homophobic slurs in specific locations on campus; biphobia stereotypes, and misunderstandings of bisexuality and pansexuality; participation in educational panels; unequal treatment related to gender identity in process and policies; lack of access to LGBTQ social and relational spaces; learning about oneself within the context of university; access to mental health care; comfort or discomfort discussing sexuality within a classroom; role of religion or secular affiliation and sexual identity; negative experiences with housing and roommates; and experiences within particular program or department.

While there were many themes that emerged from the individual interviews, the use of panels as an educational tool and the experiences of bisexual, pansexual and fluid sexualities stood out as the strongest options for the focus groups. These two themes were used as the organizing structure of the focus groups, but the other themes that emerged in analyzing the 
individual interviews also helped to drive the specific focus group protocol questions and the funneling of the discussion in the focus groups. In writing up the results, the themes from the individual interviews also were pulled back into the analysis to use in conjunction with the data from the focus group interviews to highlight, disrupt, or provide a variety of perspectives from the information gathered within the focus groups. I discuss the reasons and process for choosing the foci of the two panels in detail below.

Selecting the themes for the focus groups was not a simple or clear-cut process. There were many themes that emerged from the individual interviews, with a variety of frequency and resonance among participants. While the discussion of the themes that emerged in the individual interviews is not exhaustive of every theme that came up, it is representative of the types of themes and reasons that they were excluded as topics for further focus group exploration. Some themes reflected the research questions, while some themes were outside of the scope of the study.

For those themes that were reflective of this research, sometimes there were other reasons for why they would not have made for good focus group topics. Some themes would not have had enough participants interested in or knowledgeable of them to coordinate a focus group. If there were under four individuals who reflected a theme, it would not have allowed for anyone to be unavailable for the focus group scheduling conflict or to decide to not participate. I was therefore looking for themes that had at least five or more individuals would be available to participate in a focus group surrounding. The theme of on-campus housing and conflict or fear of conflict with roommates regarding one's identity was a theme that emerged four times in the interview process, with a fifth participant mentioning hearsay of this phenomenon. To discuss individual experiences, this would not have included enough participants to constitute a focus 
group.

And while other themes reflected the content of the literature review, these would not have necessarily worked well logistically for a focus group. For instance, many students had difficulty articulating the places in which they felt safest and most comfortable and those in which they felt the least safe or comfortable. Bringing participants back together to discuss this in a group may have yielded some information, but more likely they would merely be influenced by what others in the group were saying. For instance three separate participants stated that they had heard about others hearing homophobic slurs in the downtown area and on High Street. Participants evidenced in individual interviews that they were already easily influenced by previous hearsay and so this did not seem an effective means for drawing out true perceptions of campus comfort levels. Further exploration of possible future research around perceptions of space and safety is explored in chapter five. Several students discussed their experiences with mental health care within the context of the campus. Some of the implications related to these statements are discussed within the analysis, but hosting a focus group around students' experiences of mental health care would not be an appropriate or responsible research decision and so this information was only discussed with participants within the context of the individual interviews.

Finally, some of the themes reflected the content within the literature review and were discussed by enough participants to constitute a focus group, but were too specific around which to design a focus group singularly. As many of these themes tied into the topics of the selected focus groups, they were thus included in the respective focus group for discussion. Several participants brought up the concepts of identity labels and the application of labels that resonated most for them, as there were often multiple labels by which the participants identified for sexual 
orientation and gender identity. This was the case for some of the participants who did not identify as bisexual, pansexual, or sexually fluid, but it was the case for almost everyone who did identify this way. Many participants also discussed biphobia, stereotypes, and misunderstandings of bisexuality and pansexuality. For that reason, all of these were included as topics for discussion within the focus group on bisexual, pansexual, and fluid identities (see Appendix E: Focus Group B Protocol Questions).

Themes emerged surrounding the concepts of using one's voice to speak out, helping others, discussing identity within classes, and overall inclusion of sexual orientation and gender identity within curriculum. While these came up both inside and outside of the context of educational panels, the frequency of many of these showed that they were important to participants. Because they were relevant to the concept of the broader understanding of educational panels, these were included as topics for discussion within the focus group on educational panels (see Appendix D: Focus Group A Protocol Questions). The application of the subthemes into the broader themes of educational panels and bisexual, pansexual and fluid identities were not reason enough to choose those topics for the two focus group interviews. Both of these topics had more specific rationale behind the selection, which is described below.

Theme: educational panels. The theme of educational panels came up in several participants' individual interviews and I chose it as the topic of a focus group, in part, because of the context in which it was discussed within these interviews. With one or two exceptions, the participants brought up their participation in educational panels as an example of a time that they believed that they had made an impact or a difference at WVU. This indicated to me that this could be an opportunity to explore a space in which they felt they had agency. Additionally, this was a rare example of a time in which there was a sanctioned space in which their identity and 
their academics overlapped. Seeing as how both curriculum and identity occupied key points of this study, this was a lens from which many salient aspects of the study could be viewed. Of the fifteen individual interview participants, seven of them explicitly discussed their participation in the panels during their individual interviews. While two others did not expressly discuss participation in educational panels, they did explain more broadly how discussing their experiences with others had made an impact and that they believed that they had taught others. Because I was aware that these students had participated in educational panels from my own involvement with coordinating them, I was able to connect these statements and still invited those two to be a part of the focus group. However, those two were not, due to scheduling conflicts, final participants.

Theme: bisexual, pansexual, and fluid sexual identities. The second theme of claiming bisexual, pansexual and fluid sexual identities stood out as a viable option for a focus group first because of the disjuncture between many of the participants' own words. There were multiple participants who had claimed that their experiences were "easier" than that of their gay and lesbian peers, but then said that they experienced bias from both heterosexual and homosexual peers. These were in differing contexts and made sense within the individual interviews, but still showed a level of disconnect of experience that left room for further exploration. Adding to this was the fact that multiple participants made statements about discrimination against bisexuality within the final question of the interview, when they were asked if there was anything else that they thought they had not sufficiently addressed or that they would like to discuss further. This showed that they were not just responding to a question that I had posed, but that this was an area that they would like to discuss at a deeper level. That, coupled with their earlier minimizing of any negative experiences, made this a topic that seemed opportune for a group discussion. 
Additionally, multiple participants chose various labels, or no labels, within various contexts and this also seemed like a good area to discuss with a group rather than just in the individual context. Finally, the lack of research in the literature on bisexual and pansexual identities made this a ripe opportunity to add to the existing research on the subject. While other studies seemed to have had trouble recruiting non-monosexual identities, this study had eight out of fifteen participants who identified as bisexual, pansexual, or fluid sexual identity, a rate of over fifty percent, which was quite remarkable and the experiences of those identities seemed to deserve additional exploration.

Coordinating focus groups. When I had decided on these two themes for the focus groups and had established that the participants listed in the table above were eligible to participate in the focus groups based on the data from their individual interviews, I contacted each participant individually to schedule the focus groups. Within this communication, I let participants know that I planned to bring beverages and pizza from a local bakery so that it would better encourage attendance and the evening time frame would then not conflict with anyone not having time to eat dinner. I set three evening options for each group at times when the room I wanted to use for focus groups was available and asked the participants which of these options worked for them. I coordinated it all through email to make it easier on the participants, rather than using polling software. I was able to schedule the first focus group on educational panels after a single attempt. Five participants were available during the same time slot; however, at the time of the focus group one had a last minute conflict and did not show, leaving only four participants. The second focus group on bisexual, pansexual, and fluid sexual identities took multiple attempts to schedule, but I was finally able to find a day that worked for five participants and scheduled for that time. 
Table 1.

Participants' Selection and Participation in Focus Groups

\begin{tabular}{|c|c|c|}
\hline Pseudonym & $\begin{array}{c}\text { Focus Group 1: } \\
\text { Educational Panels } \\
\end{array}$ & $\begin{array}{c}\text { Focus Group 2: Bisexual, } \\
\text { Pansexual, and Fluid Identities }\end{array}$ \\
\hline Archie & Participated & \\
\hline Corey & Participated & \\
\hline Dani & X-Asked & \\
\hline Eddy & $\mathrm{X}$ - Asked & \\
\hline Faye & Participated & Participated \\
\hline Gabriela & & Participated \\
\hline Harper & & $\mathrm{X}$ - Asked \\
\hline Jill & & Participated \\
\hline Kairi & $\mathrm{X}$ - Asked & Participated \\
\hline \multicolumn{3}{|l|}{ Lana } \\
\hline Natalie & $\begin{array}{c}\mathrm{X}-\text { Asked } \\
\text { (did not discuss explicitly) }\end{array}$ & X - Asked \\
\hline Owen & & Participated \\
\hline Penelope & $\begin{array}{c}\mathrm{X}-\text { Asked } \\
\text { (did not discuss explicitly) }\end{array}$ & $X$ - Asked \\
\hline \multicolumn{3}{|l|}{ Rachel } \\
\hline Sophia & Participated & \\
\hline
\end{tabular}

Both focus groups were recorded with a digital recording device, which I saved to a secure jump drive. I then carefully transcribed each of the focus group sessions. I conducted an initial in vivo coding on this data. I used deductive coding to categorize participants' statements in ways that were in line with both the Figured Worlds Tool (Gee, 2011), as well as Gee's (2001) four ways to view identity as a lens. I then used a second cycle coding method of focused coding to search for the most frequent or salient codes and develop the major categories of the data (Saldaña, 2013). Focused coding allowed me to compare these codes across the focus groups and participants' individual data to assess comparability and transferability (Saldaña, 2013). Focused 
coding developed into the categories and subcategories of analysis found within chapter four. Within these categories, I further explored the data using the tools of analysis of the Figured Worlds Tool and identity as a lens, discussed below.

\section{Data Analysis: Tools for Analysis}

In order to analyze the two focus groups and the aggregate data from these and the focus groups, the two major tools that I used were the Figured Worlds Tool (Gee, 2011) and identity as a lens of analysis (Gee, 2001). I tried to zoom in on identity and agency by situating the identity as a lens of analysis within the Figured Worlds Tool and then looking at these together, as explained through the diagram below "Identit(ies) and Agency in Figured Worlds." This diagram take the original diagram from the conceptual framework which was titled with the singular "Identity and Agency in Figured Worlds" and add to it the concepts of Identity as a Lens for analysis and an interpretive system for understanding the figured world. Thus, this diagram contains multiple configurations of identities. These tools served differing levels and roles within the analysis of the different themes that emerged in the analysis, being used together for understanding identities within the figured worlds and are all explained in much greater detail to follow.

Figure 3.

Identit(ies) and Agency in Figured Worlds. 
IDENTIT(IES) \& AGENCY 88

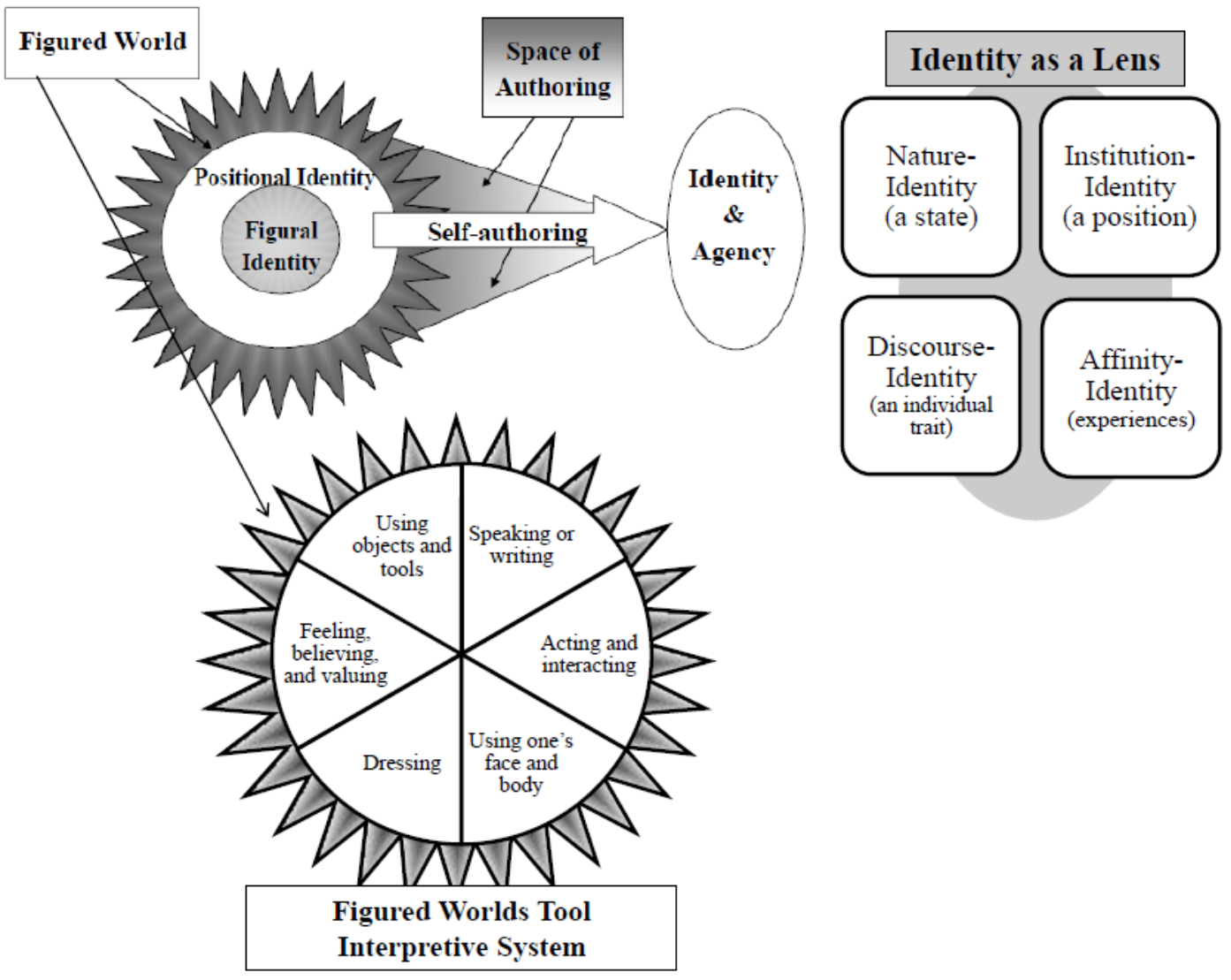

Interpretive system. In this form of analysis these identities are not separate, but intersecting within an interpretive system. In this case, this larger interpretive system is Gee's figured worlds tool (2011). Gee (2001) states that at any given context, people engage in a 'combination,' which he defines as:

A combination is some specific way of combining the following things: a) speaking (or writing) in a certain way; b) acting and interacting in a certain way; c) using one's face and body in a certain way; d) dressing in a certain way; e) feeling, believing, and valuing in a certain way; and f) using objects, tools or technologies (i.e. "things") in a certain way. (p. 109)

This specific way of combining the above elements creates the figured world. People can try to control the identities for which they will be primarily seen, but because identity recognition 
is necessary, individuals only have so much control over their own identities. When a certain "combination" becomes a way of being a "certain type of person," Gee (2001) refers to this as "Discourse," with a capital D. Because this study focuses on understanding students' experiences within the context of the campus climate, the ways in which their identity is framed within different contexts, both by them and by others, can give insight into the nature of these experiences. By using the four ways to view identity, I can look for whether or not there are Discourses on being an LGBTQ student within this campus, or if there are ways of being certain types of LGBTQ students on this campus. The figured world provides a means to "conceptualize historical subjectivities, consciousness and agency, persons (and collective agents) forming in practice" (Holland et al., 1998, p. 42). The discourse analysis of identity is also an analysis of agency. This analysis shows not just the ways in which participants' identify themselves in relation to their environment, but also how they are able (or not able) to shape their lives accordingly based off of these identities.

Figured Worlds Tool. Identity and agency are constructed within the context of the figured world of LGBTQ campus climate, as illustrated within the full conceptual framework in chapter 2. It was therefore important in this study to understand not only the ways in which participants' viewed their identities, but the ways in which they constructed meanings in the figured world and what they see as typical, as these stories can give insight into how they see the campus climate. Gee (2011) developed a theoretical tool to analyze research through the figured world. The Figured Worlds Tool is defined as:

For any communication, ask what typical stories or figured worlds the words and phrases of the communication are assuming and inviting listeners to assume. What participants, activities, ways of interacting, forms of language, people, objects, environments, and 
institutions, as well as values, are in these figured worlds? (Gee, 2011, p. 171)

I understand LGBTQ students' identity from a feminist/queer perspective, and therefore it was important to me to consider the social construction of these identities within the systems of power on campus (Bilodeau \& Renn, 2005). The Figured Worlds Tool can be a key to connecting identities to power structures and understanding this within my conceptual framework. This tool is powerful because it bridges macro and micro contexts, and helps the researcher contextualize participants' identity and agency work in the context of the figured world of which they are a part and continuously (re)making through discourse and action. Some considerations that helped to drive this understanding include examining how the university's context influenced students' comfort level at being out, given the political and sociohistorical contexts, how supportive have/will institutional leaders be in providing LGBTQ student support services, and are advocacy strategies selected in collaboration with LGBTQ students in a way that empowers identity construction and expression? (Bilodeau \& Renn, 2005).

Interviews can often be a good way to uncover figured worlds and within this study, I especially looked for participants' expressing the taken-for-granted and assumed ways of seeing the world within the interviews (Gee, 2011). For instance, participants may express an assumption about how institutional leaders would or would not provide LGBTQ student support services within a particular context. This assumption was a key towards understanding their view of the figured world. Additionally, I-statements can be helpful in uncovering figured worlds (Marsh \& Lammers, 2011), as they connect individual and group identities and meanings to the broader contexts. For instance, if a student stated "I came out in class;" exploring this statement further could be a key to uncovering the figured worlds that lay implicit. Therefore, I paid attention both in the interviews and focus groups to participants' I-statements. 
Identity as a lens. The goal of this study was to understand LGBTQ student experiences within the campus climate. Because students' identities as lesbian, gay, bisexual, transgender and/or queer are so important to this study, it was necessary to use a fine-grained analytic lens that takes into account identity. Gee (2001) developed an analytic approach which dynamically views identities vis-a-vis historical, institutional and sociocultural forces. Again, identity as a lens nests within the Figured Worlds tool as a close-up frame for thinking about the intricacies of identity. It gave me a precise language for speaking about identity that I did not have with the Figured Worlds Tool alone. Within Gee's approach there are four ways to view identity, which include nature-identity, institution-identity, discourse-identity, and affinity-identity. Gee explains that these identities are "four ways to formulate questions about how identity is functioning for a specific person (child or adult) in a given context or across a set of different contexts" (p. 101). Gee writes that these are not separate from one another, but they interconnect. He says that we should view them in this manner: "rather than discrete categories, they are ways to focus our attention on different aspects of how identities are formed and sustained" (p. 101). As can be seen in Table1 below, for each way to view identity, Gee explains the process of the identity, the power and the source of the power. For instance, nature-identity is a state that is developed from process forces (the power) in nature (the source of power).

Table 2.

Gee's Identity as a Lens Discourse Analysis Tool

\begin{tabular}{llll}
\hline Identity & Process & Power & Source of Power \\
\hline Nature-Identity: a state & $\begin{array}{l}\text { developed } \\
\text { from }\end{array}$ & forces & in nature \\
How are identities seen as biological, born, or natural? Are these shifting or fixed? \\
\hline
\end{tabular}




Institution-Identity: a position authorized by authorities within institutions
$\begin{aligned} & \text { How are identities positioned within the university? Within programs? Within organizations? } \\ & \text { Discourse-identity: an individual recognized in the } \\ & \text { trait }\end{aligned} \quad \begin{array}{ll}\text { dialogue individuals }\end{array}$

How are identities and traits recognized by peers? Recognized by faculty? By administration?

Affinity-identity: experiences shared in the practice of "affinity groups"

What types of affinity groups exist on campus? How are identity shaped by these?

The type of identity, process, power and source of power are listed, with the types of questions asked of the data in this study to ascertain when that identity was present.

To further explore each category of identity, by saying that nature-identity (N-Identity) is a state, Gee means that it is a state that one is in and not something that they have done or accomplished. Institution-identity (I-Identity) is a position that is authorized by authorities within institutions, such as a role as a professor. Discourse-identity (D-Identity) is an individual trait that is recognized in the discourses or dialogue of/with 'rational' individuals, such as someone being recognized as charismatic. Lastly, affinity-identity (A-Identity) is based on experiences that are shared in the practice of 'affinity groups,' such as Star Trek fans who may have very little in common with one another besides their interest in Star Trek. While all of these examples are specific to each type of identity, for many aspects of someone's identity, it could be classified within more than one category depending on the context, how it is treated by others, and the discourse and experiences surrounding it. One's sexual orientation and gender identity for example could very much be examined within any of these ways of viewing identity.

\section{Analyzing the Researcher's Roles through Analysis Tools}

My goal within this study was to create an open discussion about LGBTQ issues on 
campus. My roles within the university, within the LGBTQ community, and as the researcher must all be understood in order to enable that dialogue. In all research it is important for the researcher to monitor their own subjectivity and position the framework of their study. Seeing as how I was using the figured worlds tool, as well as identity and agency as an analytic lens, with the participants, it seems only appropriate that I applied both of these to my own identity and context within the study. I further expounded upon Gee's four ways to view identity: natureidentity, institution-identity, discourse-identity, and affinity-identity as they can be used to understand my own identity, how I related to the campus and participants. Gee (2001) stated that a "focus on the contextually specific ways in which people act out and recognize identities allow a more dynamic approach than the sometimes overly general and static trio of 'race, class, and gender'” (p. 99). I looked at these identities within myself, but more so tried to examine the ways in which they are contextually significant for this study and how they have been acted out in that case. Gee (2001) stated that:

What is important about identity is that almost any identity trait can be understood in terms of any of these different interpretive systems. People can actively construe the same identity trait in different ways, and they can negotiate and context how their traits are to be seen (by themselves and others) in terms of the different perspectives on identity. (p. 108)

Because sexual orientation, gender identity, and gender can all be analyzed within all four of these lenses, I applied each lens to each of those aspects of my own identity. I tried to contextualize the way in which these identity traits were negotiated by others and myself in regards to my life. I looked both at the ways in which these identities presented in the past and how they were manifesting themselves at the current time of the study, as updated through my 
researcher's journal. Lastly, I tried to apply the figured worlds tool to my own position and understanding of the university world around me.

Nature-Identity. Nature-identity would include any state that I am in and not anything that I have done or accomplished. The process through which the nature power works is that of development. I was born a 'biological' female and raised as such. This gender identity seemed to fit me and thus was never anything that I questioned. While the sex of a child, in my case female, is often seen as a purely biological concept, it is in many ways a social construct. My designated sex of female is an excellent example of the way in which the nature-identity is considered something over which I have had no control, but yet must be recognized by others in order to exist. If our society did not make the biological distinctions at birth of female versus male, then I would not have been raised with the gendered expectations under which I was raised. Because I was relatively comfortable within the socially-sanctioned role of a female, my gender identity was thus cisgender. My cisgender identity, or comfort level of being a feminine biologicallyborn female, could be seen as something of which I had no control while at the same time relying on the definitions of gender expectations to exist.

My attractions to both females and males throughout the course of my life have led to me identifying as bisexual. While I did not understand or label myself as bisexual until I was an undergraduate in college, the nature-identity of my sexual orientation would be those experiences, attractions, and relationships that I had throughout my life up to that point. How they were labeled would be less relevant to the nature-identity of that aspect of my identity. The ongoing social debate on whether sexuality is biologically determined can create tension between those who are attracted to only one sex or gender and those who are attracted to more than one sex, gender, and/or gender identity. The nature-identity of individuals who identify as bisexual is 
sometimes silenced and not seen as a legitimate experience. This plays out within both gay and straight communities and I have experienced many instances of others disregarding the existence of the nature-identity of my sexual orientation. When LGBTQ activism is conducted in strictly assimilationist methods, the dynamic nature of bisexuality can disrupt the 'we are just like you,' assimilation message. This tension has not only affected my own understanding and presentation of my nature-identity, but could impact that of my participants and their perceptions of me.

I am White and when I was born a White family adopted me, thus not calling into question the nature-identity of my whiteness because it became reinforced by the social context within which I was raised. However, I believe the lack of a genetic connection to my family helped me to become aware at an earlier age of the ways in which race is socially constructed and the privileges that come along with this construction as a White individual. As with other nature-identities, this only exists in that it is recognized and reinforced by a larger social understanding.

Institution-Identity. There are many aspects of my own identity that must be understood as an institution-identity process within this study. The power of the institution-identity comes from being authorized by some institution. In this case my institution-identity could be authorized by the college in which I am studying, the department within which I formerly taught, the department within which I currently work as a graduate assistant, the administration with whom I work, and/or other institutional players. The process through which this power work is authorization and that authorization can come through laws, traditions, rules, and principles and thus can give power to those who are authorizing the I-identities. Some of the I-identities which I have held in this context include student, instructor, graduate assistant, student leader, committee member, organizer, and activist. Some of these institutional-identities carried more power than 
others.

Gee (2001) notes that I-identities run along a "continuum of how actively or passively the occupant of a position fills or fulfills his or her role or duties" (p. 103). I actively embraced many of these roles, but especially those which involved advocating for equity around the university. Some of the roles I filled may have held less institutional power, but I actively fulfilled my role it was more of what Gee would refer to as a calling rather than an imposition. Just as the institutional rules authorize the identities into existence, so too can they take them away. For instance, this was the case with my instructor identity on campus. I taught women's and gender studies for five years, however there was an institutional rule that a graduate assistant could not teach within the same department longer than that. Therefore, even though I no longer held the Iidentity of instructor, others would still perceive that this identity was attached to me by calling me an instructor, coming to me for recommendations, and to discuss student issues. It can be seen then that the outside perception of identity does in many ways tie into the existence of these identities.

Much of my institutional-identity revolved around gender equality. All of my roles of teaching, institutional positions of leadership, and official organizing capacities were I-identities related to gender. The concepts of sexual orientation, gender, and gender identity are a little less explicitly tied into my institutional-identity, which does in some ways speak to the institution itself. Much of my activism involved student-led committees or bringing the inclusion of sexual orientation and gender identity into conversations on diversity where it would not have otherwise existed. There is little power held in my institutional-identity related to sexual orientation and gender identity.

Discourse-Identity While my institutional-identity is less related to issues of sexual 
orientation or gender identity, my discourse-identity may revolve heavily around this. Discourseidentity is an individual trait and the source or power comes from the discourse or dialogue of other people, other rational individuals. Even though I did not hold official roles, the recognition I received from students, faculty, staff, and administration recognized this identity. I can only speculate on my own discourse-identity because it is based on how others treat, talk about, and interact with me. This context for Discourse-identity is very important in this case. For instance, I am often seen as liberal or progressive, but that is within the context of a more conservative university. I may or may not still be seen as unusually passionate and engaged if I were on another campus where more students and faculty were participating in justice-seeking activities.

As with the institutional-identity, discourse-identities run a spectrum from passive to active, where the individual can recruit the identity for oneself. This in my case is inexplicably tied to the institutional culture. I have actively embraced an LGBTQ activist role and have been very open about my identity as bisexual and pansexual in large part because the institutional culture was, in my perception, lacking equity towards the populations. Because of a lack of inclusion then, I have often been the person to speak up about what is missing and thus have gained a discursive-identity of an LGBTQ activist. Gee (2001) comments on this phenomenon stating that, "as people attempt to negotiate and sustain these identities" they "may seek to create new institutions or affinity groups" (p. 105). This shows the overlap between all the types of identities and how context is so important to understanding them.

Affinity-Identity. Affinity groups are made up of people dispersed across a large space. Affinity-identities are created through the process of participation or sharing. The allegiance of affinity groups is primarily to the endeavor, or that which you are organizing around, and secondarily to the other people. It is a connection that otherwise would not have existed without 
that affinity. There are several ways in which I was united in affinity-identity with other LGBTQ students and employees at this university. As an active member of the Queer Student Union, I was united in that affinity-identity. I was also a member of the faculty and staff organization. Affinity-identities can be cause-oriented and can dissipate once the issue surrounding that cause is resolved. I have had many affinity-identities such as this throughout my time in this context. For instance, when a group of students on campus has come together to support a specific issue, such as an SGA resolution to incorporate gender identity, we formed a sort of affinity-identity. While this A-identity dissolved after the issue is resolved, it did, in many cases, bring a larger core group together in the formulation of the next A-identity cause.

Businesses, and in turn universities, can create affinity groups. Within this context, the university supports student groups, sororities and fraternities, sports teams, sports fans, and alumni, all of which have their own affinity-identities. The focus of affinity groups is on distinctive social practices. If these practices are sexist, heteronormative, or transphobic, then a non-dominant gender identity or sexual orientation could therefore preclude someone from participation in other affinity-identities. Universities have the power to create and sustain the events and traditions that give, or do not give, affinity identities to their members. When they do not, then students may seek this connection elsewhere. The affinity groups with which I have shared experiences and shaped my identity include not just those groups at the university, but also broader groups. By attending conferences and being involved in activism I often share affinity-identities with others at the state context, within national organizations, or even just online groups and connections.

Figured world tools. I occupy the figured world of the university as a professional within that world on many levels, or, rather through many figural identities. As an instructor and 
a graduate assistant, I embody professionalism through my manner of speaking, acting and interacting with gestures that convey white middle-class business standards. I use my face and body and dress in accordance with these figural identities that help to move the actions of the institution, or the figured world, forward. My feelings, behaviors and values though may be more indicative of my positional identities, those of bisexual and pansexual, or graduate student. The last component of Gee's interpretive tool is that of using objects, tools, or technologies and this could be considered a part of both my positional and figural identities. As an instructor of online courses, I use the university's tools in ways completely prescribed by the institution. As a student and an activist, I use the internet and social media to connect over identities.

Other positional identities that I hold could include that of feminist, which could in this case be institutionalized in some ways due to teaching within Women's and Gender Studies. Since the objectification of positional identities often become the organizing basis of resentment and the basis of more active resistance (Holland et al., 1998), this is consistent with my feminist positional identity. It is a site around which I have organized with active resistance, with planning such events as Take Back the Night and The Vagina Monologues. To further complicate this, I have been institutionally recognized for this organization with awards like the "Vagina Warrior Award," which was given to recognize my given to me to recognize my commitment to stopping violence against women and girls. This shows some of the ways in which positional identities (feminist) can become Institutional-Identities (Vagina Warrior), when backed with support within the figured world. My own experiences and identities are full of complicated intersections that I have only begun to explore in this section as a basis around which to organize the tools of analysis. The same can be applied to the participants and can be 
seen through the analysis portion of this study when it comes to their positions within figural worlds and their complex identities.

\section{Monitoring for Subjectivity}

This view of my identity through Gee's framing is only one snapshot of the ways in which my identity is created within the context of this study. As the study progressed, it had to be reinterpreted within that developing context. Therefore, throughout the study, I kept memos in a researcher notebook, updating and revisiting my researcher identity and then further updating the analysis through these identity lenses. Understanding a more nuanced analysis of my identity, helped me to understand the ways in which my identity also shaped my researcher subjectivity. Glesne (1999) stated that:

Monitoring subjectivity is not synonymous with controlling for subjectivity, in the sense of trying to keep it out of your work. When you monitor for subjectivity, you increase your awareness of the ways it might distort, but you also increase your awareness of its virtuous capacity. (p. 109)

My researcher subjectivity was framed within the nature, institution, discourse, and affinity aspects of my identity. The role of my gender, sexual orientation, gender identity, race, and position within the university, impact that subjectivity in complex ways. According to Brown \& Gortmaker (2009), the identity, sexual orientation, and gender identity of the interviewer may impact the outcome of focus groups and interviews and scrutiny must be paid to the wording of questions. By analyzing my own identity within this analytic framework, it will assist not only in the questioning of participants, but in all aspects of the methods and analysis of the study. All of this (and more) creates my subjectivity. Glesne (1999) continued the earlier quotation to say that: 
You learn that your subjectivity is the basis for the story that you are able to tell. It is the strength on which you build. It makes you who you are as a person and as a researcher, equipping you with the perspectives and insights that shape all you do as a researcher, from the selection of topic clear through to the emphasis you make in your writing. (p. 109)

My subjectivity has indeed made me the individual and researcher that I am today. It has led me to research this topic, which, being a topic situated around sexuality and identity, makes the story of my subjectivity all that much more personal. Inside and outside the context of my experiences within the context of this study, I believe that in many ways, sexual orientation has been such a salient aspect of identity for me because it has played such a large part in establishing my own understanding of all other aspects of my identity and positionality. I see my sexual identity or orientation as a part of my whole identity and not some compartmentalized notion. It has positioned me inside, outside, and on the edge of many groups that I would not have otherwise known. However, while for me I see this aspect of identity as very salient, this may not be the case for others. It is important in my research to see all individuals' identities as they construct them themselves regarding gender, race, class, sexuality, gender identity, ability, nationality and/or any other identification that is important to them. It is also important to see how all of those forms of identity are framed as nature-identities, institution-identities, discourse-identities, and/or affinity-identities based on the context within which the participants are situated.

\section{Trustworthiness}

I used many strategies to ensure the trustworthiness of my data. The use of individual and focus group interview as my choice of methods were an adoption of research methods that are well-established in qualitative research and have been successfully used in comparable projects, 
which is in itself a means of establishing credibility (Sheldon, 2004). My researcher role and various identities also served to ensure trustworthiness. The relationship I have developed with many student organizations, faculty, staff and administration over the past eight years gave me an early familiarity with the culture of participants before the first data collection dialogues took place. Even though participants did not know me personally, it gave me access to the groups both in person and virtually through their social media pages like Facebook where I had already had a virtual presence. Both of these, this access and the background, qualifications, and experiences of me as the investigator, served to increase the trustworthiness of the study. While the study was not completely random, I did search from a variety of student groups and through multiple instructors and course lists and emails sent out through departments in order to get a wider variety of experiences.

In order to ensure honesty from the participants, I stressed that I wanted to hear their experiences and that I was not looking for any particular answers and that this was an independent research study for fulfillment of my doctoral degree. I also stressed that they were able to drop out of the study at any time and were not required to disclose anything that they did not want. These types of statements encourage participant involvement from those who are genuinely willing to take part and allows participants to "contribute ideas and talk of their experiences without fear of losing credibility" from those in positions of authority (Shenton, 2004, p. 67). My intention with the study was to provide a type of triangulation with the three methods of data collection: individual interviews, focus group interviews, and follow-up journaling, however one method of analysis was lost when all participants declined to take part in the journaling. The individual and focus group interviews did, however, allow for iterative questioning in that I could return to matters previously raised by a participant and rephrase the 
questions. This allowed me to raise contradictions and provide greater transparency to discrepancies, as well as offering possible explanations (Shenton, 2004).

Throughout my work on this project I have had frequent debriefing sessions with my committee chair and committee members. This discussion has helped to keep the vision clear and allow for a perception that calls attention to the possibility of my own biases or preferences coming out. I have also participated in scholarly events that have allowed for peer scrutiny of the research project, such as the WVU College of Education and Human Services Research Poster Forum where I was able to present the project to the entire college and received feedback on how to improve and shape the work. I maintained reflective commentary throughout the work and this helped to guide not only my impressions of the data collection and the patterns as they began to emerge, but also informed the reflective commentary and was used in discussion with the peers and scholars as I made decisions about the study.

The study is meant to be specific to the context of West Virginia University and the students that participated, but there are some findings that may be of interest to others. The dependability of the research could be duplicated in different contexts. The use of the overlapping methods of focus group and individual interviews serves also to ensure both credibility and dependability. The reasons for the approaches taken within this research are detailed within the analysis and the data-oriented approach shows how the data eventually led to the formation of recommendations processed during the course of the study (Shenton, 2004). Confirmability is also made possible through recognition of the study's limitations and the admission of researcher's positionality throughout.

\section{Confidentiality and Ethics}


Names and identifying information were changed in order to protect confidentiality. I decided to give participants input and final say over the pseudonyms for this study. In order to simplify the transcription and the name-selection process, no repeated first letters of names were used. I assigned a first letter to the participant and chose two or three names for them that seemed fitting based on their personality and the connotations the names evoked for me. I then asked them for feedback on these names. In some cases the participants did not care at all, so I assigned them one at random. In other cases, the participant suggested a name with the same letter that was not on my list and I used that. Most of the time, the participants chose from the three sample names I had provided for them. I decided to use this process because I think that the act of naming is important and I wanted the participants to have some autonomy within this. If I used any direct quotes and member-checked their accuracy, I did not want to surprise them with a name that was unsettling. This decision was particularly relevant given the nature of the population and the importance of names and self-determination within that population. One participant chose a name that was not on the list I gave her, saying that she felt it supported the "gamer" element of her identity and strongly asked that I not use one of the provided suggestions because it was the name that her mother had given to the stray opossum that had been roaming in their back yard. While this is a quirky example of circumstance, it was an instance in which I was able to connect authenticity to the voice of the participant, as opposed to what would have been a really unfortunate and coincidental name match.

Even though this study takes place on a campus of approximately 35,000 students, there is still a relatively small population of out and active LGBTQ students. Great pains were taken to protect those involved from recognition to the extent it could be done without compromising the findings. For instance, a table that includes gender identity, sexual orientation and race is 
included in the analysis section of chapter 4 , but more specific identifying information was left to be discussed in an aggregate form at the end of that chapter so as not to distinguish students at too detailed of a level. Given that some of the population had already been involved in LGBTQ issues on campus, it was unlikely that they came into the study with a complete unawareness to the issues on campus. However, it was possible that participation in the focus groups would make some of the participants aware of problems they did not know existed previously. This new awareness could have shaped their experience of the campus and their perception of that experience. Thus, the participation in the focus groups and hearing other students' perspectives may have in turn changed their original perspective. It was necessary to be mindful of the ways in which the knowledge of the individual experiences was in many ways being jointly created by all of the participants and myself, as the researcher.

Within this process, students were not only learning from others, but also learning more about themselves. Tennessee Williams stated in 1982 that "being interviewed does have the advantage of self-revelation. I must articulate my feelings and I may learn something about myself. It makes me more self-aware, more aware of my own unhappiness" (quoted in Kvale \& Brinkmann, 2009, p. 8). It was important that within this study I did everything possible to empower the participants. While they could have potentially become more aware of their own unhappiness, this did not have to be accompanied by a feeling of a lack of control over that unhappiness. I made a conscious effort to create a positive atmosphere within the focus groups and inquire about ways in which participants have improved their own lives and the campus climate, rather than only examining the negative aspects. These ethical implications of concern for the wellness of the participants may be subtle and nuanced, but they carried through the data collection and analysis. 


\section{Chapter 4: Analysis of Data}

The overarching research question of this study was, "How do students who openly identify as lesbian, gay, bisexual, transgender, and queer (LGBTQ) perceive the campus climate at this university and in what ways are their experiences shaped by that climate?" Through the preliminary analysis of the individual interviews, I was able to pull out the two predominant themes that came up in many participants' experiences at WVU and explore these in greater depth through the focus groups. The first theme was the affordances and constraints of using panel discussions as an educative tool in university settings, and the roles of panels in shaping and maintaining LGBTQ campus climate. The second theme was how bisexual, pansexual, and

fluid sexual identities mattered in forming and instantiating the figured world of campus climate under study. I will look at these two themes separately through this analysis and then make connections across the data. While the individual interviews served as a starting point at which to bring together the two focus groups, I did also choose to include relevant information from the individual interview data to either support or complicate the findings of the focus groups. As it was not logistically possible to coordinate all qualifying participants into the focus groups based on their availability, it was important to me to not completely leave out the voices of the other participants. It should be noted, however, that these 'supporting' or 'complicating' voices should be viewed as not having the benefit of the joint knowledge construction of the focus groups. Additionally, there were two participants who did not touch on either of the topics of the focus groups and therefore their individual interviews were only considered a part of the overall data in the places where it was relevant and not related to either of the major themes.

The data analysis is broken into the five following sections: Participant Identity (De)Construction; Curricular Inclusion of Sexuality and Gender Identity; Cultural Worlds of 
Panels; Positional Identities: Pansexual, Bisexual, and Fluid; and Intersections of Identit(ies). The analysis section begins with the (de)construction of participant identities because these identities were much more complex than that which could be listed as dichotomous demographic categories. Since all the questions were open-ended and participants often gave multiple answers regarding identities, it was important to explore these first in the analysis. While participants' identities did in many ways influence their perceptions of the campus climate and curriculum, there were also themes regarding curricular inclusion overall related to gender identity and sexuality that emerged from the data. One of the major ways in which participants discussed sexuality and gender identity being incorporated into that curriculum was through educational panels. These also had a major impact on participants on a personal level and were, therefore, discussed at greater depth in a focus group. While these curricular themes were across identities, there were some identity-based areas in which a particular figured world of campus climate and curriculum could be seen. This was most noteworthy among bisexual and pansexual identities, but is also discussed in terms of the ways identities intersect, looking experiences within some specific axes identities, such as gender identity, religion, and race.

\section{Participant Identity (De)Construction}

Discussion of participants' identities was included in the analysis section because of the complexity of this topic and will not be limited to this section, but will carry through the entire analysis. The level at which participants' identities were explored in this study was much deeper than simply checking off a category on a form. In fact, all of the information collected from participants, even in the Demographic Surveys, was open-ended. All participants are listed below within Table 3, "Participants' Identit(ies) and Focus Group Participation" below to denote their gender identity, sexual orientation, race and/or ethnicity, status as a student as undergraduate or 
graduate and whether or not they discussed the topics of the focus groups in their individual interviews. If they did discuss these topics, then that column is marked with an X. If they were able to participate in the focus group on the topic, then they have the abbreviation "part." for participant listed. Their gender identities and sexual orientations are written out using the terms that they described, primary designation first, but also including additional identifiers if they used these to describe themselves. It should also be noted that identity markers related to socioeconomic status or geography did not come up in many of the interviews and are not included in the table, but the overall context of the state is rural and more impoverished than the rest of the nation, as discussed in chapters one and three with the context of the research institution.

Table 3.

Participants’ Identit(ies) and Focus Group Participation.

\begin{tabular}{|c|c|c|c|c|c|c|}
\hline Pseudonym & Gender Identity & Sexual Orientation & Race & Status & $\begin{array}{c}\text { FG1: } \\
\text { Panels }\end{array}$ & $\begin{array}{c}\text { FG2: } \\
\text { Bi/Pan/Fl. }\end{array}$ \\
\hline Archie & Cisgender Male & Gay, Homosexual & White & Undergrad & Part. & \\
\hline Corey & Cisgender Female & $\begin{array}{c}\text { Lesbian, Gay, } \\
\text { Homosexual }\end{array}$ & White & Undergrad & Part. & \\
\hline Dani & Cisgender Female & Lesbian & $\begin{array}{l}\text { African } \\
\text { Amer. }\end{array}$ & Undergrad & $\mathrm{X}$ & \\
\hline Eddy & Cisgender Male & Gay & White & Graduate & $\mathrm{X}$ & \\
\hline Faye & $\begin{array}{l}\text { Genderqueer Female, } \\
\text { Girl, Tomboy, Butch }\end{array}$ & Pansexual, Bisexual & White & Undergrad & Part. & Part. \\
\hline Gabriela & Cisgender Female & Bisexual, No Label & Latina & Undergrad & & Part. \\
\hline Harper & Cisgender Female & Bisexual & White & Undergrad & & $\mathrm{X}$ \\
\hline Jill & Girl, No Gender & $\begin{array}{c}\text { Bisexual, No Label, } \\
\text { Pansexual }\end{array}$ & White & Undergrad & & Part. \\
\hline Kairi & Cisgender Female & Bisexual, Pansexual & White & Graduate & $\mathrm{X}$ & Part. \\
\hline Lana & Cisgender Female & Lesbian & White & Undergrad & & \\
\hline Natalie & $\begin{array}{c}\text { Genderqueer, Non- } \\
\text { binary, Don't Identify, } \\
\text { Fluidity }\end{array}$ & $\begin{array}{c}\text { Don't Identify, } \\
\text { Pansexual, Fluidity }\end{array}$ & White & Undergrad & $\mathrm{X}$ & $\mathrm{X}$ \\
\hline
\end{tabular}




\begin{tabular}{|c|c|c|c|c|c|c|}
\hline Owen & Male, Cross-Dress & Pansexual, Bisexual & White & Undergrad & & Part. \\
\hline Penelope & $\begin{array}{c}\text { Gender-fluid } \\
\text { predominantly female, } \\
\text { sometimes neither } \\
\text { female nor male }\end{array}$ & $\begin{array}{l}\text { Pansexual, Queer, } \\
\text { Polyamorous, Fluid }\end{array}$ & $\begin{array}{l}\text { Latina, } \\
\text { White }\end{array}$ & Undergrad & $\mathrm{X}$ & $\mathrm{X}$ \\
\hline Rachel & Cisgender Female & Gay & White & Graduate & & \\
\hline Sophia & Cisgender Female & Gay & White & Graduate & Part. & \\
\hline
\end{tabular}

As can be seen in the table, in many cases the terms participants used to describe

themselves were much more complex than what is often listed in any demographic questionnaire. Participants have multiple identifiers not because they are uncertain of their own identity. In fact, it is more so in response to external pressures that they choose the terms. Especially for participants who identified as bisexual, pansexual or fluid sexual identities, they would state the identity that they believed was the most accepted. However, this was not only common to those identities. For instance, one male, Archie, identified primarily as homosexual at the beginning of the individual interview because he thought that was the appropriate identifier for a researcher study. It is not that the participants do not know who they are, it is that they are aware of others' perceptions of what that identity means and they adapt it accordingly. Additionally, it should be noted that not all individuals listed as "cisgender" employed that term to describe themselves, but as it is a sort of label of privilege, if individuals described themselves as fitting comfortably within the identity of female or male and the corresponding femininity or masculinity, I attached this label. The identities listed come from the participants' own self-descriptions. Participants are listed with an $\mathrm{X}$ if they only discussed the topic of the focus group within their individual interview and are marked as "Part." if they both mentioned the topic in their individual interview and participated in the focus group.

These identities are complex and not constructed in isolation. Because of the complexity of the identities and the ways in which these were not just something that were "known" or 
checked off on a demographic sheet, but rather were only revealed in their entirety through the analysis of the data collected within the individual and focus group interviews, I chose to include the (de)construction of these identities within the analysis rather than the methods. The participants experience the world around them and the campus climate and curriculum based on these identities. In fact, these identities are a part of the figured worlds of campus climate and curriculum and will shape and mold that world accordingly.

\section{The Figured Worlds of Campus Climate and Curriculum}

The analysis of data in this project confirmed that the WVU campus climate is a complex figured world, continually made and remade dynamically through language. The curricular inclusion and exclusion of sexuality and gender identity at an institutional level serves as a part of the construction of the figured worlds of the classroom spaces where students spend much of their academic time. The overall campus climate is its own figured world that includes, but is not limited to what happens in those classroom and curriculum-specific spaces. Because Holland and her colleagues (1998) describe figured worlds as historical phenomena and social encounters in which participants' positions matter and are socially organized and reproduced, it is important to understand the participants' broad perceptions of campus climate and curriculum. The participants' responses about their perceptions of campus climate and curriculum inclusion were used in conjunction with Gee's figured worlds tool (2011) to create a framework of what the cultural world of curriculum and climate looks like on this campus. Gee's tool, and therefore the cultural world, recognize a specific way of combining the following:

- speaking

- acting and interacting

- using one's face and body 
- dressing

- feeling, behaving, and valuing

- using objects, tools, or technologies

There is no single figured world of the campus environment. Rather, there are innumerable conceptions of figured worlds and the goal here is to show a few of these realities, specifically those that the participants revealed as important through their words and actions, as uncovered through this data analysis. The following will be included as a part of the figured world understanding: "appropriateness" and inclusion in the classroom; gender identity and cultural worlds; and figural identities and cultural worlds, or the impact of a single person. While these should not be taken as the only components of the figured world, these three stood out among the realities of the participants. An individual's gender identity is a key component in creating the structure of the figured world. What this figured world looks like and how it functions is directly determined by the person's gender identity. How students viewed curriculum and they ways in which they saw, or did not see, sexuality and gender as being "appropriate" for discussion within an academic setting influenced their figured world and their space of authoring. Lastly, having a single individual in a mentor or teacher role within one's life often made a difference for students. This had an impact on their experience in many ways. All three of these worked together to create their experience of their figured world. These are depicted as gears or spokes because they could work to positively influence participants' experiences and, if that was the case, this would move them towards the space of authoring and thus identity and agency. However, these could also all negatively impact a participants' experience of the figured world of LGBTQ campus climate and, if that was the case, this would limit their mobility towards that space of authoring, thus limiting their experience of identity and 
agency. Much like a metaphorical gear, if any one of these was "stuck," then it would impact the entire machine, or the entire function of the figured world.

Figure 4.

Figured World Understandings

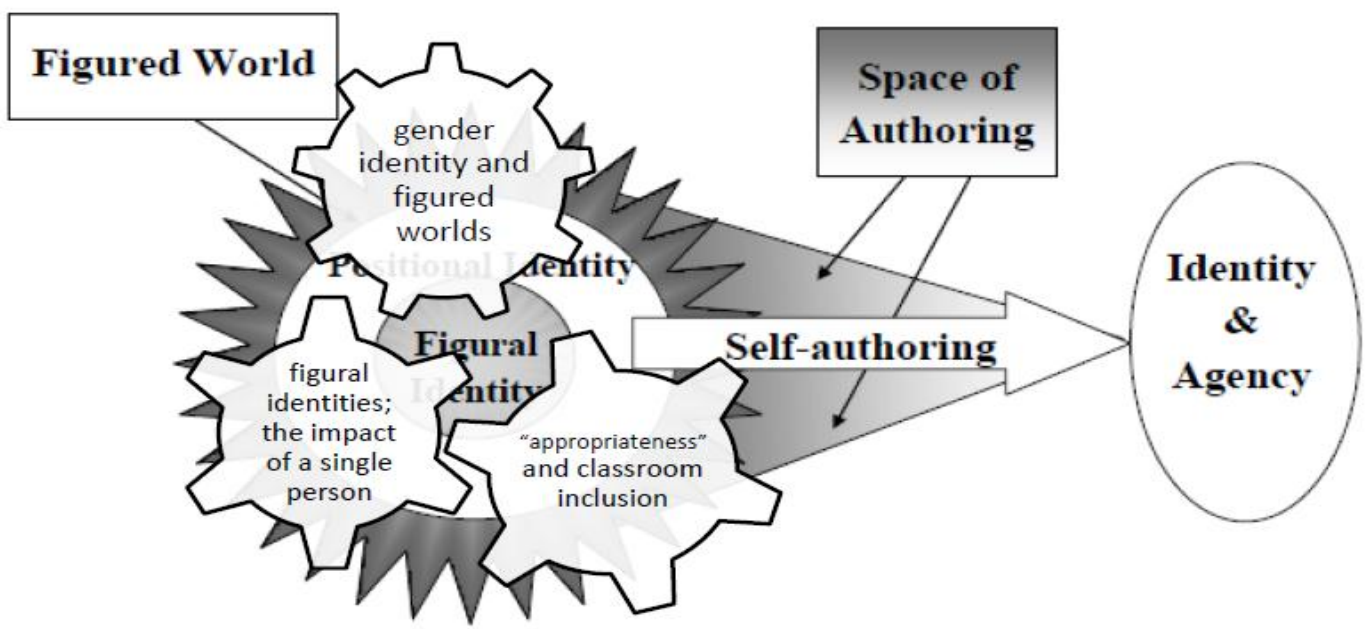

While these are the three areas that are focused on within this study, they should not be seen as all-inclusive understanding of the figured world. There are other aspects that affect each student's experience, but these were the most salient to this study. The cultural world of the campus is also tied to the larger cultural world of the state and even the national climate when it comes to LGBTQ rights. At times students recognized these connections and saw their experiences here as situated as much within those often national contexts as within the specific institutional context of WVU. For instance one student is considering a career path after graduating that involves civilian contracting with the Army, which is something she probably would not have considered a year ago, referring tangentially to the changes in the Don't Ask Don't Tell policy of the military and other federal changes that have occurred over the past year. 
These national contextual changes play into the state and local cultural worlds that students inhabit. One student, Faye, reflected on this as follows:

With regard to queer culture right now, it's in such an exciting time and it's evolving so much and so rapidly that there's bound to be new things thought up almost daily and I do see myself very much tied to that culture as much as I am the culture of WVU and the culture of West Virginia as a whole.

There was a difference in perspective between undergraduate students and graduate students when it came to their views on curriculum and inclusion. While this difference may not have been a better/worse perspective, it was more of a matter of a distinction in what the students expected out of the peers versus what they were seeing delivered. Multiple graduate students in various disciplines commented that their peers within their discipline were not as open to concepts related to sexuality and gender identity as they had expected them to be. In part this was due to the fields that these students were studying and their expectation that a certain level of knowledge and open-mindedness was to come standard in that field. One participant was surprised to find her cohort very accepting and welcoming. She also said that she thinks that her relationship with them influences some of that; that they are possibly more supportive in bringing up LGBT topics in class and commenting in ways that she is not sure that they would be vocal if there was not someone who was gay in the room.

\section{"Appropriateness" and Inclusion in the Classroom}

The figured world of sexuality and gender identity within the classroom was one of silence and omission. Many participants were unable to give examples of any inclusion of gender identity or sexual orientation in their curriculum throughout their entire college career. In large part, they attributed this lack of inclusion to an "inappropriateness" or it just not fitting with the 
topic. This happened regardless of the student's major. At times, even when more emphasis was placed on sexual orientation within a course, LGBTQ participants found it unsettling or inappropriate. For instance, one participant, Archie, had a literature class within which he said he "kind of wished [the professor] had whitewashed his curriculum a little bit more to be more traditional. It kind of seemed more appropriate for a gay studies course than American Literature 2."

Participants seemed better equipped to discuss the role of sexual orientation and gender identity within the university curriculum when they were within their peer focus groups than when they were in individual interviews. There is the possibility that these individuals were more aware of the concepts overall, but given that some of them elaborated more in the focus group interviews than they did in the individuals interviews, it is more likely that there was less of a tendency to personalize the subjects with others around. They may have applied less internalized homophobia, biphobia and transphobia to their analysis as well. Being amongst their peers, it is possible that they felt more supported in recognizing the importance of curricular inclusion, but it is also possible that they just felt personally supported and therefore did not internalize the phobias that could have led to processing this differently during the individual interviews. During the focus group on panels, one participant, Sophia, stated the following "if it was across the board in a lot of classes, then people would realize that this applies to everything; that it applies to every field, and it does, I mean there's gay people everywhere."

It's important to note that heterosexuals' identities are considered in the unofficial campus curricula, for instance university-sponsored holiday events, while LGBTQ identities may be excluded by omission. For instance, one participant gave an example of a speed dating event sponsored by the university for Valentine's Day. When they showed up for this event, there was 
no mechanism in place for anyone who did not identify as non-heterosexual. Upon realizing this, the host of the event said "if you are heterosexual go through and people of homosexual descent will be sitting opposite, basically so that everybody had a chance." Those who identified not as heterosexual were then given a chance to talk to heterosexual attendees, but these were much more of friendship conversations than a romantic conversation, since the person opposite identified as not being interested in others of the same gender. While this participant appreciated the conversations, it was not the "speed dating" event that was promised. They also felt that the inappropriate use of identity language really was a misstep on the part of the organizers.

Instructors who are also students or who have been students in the past have multiple identities with which to contend, inside and outside of the classroom. Of the graduate student instructors interviewed, each one handled that negotiation of identities differently. One thought that instructors should not be going out of their way to "inject stuff that doesn't belong" into the curriculum or "inserting a progressive message, because it's not relevant." In other words, silencing LGBTQ identities in the curriculum was preferable to that participant. For Sophia, as an instructor, it was important to be open and that presence was more important than trying to affect the curriculum. It's important to note that she did not necessarily believe in handling the situation the same way outside of her instructor identity, but that this was a part of a larger view of creating a classroom environment in a particular way.

Participants' views on appropriateness of bringing LGBTQ issues into the classroom reflects on their views on bringing their own identities into the classroom and thus also their position within the figured world. The silencing of discourses within the figured world shapes moves them into a positional identity rather than a figural identity position, thus creating a situation in which they are less capable of self-authoring and moving into agency and identity. 
Their views on how to handle when these topics are incorporated inappropriately can depend on many things, not the least of which are aspects of their identity. Within one of her classes, Corey had another student sitting near her who said some transphobic remarks during a lesson and Corey said that she just responded to that student by saying "ouch." Corey felt that at this point in her life (at the time of the interview) she would have probably said something more, but being that it was a big class and she was still struggling with herself (with her identity), she didn't want to speak up.

There were student exceptions to this idea that it was not appropriate to include concepts of sexuality in the curriculum. Owen first learned about sexuality and gender identity both inside and outside of academic classes during his second semester at college, stating that before that he "had YouTube and the internet, but here was the first place I ever saw people in person kind of doing things and being active." Owen stressed the importance that he thought all students should be exposed to these topics through their general elective courses, but that they are not necessarily. He said that he could have chosen to "remain insular" had he wanted to and, in fact, he believes that it is institutionally reinforced that students are not encouraged to broaden their knowledge base through the GECs. Owen said that he was advised during orientation on ways to double up GECs within your major or in order to minor in something related. His perspective was that this was defeating the purpose of the courses because they were then not reaching the students who would not seek them out on their own.

\section{Figural Identities: The Role of One Person}

In many cases participants gave examples of a single faculty mentor serving as their example for including sexuality and gender in the curriculum and the classroom. Sometimes it was just one instructor that could "make it bearable," as Penelope said. As the participants 
pointed out, an individual instructor can impact a student, even when they otherwise feel disengaged from the campus. Natalie said that during her time working with one faculty member, being an undergraduate teaching assistant for his class and working with him as an adviser, he was "one person who has really made me feel like I belong and I really have a voice and a stake academically at the university or just in general." Penelope commented on the role of the same instructor, stating that the department within which that professor is based is one of the only places within WVU that is structurally and systematically inclusive. She went on to say "I don't want to say 'gets it right,' but it gets it better than most places because I mean there are so many things you can mess up on and we all do it." While this instructor had a figural identity position within the figured world by the basis of their Institution-Identity of "professor," it seems that for the students that commented upon his role, it was due to some other identity that he held such importance. There was a sort of Discourse-Identity that he held, as it was recognized in the dialogue with rational individuals, or students specifically, that he was seen to "get it." Penelope stated that this structure was due in large part to the employees within the department; that sex and gender inclusivity is "absolutely dependent on the people who are currently in the department, not the policies of WVU or the department. It's the people." It is the DiscourseIdentity of the individuals that makes the difference. It is not enough that they have the Institutional-Identity.

Even small examples of positive identity reinforcement can stand out for students. One student, Jill, commented that it was affirming for her to see that there are the little triangles, which are the symbols for Safe Zone, on some of her professors' offices. For instance, Dani used gender appropriate pronouns to answer a question in her French class regarding relationships and was concerned that the instructor would correct her, but she did not. To contrast Dani's 
experience, there was a time when Faye tried to say 'girlfriend' instead of 'boyfriend' in her Japanese class and even after trying to discuss it with the instructor, her teacher still seemed to not understand her perspective, but Faye thought this may have to do with both a language barrier and the rigorous structure of the class that overall did not allow much room for student exploration outside of the stated lesson plan.

The impact of one person can be both positive and negative. Corey had only taken one class in which sexuality and gender identity were explicitly covered. She felt that the instructor was a huge advocate for the LGBTQ community, but that the instructor had gotten some things wrong when the class was discussing gender identity. Specifically Corey said that there were terms in the text that had definitions that were not congruent with how she understood the terms based on people who she knew personally that identified with those terms. The same student, Corey, mentioned a different instructor who she felt very impressed by on the first day of class who was emphatic about social justice and said "people are the way they are and that's the way it is and if you have any problem with that, keep it to yourself because that's the way it's going to be handled in this class." Corey felt really hopeful after that, but as the class drew on she said that there was lot of judgment and she felt that the instructor was hypocritical on this stance. She said that the instructor was "very good, very much an advocate, but her definitions were a little off and it definitely made some people uncomfortable." In both of these examples, the instructor was purporting to have an Affinity-Identity with the social justice advocacy work and LGBTQ community, however what was seen as most important to Corey later was the lack of a Discourse-Identity to back up this assertion. Some instructors may have good intentions, but their implementation may be lacking and this can stand out for students. These instructors were 
unable to engage in the identity through dialogue and in turn their proclaimed Affinity-Identity was seen as a disappointment to Corey.

While this Discourse-Identity seems to be most important in making a difference to students, the position that a person holds, or their Institutional-Identity, also carries weight when it comes to the role of their impact on students. Multiple students spoke of times that administrators listened, or didn't listen, to what they had to say. On occasions when the administrator took the time to discuss the students' concerns and when the students' perceived that they were heard and taken seriously by the administrator seemed to mean as much or more to the students than the immediate or tangible outcome of the situation.

\section{Gender Identity and the Figured World}

The cultural worlds that those who identify as genderqueer, non-binary, gender fluid, trans* or gender nonconforming inhabit look very different from the worlds inhabited by those who identify as cisgender, regardless of sexual orientation and other identity markers. It is a basic part of their everyday lives and should be explored as such.

The figured world of some gender nonconforming individuals involves making every decision in order to survive the day in the least hostile way possible. For Natalie, it means that one is in a constant state of position identity and is unable to make meaning of their experiences. There is no space for self-authoring; there is only space for survival. This means, therefore, that for some of those who identify as gender nonconforming do not have space for identity and agency within their own lives. Natalie describes her experiences of daily navigating this world as

follows, and, according to her, she has done this to avoid direct hostility and the possibility of having slurs and negative remarks made towards her: 
I've been so, so very careful about my transition and how I reflect on cis-eyes. Every single part of my decorum, behavior, when I decide to go out, how I'm dressed when I go out, for the longest time was placated on 'Is this acceptable to cis people?' and 'Am I not going to be received hostilely today?' To have that structure in your life is kind of hostile because you don't have a lot of actual agency, but you don't ever feel the hostility from other people.

Natalie was not privy to the framework of analysis for this study. I did not share it with her or ask her to discuss its relevance in her life. Rather, when an individual does not have autonomy over the way in which they conduct themselves within the figured world that they occupy, their lack of autonomy is ever-present and clear to them. It does not need to be directly asked or positioned for them for comment. In this statement Natalie constructed her daily figured world and showed the ways in which she was being denied identity and agency by having to constantly navigate the world in such a way as to not occupy it in a positional identity. She may have had a figural identity, one in which she was able to be a part of the events and actions of the figured world, but she lacked the space of self-authoring and was keenly aware of that. It is important to note that this figured world that Natalie constructed was based specifically on her experiences with the campus environment. While one may intuitively think that the campus environment would be more inviting and based on the figured worlds constructed by others from a perspective of sexual orientation, it appears that to most participants the campus climate is more accepting and more open than the off-campus climate. This did not necessarily seem to be related to the climate of students versus local residents. Many participants' gave the example of "High Street" or "downtown" and hearing slurs and negative statements in these locations as examples of the climate being less accepting off-campus. It seemed to them that these were 
fellow students making the remarks. Therefore, it seems that it is more related to different codes, values and understandings governing behaviors in the areas that are deemed "off-campus" versus those that are deemed "on-campus." To offer a counter-point to this, for Natalie this was not the case. She describes that she does not monitor or spend as much time focusing on the details of her appearance if she is going to purchase food or run an errand off-campus, stating:

It doesn't matter as much. I'm more willing to have sloppy clothes and maybe like not tucked and maybe I didn't shave that one day. I may feel like really, really panicked and even flat-out dissociated, but I'm fine going to those places. I could never be in a classroom or be actually on campus (this way.) It's specifically about being on campus and having all of those people around you. It's this highest concentration. I don't care what people think out on the street - I care about on campus.

For Natalie though, the ability to care less in an off-campus setting had more to do with anonymity than it did with the climate or the perceptions necessarily being more positive or accepting. Penelope, in contrast to Natalie, found the climate off of campus to be so difficult to deal with at one point during her transition that she said that even small errands were difficult and she would just order food to her house instead and choose to not go out in public. She on the other hand, found that it was not students, but those that live in the area that were more of a struggle for her to be around. She discussed the struggle of "passing" and the ways in which labeling this as "conditional cis privilege is a misnomer because this is not even actually a conditional privilege - it is a condition that is predicated on a privilege that is assumed, but since it is not actually possessed and can be lost at any moment, whether it be through conversation or something one says or someone seeing one's mail, it can be lost instantaneously." She prefers the term "surface-level cis privilege" because this more accurately describes her experience of 
someone seeing her on the street and assuming her identity as a cisgender female, but sensing latent danger behind this surface level. She does not hide her identity if it comes up, but she does not choose to share it in these types of surface level interactions where it very well may not have to come up.

Besides the everyday climate, there are specific challenges that gender non-conforming students face on campus that could be better accommodated by the campus. Housing is a major example. Natalie described her experience as a first-year student in a dorm as a period of just waiting to have her own place so that she could start making material steps forward in her life. She didn't want to start hormones too soon and have changes happen because she felt that could lead to experiencing bullying in the dorm. She was "always moderating safety and privacy and that made me feel very isolated with it." The process for changing one's preferred name and having access to more gender neutral bathrooms on campus were both institutional areas that were addressed as needs by Penelope. She recognized progress at the university, stating that these have been addressed by the SGA and she believed that progress was being made on them institutionally, but expressed her frustration that as a land-grant university that should be supporting its students, she did not see the institution moving fast enough to make changes, stating “you're a school, this is your job, this is what you're supposed to be doing - people can't learn if they don't feel safe and included."

Another institutionalized aspect of life that the university controls that affects trans* and gender non-conforming students disproportionately is that of healthcare and insurance. Natalie discussed the new mandated insurance plan that the university had implemented and that this did not include coverage of healthcare specific to trans* needs. She said that the lack of her healthcare meeting her immediate needs was a big part of why she was not performing as a 
student because she was "constantly having to cope with my genitals and I don't have good therapy here and there is no surgery available in the health plan." Her most immediate needs are those that are not covered and the combination of paying additional money and being mandated to pay for a plan that does not cover these needs has influenced her to consider as a further incentive to leave the university. Penelope echoed that insurance should cover student benefits, such as hormone replacement therapy.

Gender identity and gender expression affect more students than those who identify as trans* or gender nonconforming. For instance, Dani was one of the few participants who selfidentified as a cisgender female, thereby recognizing her privilege in her gender identity. This did not, however, mean that everyone else saw this privilege in her. Dani relayed the story as follows:

There was one awkward moment where somebody called me "brother" and then I ended up seeing him again and he addressed me the same way again and then I had to correct him and he was like "oh, I'm sorry." (laughing) I think he was still confused and so he was like "so, what are you?" and I was like "I'm a female" and he was like "oh ok, ok." So that was kind of awkward.

Faye mentioned in her individual interview that her gender identity is often unacknowledged. She defined this identity as genderqueer, but for the sake of a non-academic setting she may just say, "Oh, I'm a girl." She said that she wouldn't necessarily say that she is cisgender, but she will identify as a girl because she has a more feminine appearance and it is more convenient. If people want to get more in-depth, she will say she is a tomboy and kind of butch. This in-depth discussion is in sharp contrast to the amount of detail that she gave in the discussion on gender identity within either of the focus groups. While she said that she 
"identifies underneath that umbrella" when talking about being gender non-conforming during the panels focus group, she did not get very personal about her own gender identity during the sexuality focus group. To give full context, she was not feeling well and had left the room during the part of the conversation where Owen had brought up his gender identity and so it is quite possible that she would have discussed more at this point. Owen stated that there is a disjuncture between what is acceptable for those who are male-identified and those who are femaleidentified, discussing how breaching the gender binary to cross-dress as a female is much less acceptable than it is the other direction, stating:

An observation for females, people who may be biologically female who may be genderqueer or transgender, it's a lot more socially acceptable to walk around in jeans and a t-shirt and to be, there's even a word for it, you're a tomboy or whatever, you can't - I mean, I can't go out in a skirt. It doesn't work like that.

Gender identity and expression affects everyone, but the role that it plays in the lives of those who identify as genderqueer, gender fluid, gender non-conforming and trans* completely shapes the world in which their experiences are structured. The university campus is not an exception to this, but in fact may even amplify the effect of the figured world. Natalie described the lack of supportive policies at West Virginia University as having shaped her as follows: It's going to be something I survived, not something I did, thrived in, something about my past that's an accomplishment. My accomplishment is not really graduating or succeeding here. It's just being able to make it out of here. That's how it's made my experiences - I'm a WVU survivor. 
Natalie and Penelope both described their time at WVU as having shaped them as moving forward in similar ways. They both described the outcome of their experience as making them profoundly angry, as follows:

I'm gonna be a far angrier person. Far more bitter. Probably more depressed. It hasn't really left a lot of positive. Like I said, I'm just gonna really remember it as a time when I survived and, like wow, how did I even do that? (Natalie, individual interview) I'll tell you what; it's made me angry... It's definitely made me angry, but it's also made me a better person I think. In the sense that actually experiencing these injustices, actually experiencing privilege being taken away from me, all this stuff and really seeing some pretty bad stuff - not the worst by any stretch of the imagination; I'm still whitelooking and that really, really, really helps and I'm not gonna sit here and say that I have it the worst of anybody - but it's made me better as a person I think because it's opened my eyes to how shitty things actually are. It's made me more interested in actually taking stands and doing things about it because previously I was just like well this is what I think, but I don't care enough to do anything about it because I'm not being affected. (Penelope, individual interview) Individuals who identify specifically as genderqueer or gender fluid and specifically those individuals who are gender non-conforming who have engaged in hormone replacement therapy are situated within a figured world that looks much different from those in which the cisgender students were situated, regardless of sexuality. However, one thing that many cisgender participants did recognize was the inadequacy of protection of the current policies in regards to gender identity. Within the individual interviews, when asked the question about how has policy affected their experience at WVU many cisgender participants moved beyond their 
individual experiences to specifically comment on how gender identity was not included in the equal opportunity or non-discrimination policies at WVU. Trans* and gender non-conforming individuals were especially aware of this lack of inclusion and it should be noted that there were some cisgender individuals who were unaware that it was not covered and specifically thought that it was within the policies. Their positions of privilege enabled them to be unaware, but this was not the case for those who were gender non-conforming. It's important to recognize the ways in which our policies and structures reinforce our ideas surrounding gender and its social construction. Owen gave the insightful reminder that:

Whenever we get into talk about masculine and feminine, we need to remember that these are all constructs. They aren't biological and they aren't inherent in the way that we think...there are other cultures that do it very different. The Native Americans have twospirit people who were just a third gender and that was find. And even when we just talk about masculine/feminine, you're attracted to someone, you get into this weird place where we define ourselves in terms of these social constructs, which are just that social constructs. (Owen, second focus group)

It is important to recognize these concepts as social constructs and to analyze them as such. Based on this research, it appears that there are limited spaces in which conversations like this can happen and in which students can explore these foundations of social construction on which their own understanding of their identit(ies) are built. One of these sites of (de)construction is that of the educational panels.

\section{Educational Panel Discussions}

The possibilities of educational panel discussions as mechanisms of increasing campus understandings about issues of gender and sexuality emerged as an important theme in this 
research. In fact, panel participation as a form of the participants' impact on the campus of WVU came up in 5 of the 15 interviews. Discussion on sharing their experiences to others on campus or within classes came up more broadly for others. Because I had not specifically designated a question about panel participation for the individual interviews but because it was one of two clear dominant themes across participants, I decided to open up a focus group to anyone who had discussed panel participation in their individual interview, as well as those who had participated in panels but did not discuss this in their interview. With these qualifications laid out, there were nine individuals who were eligible to participate in the focus group. Due to schedule conflicts and weather, there were only four of these individuals who participated in the focus group on panels.

Those who participated in panels, at least among those who spoke directly about this participation in the individual and focus group interviews, felt very strongly about the impact that they were having on campus. Faye said that the panels are "really important, they're really enlightening and provocative. And they do provide a really good, safe way for people to ask things that they want to ask." Sophia thought that the panels make the struggle real for students who may not know anyone close to them to make the issues facing LGBTQ people relevant. The participants all felt like it was an opportunity for them to have an impact on the campus climate and to make the changes in their own environment that they would like to see. This seemed to be true no matter how many panels the participants had been involved in. Students who had only participated in one or two panels throughout their time at WVU had also brought these up as times during which they had an impact on WVU while they were here.

Many participants had gotten feedback that this was the first "gay person" or chance to talk to someone who was LGBTQ-identified that any of the students in the class had ever had. 
One of the participants who is also an instructor said that one of her students stayed back after class to write a reflection saying "thank you for doing this in your class - I've never met a gay person." She confirmed that he had in fact met a gay person before - her; he just did not know that he had. While this seemed unlikely to the other participants based on their nonverbal behaviors during this discussion, it also seems that this is a belief on behalf of those who are witnessing the panels. A participant who said that she was the first person that many of her fellow classmates in graduate school had known who was gay or lesbian and that her presence in their program has "allowed them to ask questions openly and honestly that they may not have ever asked" reinforced this. This resonates very similarly to what was said by many of the participants regarding the panels. It shows that, if students in a high level graduate program are coming into their education with little to no knowledge of LGBTQ issues, then it stands to reason that undergraduate students have probably also had little to no opportunity to ask these questions either.

While the feedback and tone regarding the discussion of panels in both the individual and focus group interviews were mainly positive and affirming, there was hesitancy and resistance in a few areas. There were also examples that were shared where someone was present who showed homophobic ideas and Sophia reframed this saying that she sees those moments as learning opportunities as well because even if they still hold those beliefs, "perhaps I've exposed someone who's very naïve and thinks that everyone is just about (supporting) diversity, I'm opening them up to the idea that people like that still exist." Archie for instance felt that during the panels, "there was not enough dialogue or just enough [pauses]... or just enough. You know." He felt that there was not investment from the entirety of the audience. Without audience investment, there would not have been discourse and thus, if no Discourse-Identity was 
constructed through the panels, it is possible that he was feeling a lack of this or that there was a lack of construction of the figured world environment of the panels that was established in some of the settings and described below. It seemed that the Discourse-Identities that were most present within the panels were those of leader or educator or change agent. Archie did not seem to feel that he was making the impact with the panels that some of the others did and this may have come from a lack of Discourse-Identity, created through a rational dialogue with the audience members. Because he was not receiving that feedback that he was seeking, he was not feeling recognize in his identity.

Creating the "figured world." For participants, panels were transformational. They allowed opportunities for participants' identities to be explained, affirmed, and understood potentially through the act of discussing LGBTQ issues publicly in front of and with audiences publicly at WVU. While each panel may look different within each classroom or other public setting in which it was constituted based upon the classes/venues and the panelists participating in that given setting, there are some common themes that were discussed as to what this figured world of the panel looked like. One participant used an analogy to theatre, making this comparison multiple times. Faye described the interactive experience of being on a panel as follows:

You're putting yourself out there. You're presenting your art and you're presenting your information and you know the way that the audience reacts to you and picks up on you and interacts with you, it really makes a difference in your quality of work so sometimes if you want to get a better quality work out of yourself and out of your audience, you do poke and prod. 
While there was a sort of archetype of a figured world created within the discussion of the panel focus group, this was not necessarily the case for all panels that were conducted in all settings. For instance, where the focus group participants espoused mutual support, this was not something that was felt by one individual when she participated in a panel. Kairi stated that when she participated in a panel it was very uncomfortable. The students in the class asked the gay men a lot of questions about sex and the men didn't know the answers, but she did and the students in the class thought that she was straight and asked her if she was confused. She said that she felt supported at times by her fellow panelists, but there were other times that the things they said were "just like... 'no." When I asked her what would have helped to make her more comfortable in that situation, she replied that:

Possibly having someone who was in the classroom who identified like that, but I guess I should have thought about that, that student might identify with us but is having to hear all this from their classmates and we're the only people up here to really kind of switch it so - yeah. I think I was the only bisexual girl there too and it was like all homosexual girls and guys.

This shows the pressure that is on the panelists to direct the flow of the class, not just for their own sake, but for the sake of any LGBTQ-identified or questioning students in the class. The participants in the study did not all participate in panels within similar time frames and there may have been differing amounts of support provided institutionally for different panels. The panels have generally been run through the student organization, currently called Spectrum, but at times instructors have taken it upon themselves to organize panels without going through Spectrum. At different times of Spectrum's history there has been varying amounts of leadership and coordination provided by the students within the organization depending who was currently 
serving in that role. Additionally, within just one semester prior to this focus group the Division of Diversity, Equity and Inclusion began provided some support for coordinating the panels through my role as a graduate assistant within that office. This coordination included not just contacting instructors and lining up panelists for the requested educational panels, but also providing training and a framework and outline for the panels. This outline included some key disclaimers about the experiences being the participants' own and there being a wide variety of identities and experiences within the LGBTQ community. With regard to LGBTQ-identified or questioning students in the class, this understanding of within-group diversity may be key in being able to connect to others experiences.

Self-authoring in the figured world. During the process of the panels, the panelists are shaping the environment of the classes that they enter and they are also shaped by this environment. During this reciprocal process, self-authoring is happening. As the authoring self is invisible to itself and the individual can do more within the context of the support of others, the panelists are actually creating their own zone of proximal development. They are providing the support for one another. One panelist described this supportive environment as making her more comfortable talking about coming out and then in turn she has become more comfortable coming out to her friends when she visits them at home. As Holland and her colleagues (1998) stated, "the authoring comes from the I, but the words come from the collective experience." This illustrates the ways in which the panelists are able to make better sense of their own experiences through the panels. One panelist describes this as "an all-around learning experience for everyone involved." The participants indicated that they tried to involve the perspectives of everyone on the panels in order to have equal say in the discussion. Multiple participants pointed to the importance of including gender identity in this collective experience. 
While it could not be determined with just the data collected in this study, it is worth considering the ways in which the audience is also a part of this zone of proximal development. One participant described witnessing an incident where a student was trying to ask a question to the panelists and she was struggling to phrase it. They saw another classmate intervene and help her rephrase it. Sophia described this as a "kind of cool interactive there because it was like she didn't know the 'PC' way to say something and she was struggling and someone else was like 'oh I think you mean this."' Another example of audience interaction came outside of the classroom when a participant saw a student at a local gay bar soon after a panel. That student was there with her friend who she had invited into the class for the sole purpose of attending the panel. In Corey's words, the student that approached her said the following regarding the panel: I convinced him [her friend] to come and sit in and he's been in the closet for I don't know how long and this is the first night that we've ever convinced him that it would be ok to come to [the local gay bar] and just be who he is and have fun. So I just wanted to say thanks and if you see us around, come say hi or something.

These interactions that were witnessed by participants, who served as panelists, indicate that there is room for growth, not just for the panelists, but also for the audience members who are a part of this environment. The first example shows a student stepping in and assisting another student in being a better ally. The second example shows a student feeling, presumably, more comfortable with his own sexual orientation due to the interactions between the panelists and the class. While it cannot be inferred from this data alone that self-authoring is happening for the audience members, it does show ways in which a space of authoring is opened up and thus could be creating opportunities for identity and agency, not just for the panelists, but also for all who are exposed to the panels. Self-authoring is what leads one to a place of identity and agency. 
That space of authoring is a "broad venue, where social languages meet, generically and accentually, semantically and indexically, freighted with the valences of power, position, and

privilege" (Holland et al., 1998, p. 191). Therefore, the presence of tension, power and privilege does not exclude the presence of self-authoring. However, the development of a social position into a positional identity happens over the course of time through one's decisions on how to engage in social interaction. Bisexual, pansexual and fluid sexual identities were particular identities for which it could be seen that over the course of time participants engaged in such a way that led to their identities becoming positional identities.

\section{Positional Identities: Pansexual and Bisexual}

Participants who identified as pansexual, bisexual, or with other fluid sexual identities showed in both the individual interviews and in the focus groups that their identities were consistently subjected to the location of a positional identity. Positional identities, as defined by Holland et al. (1998) "have to do with behavior as indexical of claims to social relationships to others, how one identifies one's position relative to others, mediated through the ways one feels comfortable or constrained" (p. 127). These identities are positional because they are constantly being negotiated and re-negotiated on behalf of those around them, rather than on behalf of themselves. The participants choose to label or not label themselves based on their perceived reactions of those around them, or the relationships that they have with others. Their own identities were mediated through how comfortable or constrained they would be not only by the other person, but by how comfortable or constrained they perceived that they would make the other person.

\section{On Labels and Not Labeling}


Even though all of the participants gave me some sort of label for their identity at some point, for many of the bisexual, pansexual or fluid sexual identity folks, this did not come without a preface that there was some discomfort with the labels and, for many of them, a preference to do without the labels altogether. Both Gabriella and Jill did not associate with labels initially, saying, respectively, "I don't feel the need for using any" and "I've never thought of myself as particular labels before." Even though he sees himself as pansexual, Owen discussed the problems that he saw with labels as follows:

I think that labels can do us a disservice because first off they seem like this monolithic thing, right, when you, when someone internally labels themselves as gay, for instance, they feel some sort of internal pressure that that will be their label and if they start to deviate from that, it would start to change, then they can have some internal tension...I think creating any sort of category in that way, you know while it can be - while it is necessary to do such things as research, have some categories of people - referring to yourself in a sort of monolithic way can be bad.

Even as the focus group discussed other aspects of sexuality and moved on to other topics, the subject of labels kept returning. Within different contexts individuals moved from not wanting to label, to choosing the label that they feel fits them best personally (often pansexual), to labeling themselves with a more commonly understood label (usually bisexual) in order to make discussing their sexuality with others easier. Participants' level of identity and agency was very much determined by the context of the figured world within which they were situated. However, the overall cultural context of the United States and West Virginia University contributed to every cultural world, as participants could not escape the conceptions and often misconceptions that other individuals bring with them attached to labels. They were caught, 
therefore, in many situations, making a decision as to whether to use a label that may be familiar to others, but may be fraught with meaning that does not apply to them individually or to explain their sexuality either without labels or using a term that may be unfamiliar to the other person, both of which would come with the baggage of a long explanation. Gabriella described this as follows:

It is way easier to say I am bisexual than to say I am not heterosexual or I am something else. People don't know what you're talking about. Even I don't know what I'm talking about. I just like someone and I don't care.

Gabriella's statement shows the ways in which our cultural understanding of sexuality frames not only how individuals talk to others about their identities, but also how they view others' perceptions. It was clear through the rest of her individual and focus group interviews that Gabriella did know what she was talking about when it came to her own understanding of her sexuality, but without the culturally-sanctioned words to back up this understanding, she was at a loss for discussing it with others and then became at a loss for her confidence in understanding herself. It became clear through a number of examples that there is a connection between these labels, especially the label of bisexuality, and the marginalization and bias against this identity and socially sanctioned biphobia.

\section{Biphobia and Marginalization}

The marginalization of students who identify as having pansexual, bisexual or fluid sexual identities happens not just at an individual level, but also at an institutional level. It happens not only with those who identify as heterosexual and cisgender, but also among and within the LGBTQ community, and most especially with cisgender male and female gay and lesbian individuals. The biased concepts that are tied to these labels can't be viewed in isolation 
from the labels themselves. Within-group marginalization can happen in an institutional context. Harper shared that the first group of people she came out to was her LGBTQ studies class and, according to her, "there were people who identified as queer, as transgender, as lesbian, as gay, they were all there, everyone was there." Despite this though, she felt like she was judged negatively when she came out as bisexual. She compared this to a Ted Talk video of Ash Beckham that she has watched, stating that they acted, to her, as if their closets were harder to come out of than hers, as if their experience was more valid than hers (Beckham, 2013). Owen had a similar experience coming out as pansexual to someone who identified as gay, saying that they told him that it “wasn't actually a real orientation - you know, it was just a transfer or someone just trying to ride the popularity of the gay movement." Owen said that he explained that was not his experience with his identity and that it was not a transition thing and that's how the conversation ended, but that was the first time someone had confronted him in that way.

When asked if they believe that their experience is similar or different from others on campus, many of the participants who identified as non-monosexual said that because of their status as bisexual or pansexual it was easier than those who are gay or lesbian. Despite these statements, many of these same participants when I asked if they had anything else to add in the closing comments said that there is still a stigma against bisexuality from both monosexualidentified individuals; that is those who are either heterosexual or homosexual. For instance Gabriella stated that she gets the impression that others believe that "bisexuality in general is just this magical land that doesn't exist and it's just imaginary." There was, however, a distinction in this question about comparing one's experience to others in that those who also identified as gender non-conforming very distinctly felt that their experiences, regardless of their sexuality, 
were more difficult than their peers' experiences. Jill stated that she will sometimes sacrifice being true to her own identity in order to make discussion less complicated, saying:

I definitely would say that I'm pansexual, but like I said you can't explain that, even with a close friend, I don't want to get into it. I don't want to get into it, I would say (bisexual), but it's definitely not as true to who I am with my sexuality.

While the group felt that the term bisexual was more accessible and more widely known, they also thought that it was laden with many misconceptions by both gay and straight people. Though it was previously discussed in the curriculum section, it is worth noting again the ways in which when sexual orientation is included in curriculum it is often from a cisgender lesbian or gay male perspective. Natalie said this best, in stating the following regarding curriculum inclusion:

My biggest gripe with sexual orientation is that it seems (that) whenever someone is talking about sexual orientation they are talking about cis-lesbian and cis-gay men and like there's no discussion about bisexuality beyond like 'hey it exists,' like let's not be biphobic. That's all that's really touched upon - there's not even the nuances of what bi could even mean or what exists outside of monosexism. There's no mention of polyamory and stuff. I mean there's just so many sexual diversities when you talk about sexual orientation.

Bisexual and pansexual participants discussed that there were myths and stereotypes associated with identifying as bisexuality, which stem from both the heterosexual and lesbian and gay communities. One of the myths that came up was that of attention-seeking. Everyone in the focus group agreed that these included that straight people often perceive bisexuality as being a fad or trend. One participant, Jill, felt that pansexuality was beginning to be perceived that way 
as well. The focus group also all agreed that those who identify as bisexual or pansexual are perceived as doing so just to draw attention to themselves, especially from heterosexual individuals. Gabriella added to this, stating that this was especially the case with men. Another myth related to bisexuality was that they were attracted to everyone. This resonated strongly with the focus group participants, who all agreed and laughed about this and one participant, Kairi, said her response is "I have standards honey and you don't fit 'em!" Gabriella stated that she received a text message out of nowhere from a male friend asking if she would want to have a threesome with him. She strongly believed that she would not have received this unsolicited proposition if he had not known that she identified as bisexual. At the same time that bisexuality was hyper-sexualized, participants stated that they were also invalidated if that had not had sexual experiences with others of the same gender. Even if they had experiences in the past, some participants' had family members who had invalidated those experiences or negated their sexuality as soon as they were in a relationship with someone of the 'opposite' gender. The last myth was that bisexuality and pansexuality didn't really exist. While the focus group participants all felt that they got a lot of "dismissive" comments regarding bisexuality, they did think that pansexuality got a little bit less of this response. Kairi stated that she gets "more of an inquisitive thing instead of a dismissive thing" with pansexuality. This last myth is especially dangerous because it is essentially erasing an aspect of their identity. The participants are hearing from others that who they are is not real, that it does not exist.

This marginalization, however, can be used as a site for organizing. As Holland et al. (1998) states, "people sometimes fix upon objectifications of themselves that they find unacceptable. These objectifications become the organizing basis of resentment and often of more active resistance" (p. 143). This distinction was present to some extent between different 
participants of the focus group on bisexuality and pansexuality. Faye for example did not mind when people came to her with questions or identifying her primarily based on her sexual orientation because this meant that she had become an "information source" to them. She saw herself as organizing around this identity. Others did not and did not want to be seen for the primarily, but also did not seem to move into a more active resistance mode of operation. Whether it is one's sexual orientation or some other aspect of identity, erasure and silencing of that can be damaging, but it can also be a site around which individuals organize. Each aspect of identity comes together in an intersectional way, dependent on one another. These intersections of identities create the complex figured worlds in which students occupy. However, there are some things to be learned from the specific axes of identities.

\section{Intersections of Identit(ies)}

Many participants had a clear understanding of the ways in which their sexualities and gender identities intersected with other aspects of their identities; others did not. At times positions of privilege and power tied into this. A truly intersectional approach is needed, not just when discussing identities, but when discussing curriculum and the integration of identities and experiences into curriculum. Natalie addressed this by saying "I think it should just be institutionalized in education in general is just sort of intersectionality and intersectional standards." Intersectionality can be applied in an interdisciplinary way, as a way to view history, the social sciences, literature; all subjects. Natalie went on to say "Anything could be intersectional. It's really amorphous. It's a Women's Studies concept, but it can be applied anywhere and it's really important." While intersectionality is an academic concept that is often cited within Women's Studies, it can be moved into other academic disciplines, but also outside of academics. 


\section{Axes of Identity}

While many axes of identity came up within the individual and focus group interviews, there were a few that showed more prominence than the rest. These included racism and ethnic bias, invisible and visible disabilities, and religious and secular affiliations. It may be noteworthy that race came up minimally in the individual interviews, but when it was brought up in the focus group, the group went on to talk about the experiences of racial and ethnic bias that they had experienced or witnessed for over twenty minutes. With regards to religious affiliation and disability, the talk about these on a personal level came up much more in the individual interviews than it did in the focus groups. This may or may not be merely a coincidence. I allowed the focus groups to take the direction dictated by the participants and while religion was mentioned in both, it was not a topic that was picked up for further discussion. Disabilities, visible or invisible, were not brought up in either focus group, though participants in the focus groups discussed them during individual interviews. This could show a level of comfort in talking about these topics in one-on-one versus group settings.

Racism and ethnic bias. Participants were especially concerned with the climate related to racism and bias against particular ethnicities and nationalities. While racial climate came up briefly in multiple individual interviews, it is especially important to note that the last twenty minutes of the focus group on panels was spent entirely talking about racial bias and discrimination. All of the participants in this focus group were white-identified and born and raised in the United States. After the forum, the participants were invited to discuss "any last thoughts" that they had. One participant, Corey, mentioned that some students, and especially other students who were also from rural West Virginia, “don't even realize that racism still exists." The discussion branched up and out from there. It was noteworthy that this discussion 
stemmed from a statement about the context of the university being set within rural West Virginia and the importance of the panels due to the demographics and background knowledge of the students. Also telling was that the discussion on racism went on for so long that one participant thought that I, as the researcher, had originally posed the question. When I called attention to how much time they had spent in the discussion of race without any prompts from me, Sophia said "I thought you said something about race?" Eventually the participants figured out the course of the conversation, but they were so drawn into race that they did not realize that this question had not come from me, the researcher. It seemed highly likely as well that they would have liked to have continued the discussion and taken it to an even deeper intersectional level if we hadn't already been in the focus group for so long and participants had to leave, which shows that there is a desire to have these conversations while there is not a space to have them. Their increased comfort level discussing race within an all-white focus group may parallel some of the increased comfort at discussing sexual orientation within similarly-oriented groups.

One of the major ideas surrounding race and racism that came up was that it was silenced and not discussed. When I followed up to ask how open they though the conversation [on race] is on campus, all of the participants laughed. The participants believed that others felt that racism was "literally normal" and that "no one talks about it!" Despite this silence, the participants felt that there was a palpable everyday tension surrounding race. Sophia described this small city as a “quaint" place where "strangers will just smile and say 'hi' to you," but said that "black people avoid eye contact" with her here. She says that it really bothered her when she first moved here that white people would say 'hi' to her, but that if she would say 'hi' to a black person, they would keep their head down but not look at her. Since she has been here longer, she said she has come to equate this with a fear and distrust of white people. Another participant, Corey, agreed 
with this assessment based on the experiences of a friend, who is a black man. With all of this being said in the focus group, they still admitted that they do not feel comfortable discussing this in everyday life. One participant Faye disclosed her own discomfort in discussing race, as situated within this environmental context:

There is no discussion whatsoever. To the point that having been born and raised in Morgantown and we're talking about things like race, like the word race makes me uncomfortable, like seriously acknowledging that there is a difference makes me uncomfortable. Genuinely.

The racism that the participants discussed was not just a silent omission of differences and the subtleties of nonverbal behaviors, but they also pointed out blatant institutional and curriculum examples of bias. Even though she did not grow up in West Virginia, Sophia spoke of the lack of curricular inclusion of people of color, not just in higher education, but also in elementary and secondary education, pointing out the distinctions between rural and urban areas in the state where she grew up and coming from her perspective as an instructor. Corey spoke of how she didn't realize how "ignorant of issues" she was until she came to college and had a best friend and roommate who was a black man. According to her, there was so much she didn't know, "just movies, music, history... that most white people would never know unless they were that close with somebody that was black and it's just because we're not taught. We don't have to know." The participants recognized the ways in which racism and homophobia were interconnected on a very real, personal level. Sophia stated that her girlfriend was refused service at a local business and they still "don't know if it's because she is a personal of color or a lesbian." 
When asked about campus climate in an individual interview, one student stated that she "would worry more about racial stuff most of the time," explaining that LGBTQ individuals can hide it more, whereas she especially sees the negative climate racially and that she "constantly worr(ies) about the girls that wear the hijabs." While she expressed this as an indication of the racial climate on campus, this is a complicated example as it deals with a personal expression of religion rather than a racial or ethnic expression. Religious belief and expression and the intersections with campus climate and LGBTQ student experiences was another aspect of identity that came up in the research.

Religious and secular affiliations. Religion came up many times in the interviews and focus groups as a source of strife, but also at times a source of empowerment in participants' lives. This often served as an avenue for both religious and secularly affiliated students to find social groups and commonality, as well as a way of affirming their sexuality. One student, Corey, told a story about an event that she went to with a speaker who had planned to discuss the debate between being gay as a sin or not being a sin and where people stood on that, however everyone in attendance at the event was open to non-heterosexuality sexuality and did not see it as a sin and so he changed his approach for the evening to discuss how the other side feels from a more hypothetical stance. Corey shared this experience as being a time when she felt a sense of belonging and involvement at the university. It was also one of the first events related to sexuality that she had chosen to attend. She described its impact on her as:

And being a Christian and being raised as a very, very Protestant Christian, obviously being gay wasn't an option. I spent a long time trying to figure out how my belief in God and being gay could work together or if they could at all. So it was really, really cool that all of a sudden that popped up and then it [her involvement] went from there. 
Corey also attended one of the local churches during her time on campus and said that they have an institutionalized outreach program and that the Presbyterian denomination has made an official statement that they see no wrong in the LGBTQ community and "yes they are born that way and God still loves them for everything."

There was a range of openness for students as far as feeling comfortable discussing their beliefs with others when they identify as atheist or agonistic. One student who identified as atheist or agnostic said that she is open to telling people what she thinks and also open to hearing other's views. She believes that "religion can be a really good thing: it's unifying, it gives you a sense of self, and I just don't happen to identify with one.” Another atheist student felt that she would not be comfortable telling people she was atheist, saying as she would telling someone her sexual orientation, saying "probably even more so with someone I know, which is really silly sounding." Another atheist student was open in discussing the progression of his beliefs and the struggle he had with accepting others that didn't see things the same as him. He said that after taking a particular religious studies class, it helped to explain a lot of things and he read more books on many different traditions and he came to be much better able to see others' perspectives. Owen explains his process as follows:

I guess that's part of getting educated is that the more you get educated, the less sure you are of your positions and so it's not like I'm teetering on the edge of anything, but I can definitely understand where a lot of people are coming from. I understand where our base differences are. How we answer these more base, deep fundamental questions that differ and how even though we have these very different conclusions, we can be very similar people and just disagree on one or two things and diverge from there. I guess just a lot more accepted in that way. 
The statement above came from an atheist student who learned more about others' beliefs through his general education courses and it had a profound impact on his life, not just in how he treated other people, but in how he approached education and religion. Before this revelation, he said that he came to WVU “very, very certain and very upset that other people didn't see it as [he] did - (laughs slightly) to put [himself] in the most favorable light.” To be clear, it wasn't that he wanted to change or sought out this knowledge or transformation, but he definitely was grateful for it and feels like a better citizen and well-rounded individual.

I think that this experience could very much be viewed in comparison to inclusion of sexual orientation and gender identity in the curriculum. It would be through a mechanism similar to Owen's exposure that those who may have very steadfast and strong beliefs would first be exposed to those who have different experiences from theirs. This exposure may be something that they would not seek out on their own, but it very well could be something that is transformative and positive, not to mention productive in creating a well-rounded student and citizen.

Invisible and visible (dis)abilities. While the prevalence of the theme of the role of disabilities, both visible and invisible, in individuals' lives was not exceptionally high, I believe it is important to include in the analysis because the role that it played in the life of those that it did affect was so profound. While there was some mention to physical disabilities, the most mentioned category was invisible emotional and psychological disabilities. One student who had struggled with mental health issues through middle and high school was extremely grateful for the support that she found at WVU. She was able to work through past trauma and abuse and get the assistance that she needed to function at a much higher level. Some students seeking support with sexual orientation and coming out stated that they had a positive or even "really good 
experience" working with the counselors on campus. Trans* and gender non-conforming students did not always have as positive of experiences working with counselors on campus, stating that our campus did not have the resources to offer that they needed for basic health and mental health care needs.

These identities are all intersectional in nature. Various identities take priority or prominence at different times in one's life. They may be visible, invisible or vacillate between visibilities. Whether for positive, negative, or neutral reasons, there may be one aspect of one's identity that presents as a more primary identity than others. The identities that were considered in this study as primary were not, however, that which may have always been seen as primary by those participating in the study. Understanding how all of these intersect can help to complicate that which is seen as primary and help to see primary identities from the participants' lenses.

\section{Complicating Primary Identities}

One of the concerns of being “out” or discussing one's sexual orientation and/or gender identity on campus was that this would in turn become one's primary identity. For some students, this was a small price to pay in order to try to improve the climate. For others it was reason enough to remain "closeted" or to choose very carefully when and to whom they did decide to disclose sexual and gender identities.

Primary identit(ies). There can be conflict between primary identities and that is part of what makes the use of the figured worlds tool so helpful in understanding these experiences. For instance, the panels allow for an environment where the interaction and the details shared within that interaction is to remain confidential among the panelists and the audience. This situates the panelists temporarily as sexuality and/or gender identities as their primary markers. However, they can move back into the other figured worlds in which they occupy with minimal concern as 
to the effect that this will have on their lives or their identification by others. For instance when discussing confidentiality within the panels, Sophia said 'that's really important to me because I don't come out in the classes that I teach... I do that because of the students who are homophobic. I don't want them to feel silenced." This allows her then to maintain the primary identity of instructor in her classroom environment and structure that environment in the way that best works for her classes, while also being able to participate on the panels and have those moments in which her sexual orientation does become a primary identifier. Some participants seemed to feel a fear that their sexual orientation would come to define them as a primary identifier. Harper said in her individual interview:

It's not really something that defines me as a student and I don't want it to in a sense. It defines me as a person, but I don't want it to define me as a student. I don't want it to be something that would hold me back. I want to be defined by how well I do, by the products that I put out.

Students are complex individuals. It should not be surprising that they want to be seen as such. Nor should it be surprising that they would like to be seen by the caliber of the academics and production within the academic realm when they are in an institution of higher education. However, when sexuality as an identity is brought up, they fear they will not be seen for these things. Further, the participants were not just products of their academics and their sexual orientation, or even the additional identity components that have already been discussed. There were many and varied complexities of identities within the aggregate of the participants and these complex identities came together to create their own unique experiences.

Complexity of identities. During the course of this study, participants revealed many additional identit(ies) and aspects of their identities besides those which have been heretofore 
mentioned. This study seeks to more fully recognize the ways in which students are complex human beings beyond their sexuality and gender identities, as well as beyond the other typical markers of identity, some of which are explored in this section. To do this, I unpack the aspects of identity that were individual and important, as seen from the participants' perspectives. My goal is to create a more complex narrative about the lives our LGBTQ* students. Because piecing together these very specific aspects of identity with individuals could make it easier to identify participants, I chose to completely omit the use of pseudonyms within this section to protect participant confidentiality.

Identities that are a part of a creative outlet were a common theme among participants. Multiple students discussed "gamer" as an important identity to them. One described gaming as "a fun cultural experience to just be able to put everything down and get away." Theatre was an identity that was important to more than one participant. One student said that being a part of theatre made her feel that she has a place where she feels very comfortable with herself. She described it as “all working towards the same goal - getting a show out on the stage - we don't have time to judge each other and things like that because we're a team and we work as a team." Being a part of a team was important to the student who identified as an athlete.

Political and activist groups and identities were a connection for some students. One student identified as a socialist and their political engagement was very important to them. Another student felt that their vegetarian identity was one that was not adequately served at the university. Students also found support in unexpected places, such as with affinity groups that they may seem to at first have no connection. One student was a part of a foreign language club, in a language that she did not speak, when she was an undergraduate student because of the support offered by the advisor of that club. This student saw this particular professor as really 
pushing for gender equality and it was because of how much she learned in her classes that she wanted to be more involved in the professor's causes outside of class.

Social and status identity groups were an aspect of many students' identities. One of the male students was a part of a fraternity on campus and while he was not out to his fraternity brothers, he did say that there was an openly gay member and "it's perfectly fine and everyone loves him" and so he did not think that his potential coming out would be a big deal. One graduate student was recently married and her status in the "wife" role was relatively new for her and sometimes difficult to navigate in conjunction with her demanding graduate program. Two other graduate students were engaged and the status of fiancé was pertinent to their identity. One participant mentioned their pet and being a caregiver to their pet, a "mom" to him, as an identity.

Additional identities that the participants listed as important to them included: musician, poet, vegetarian, slut, and sex worker. These are the identities that participants made visible to me. There are undoubtedly many others that are important to them in varying degrees that they did not mention within this study. It's important to recognize the vast array of identities and experiences that students bring into the university. There was also overlap among the participants. All of the participants identified that the 'student' identity was relevant, though the salience that they placed on being a student varied. Some discussed how the importance of that role has gotten greater or lesser over the years that they have been in school. For all of the graduate students, their department of study was a part of their identity and the role of researcher and/or teacher and instructor was important to many of them. Lastly, almost all of the participants indicated some kind of connection with an oppressed identity that they could not claim as their own and working as an ally to end that oppression. All three of the male identified 
participants mentioned that they were interested in anti-sexism work. One stated that he has learned how issues that seem on the face to be women's issues actually do affect most everyone.

The positional and figural identities that students have within figured worlds shape their experiences and the perception of what that world looks like. Positional identities, such as bisexual and pansexual, can be marginalizing, but they can also become a site of resistance. The same is true for all of these identities. It is not just the position that individuals occupy within the institution that matters. There were plenty of examples of individuals with Institutional-Identities of the faculty or administration, but this made little difference one way or another to the participants. They put some weight on Affinity-Identities, or faculty's claims that they were aligned to certain groups, but these were tentative identities that were either proven authentic or not authentic through dialogue. It was truly through Discourse-Identities that most students seemed to connect with faculty, as well as other students. It also was through these identities that they had the most feeling of impact in their own work on campus when it came to institutional change. These tools of analysis, the figured world and identity as a lens of analysis, can help to understand the findings of this study and the implications as they apply to the site of the study, West Virginia University. 
IDENTIT(IES) \& AGENCY 151

\section{Chapter 5: Discussion of the Findings, Implications, and Conclusions}

This qualitative study was designed to understand the ways in which students who identify as lesbian, gay, bisexual, transgender, and queer (LGBTQ) perceive the campus climate at West Virginia University. By also including the language "or other non-cisgender/nonheterosexual identified" in the advertisement of the study, I was able to open this up to a broader population than just LGBTQ students. Through the use of individual and focus group interviews, I honed in on two major areas from which to understand the ways in which students' experiences are shaped by the climate: that of participation in educational panel discussions on sexual orientation and gender identity and that of claiming bisexual, pansexual, and fluid sexual identities. This research used a framework that draws especially from identity and agency in cultural worlds (Holland et al., 1998), showing the ways in which individual student experiences are shaped, influenced, created, reflected, and/or formed in relation to the climate that they perceive at WVU. Intersectional identities (sexuality, gender, race/ethnicity, class, (dis)ability, and religion) are crucial conceptually for understanding the complex dynamics of participants' figured worlds.

Campus climate is defined as "the cumulative attitudes, behaviors, and standards of employees and students concerning access for, inclusion of, and level of respect for individual and group needs, abilities, and potential" (Rankin, 2006, p. 7). The campus climate for students who identify as LGBTQ is shaped not only by individual interactions, but through inclusion in curriculum, the existence of LGBTQ-specific support, domestic partner benefits, and policies on non-discrimination, equal opportunity policies, and housing options, among other factors. I asked about many of those issues specifically. A lot can be learned not only by what students said about different aspects of the campus climate, but also those things which they either left unsaid 
or of which they were unaware. Using the figured worlds tool provided a means to understand students' positionality within the campus climate and the ways in which they viewed their identities in varying contexts. Understanding this can help educators, administrators, and everyone working with college students, especially at West Virginia University, to improve the campus climate for LGBTQ and other non-heterosexual and non-cisgender identified students.

\section{Discussion of the Findings}

The analysis of this study revealed many interesting outcomes, which connect to the broader literature related to campus climate, gender, and sexuality. The findings from this analysis can be understood within three major categories. The first category is curricular findings, which includes the idea that the collective lens of curriculum is has more possibilities available than the individual lens for improving curricular inclusion. The second category is figured worlds findings. These include the finding that students self-author in figured worlds and that the figured world of gender non-conforming students is substandard. The last set of findings relates to identity and includes the finding that non-monosexual students occupy positional identities and that agency is dependent on intersectional access.

\section{Curricular Findings}

Campus Pride recommended that universities improve LGBTQ college students' experiences by integrating LGTQ issues and concerns in curricular and co-curricular education (Rankin et al., 2010). The curricular results of this study consider this recommendation in relation to the findings. The curricular findings include the finding that students' collective lens of curriculum was greater than their individual lens. It also includes that a single faculty, staff or administrator made a difference in students' perceptions of inclusion in curriculum and climate. 
Students' collective curricular lens differs from the individual lens. This study found that students were less able to see the appropriateness of including sexual orientation and gender identity in the curriculum when they were discussing it individually, than when they were discussing this in groups. This is perhaps a direct reflection of internalized homophobia, biphobia and transphobia. There was a resistance when students were discussing curriculum as individuals to believe that there was a place for discussing gender identity and sexual orientation within the classroom.

Rankin et al. (2010) found that LGBQ students and faculty were less likely than their heterosexual peers to believe that their institutions' general education and departmental curriculum was inclusive and representative of LGBT contributions. While this study does not compare LGBQ students' perceptions to that of the general population or their heterosexual peers, it did question them about their perceptions on curricular inclusion. It was not that participants necessarily thought that the curriculum was inclusive and representative of LGBT contributions, but, rather, it is more that they recognized that it was not inclusive or representative of these, but also that LGBT contributions were not appropriate to include within the curriculum. The role of incorporating LGBTQ issues and concerns into the curriculum is to provide a space in which all individuals on campus are able to challenge heterosexist beliefs and to respond appropriately to anti-LGBTQ incidents and bias (Rankin et al., 2010). This curricular incorporation challenges the internalized heterosexism, homophobia, biphobia, and transphobia of those who identify as LGBTQ as well. It is entirely possible that the belief that it is not "appropriate" to include LGBTQ-relevant topics in the curriculum is a part of these internalized biases. 
It is important to recognize that sexuality also includes heterosexuality, and by virtue of this, many more professors are likely to be incorporating sexuality into their classes than are aware, however this is done in a heteronormative way (Skelton, 1997). The heteronormative nature of sexuality cannot be solely seen as a trap in which faculty are vulnerable. Students are a product of the same heteronormative culture and may be unaware of the ways in which heteronormative sexuality is being infused into the curriculum while at the same time they are hyper-aware of any disruptive sexuality that is present. For instance, one participant, Archie stated that he wished one of his professors "had whitewashed the curriculum a little bit more to be more traditional." He felt it was more appropriate for a gay studies course than a class not geared specifically towards queer content. It can't be seen with certainty whether or not similar heterosexual examples would be seen by LGBTQ students as being inappropriate, though at least one student did speak up to say that this was the case. Regardless, the teaching of sexuality in general triggers more anxiety in the classroom than any other subject because of the deeply personal nature (Skelton, 1997). This happens not just when sexuality involves LGBTQ identities, but whenever sexuality is brought into the classroom.

Curriculum can be a tool to create change in attitudes, but the students who are likely to enroll in optional courses are the ones who are already willing to expand their views (Engberg, Hurtado, \& Smith, 2007). While not all participants held the belief that inclusion was inappropriate, those who believed in curriculum as a tool to change attitudes shared some concern about this curriculum reaching student who would not already be seeking it out. Owen voiced this concern over general education courses, expressing that students would find institutionally-sanctioned ways, such as doubling up within one's major or getting a relevant minor, to avoid taking courses that would require them to broaden their ways of thinking. To be 
clear, while Owen disagreed with some of the other participants as to the appropriateness of including topics of gender identity and sexuality in classes, this does not mean that he was witnessing it happening, saying rather, that "if it can be avoided, it pretty much is." The idea that Women's and Gender Studies classes were filled with students who were Women's and Gender Studies majors came up within the educational panels focus group and both Sophia and Faye clarified that there are many majors and varieties of students within these classes, taking them for a variety of reasons. There are still some students who will try to avoid taking classes that challenge their beliefs if they are able take classes that are more comfortable instead.

One person can alter curricular perceptions. The literature shows that LGBTQ students' relationships with faculty and staff can impact their experiences inside and outside the classroom. This, too, was reflected in this study. Many students gave examples of finding support from a single faculty member. Interestingly, in one study Garvey \& Inkelas (2012) found that LGB students reported significantly higher rates of satisfaction with faculty and staff interactions than heterosexual students and that bisexual students' satisfaction was the highest. While this study makes no contrast to heterosexual students' experiences, students who identified as bisexual or pansexual almost across the board specifically made mention of at least one faculty member with whom they had positive interactions and with whom these interactions impacted their perceptions of faculty and staff's role on campus and/or the inclusion of LGBTQ issues in curriculum. In this study, students generally made no mention of the sexual orientation or gender identity of the faculty or staff, however, the faculty and staff identity in the interactions in the Garvey \& Inkelas (2012) study was also unknown.

Mentoring between faculty and students can be valuable for students identifying as LGBTQ and there were a couple of students who discussed having informal mentoring 
relationships with faculty or staff. One of the strongest examples of a mentoring relationship that was discussed was that between Natalie and her adviser, whom she said really made her feel like she belonged and had a stake at the university. While a mentoring relationship can be invaluable, it is not to be seen as a substitute for social change on campus to improve the status of LGBTQ students and free up the demands of the mentoring relationship for personal, academic, and professional growth (Russell \& Horne, 2009). This is reflective of Natalie's experience. While she was appreciative of the relationship and placed value on the mentoring, it did not compensate for the areas in which social change was needed on campus to improve the status of LGBTQ students, most specifically related to gender identity.

\section{"Figured Worlds" Findings}

The findings of the figured worlds speak to the overall campus climate and the creation of this climate within specific figured worlds. The rural university setting creates a specific personal and professional challenge for students, faculty, and community members that can make it even more difficult to develop informal helping resources for local LGB people or to foster institutional and policy changes to make the university a safer place (D'Augelli, 2006). The figured worlds are constructed within this cultural context. The first figured worlds finding is that students create their own spaces for authoring through the figured worlds of panels. The second figured worlds finding is that gender non-conforming students occupy a substandard figured world from that of cisgender students.

Students self-author in educational panels. This study found that students created their own spaces for authoring through figured worlds of educational panels. Participants of educational panels felt very strongly about the impact of the panels not only on the environment around them and their peer students, but also on the impact of the panels on their own 
experiences. They identified panels as a mutually educational experience that gave them an opportunity to openly talk about themselves in a way that they may not have at any other time. Their sexuality was constructed as a Discourse Identity through their participation in a dialogue with their peers, and it was constructed on their terms.

The self-authoring that takes place within educational panels may include a prioritizing of identities as a panelist, a leader, and/or educator. Renn (2007) found that being involved in LGBTQ student activist organizing changed some students' academic lives and careers goals, influencing them to align their studies more with LGBTQ and queer studies. Multiple participants who had experience with panels indicated that these led them to a higher level of involvement in activism and had shifted their academic and career goals. Sophia said that she had become more involved as an activist on LGBTQ issues due to the climate at WVU. Faye discussed that panels and that being able to present on and inform others about issues of sexuality and gender identity affirmed that she knew something about her major, that it also reinforced her identity as a student, not just her sexual and gender identities.

There were examples of times, however, when these panels were not structured in such a way to allow for self-authoring and, in those situations students' agency would become mitigated, and identities would fragment. For instance, when Corey's friend was asked if he had ever had sex with his gay brother or when Kairi felt unsupported by her fellow panelists, a supportive environment was not being created in which students were able to make sense of their experiences and push forward. If self-authoring did happen, it was despite the environment created in those panels or in a space created after the actual educational panel, not because of that environment. As the institutional planning and support process for the educational panels has 
been inconsistent over the past several years, providing a supportive space outside of the classroom has not been an option that WVU students have received.

The gender non-conforming figured world is substandard. Students who are gender non-conforming occupy a figured world that is very different from that of cisgender students. Those who are transsexual and/or have sought out hormone replacement therapy are in an even more vulnerable position. Their needs and the ways in which they are being met or are not being met are often overlooked by the conventional policies and practices that are in place institutionally. The litany of needs that were discussed by the transgender participants of the study were similar, if not identical to, those named as best practices by Beemyn (2005), such as health and counseling training, providing health services to transitioning students, such as endocrine tests, offering “all gender" housing on campus, getting gender-free bathrooms, and broadening identification-card policies to include transgender and transitioning transsexual students.

Transgender students become positioned as less-than within the figured world of the university. For trans* students, an identity that they do not hold as their own, that which they are assigned at birth, becomes the most salient identity in relation to their experience on campus. Trans* students become attached to a Nature Identity that is not one that they see or claim for themselves and this identity is named for them by the university, thereby also becoming an Institutional Identity. Many of the best practices and the needed services asked for by participants in order to provide a safe learning environment, regarding gender identity are those things that would create channels that make it easier for students to change this Institutional Identity to not be misaligned with their own identifications, such as school ID cards and preferred name-changing processes on class rosters and email. 
The figured world occupied by gender non-conforming and trans* individuals is one in which basic needs such as housing, health care, and restroom access are not being met. As Natalie said, “people can't learn if they don't feel safe and included." While curricular, policy and inclusion changes can improve the environment the institution does not have control over students' Affinity Identities or Discourse Identities. They do, however, have clear control over which identities are accepted as Nature Identities and which are not, and they are able to institutionalize these as Institution Identities. This creates a space that gender non-conforming students are navigating just to meet their basic needs.

\section{Identity Findings}

Identity was analyzed within this study from multiple perspectives, using both the Figured Worlds Tool, which had as a part of it the understanding that identities could be positional or figural, and the tool of analysis of identity as a lens. Identity as a lens included four types of identity: Nature Identity, Discourse Identity, Affinity Identity, and Institution Identity. While aspects of all of these tools of identity were discussed in other areas of the findings, there are two specific findings related to identity in this study. These included that bisexual and pansexual (or non-monosexual) identities occupy positional identities within the figured world and that identity and agency are dependent on intersectional access within the figured world. Non-monosexual identities occupy positional identities. Students who are non-monosexual, those who do not identify as either heterosexual or gay or lesbian, occupy positional identities within their figured worlds. Their identities are constantly being negotiated and re-negotiated on behalf of those around them, rather than on behalf of themselves. They choose to label or not label based on their perceived reactions of those around them. The language that we use 
institutionally and the models that we use to define identities do not adequately cover their experiences and the students with such identities must negotiate around these inadequacies.

Fine (2011) found that many LGB college students make meaning of the heterosexism and homophobia that they encounter in their daily lives by minimizing, or making light of, incidences of heterosexism and homophobia. Bisexual and pansexual participants minimized the heterosexism and biphobia that they saw in their everyday lives both from heterosexual and homosexual individuals. When asked to compare their experiences at the university to other students, they consistently minimized biphobia as compared to homophobia. Fine (2011) states that this minimizing comes through a desire on the part of many respondents to develop an identity apart from, rather than integrated with, sexual identity. This suggests that heterosexism and homophobia can be countered by the participants' resistance to it, leading to a view of the campus climate that is generally positive. Indeed many of these same participants were striving to claim an identity that was apart from, rather than integrated with, their sexual identity.

Despite stating that their experiences were probably easier and better than that of their gay peers, bisexual and pansexual students did bring up the existence of biphobia coming from both heterosexual and gay communities and their difficulties in navigating these biases. An analysis of several studies showed that, overall, bisexual students have significantly less favorable perceptions of the campus climate and often encounter ostracism, discrimination, and oppression from both the heterosexual and gay communities (Dugan \& Yurman, 2011). Even though the bisexual and pansexual students, at first disclosure, seemed to have more positive experiences, upon further discussion in both individual and focus group interviews, it became evident that they experienced negative outcomes from both communities. Several of these students said that their position of privilege was in part due to not having been in a relationship 
with someone of the same gender and not having to navigate that part of their identity openly. Therefore, the privileged aspect of the students' identities may be conditional and fleeting.

Participants even gave examples of occupying positional identities within classes and academic settings. For instance, Harper shared that she felt that she was judged negatively when she came out as bisexual to her LGBTQ studies class. This is not an uncommon phenomenon to happen within sexuality studies. Alexander (2011) discusses the importance of reconsidering the “queer pedagogical methods necessary to foster, rather than alienate, students' active engagement with sexuality studies" at those times when LGBTQ students look to queer studies as a place for community, but yet they meet critical queer perspectives that disrupt the truths that they hold about their own identities (p. 61). This seems to reflect a similar situation to what Harper experienced in her class. When there is not adequate support for identities within other contexts of the campus environment and then they arrive into a queer studies class that disrupts previously held notions of sexuality, they may not feel the sense of support that they were expecting from that environment. It's important to recognize the ways in which these academic settings are serving as one of the only sources of support for students and thus pedagogically engaging in such a way that supports their identities while also actively engaging them in challenging previously held beliefs.

Agency is dependent on intersectional access. Students operate within figured worlds embodying all aspects of their identities simultaneously, however some aspects become more salient or isolated depending on the context. Recognizing and affirming sexuality and gender identity within all aspects of students' identities can help them to live fuller lives as whole individuals through an intersectional approach. For instance, Corey became involved in both the LGBTQ community and the local Presbyterian community after attending an event that was 
specifically geared toward supported both her lesbian and her Christian identities. Prior to knowing that these would be mutually and reciprocally supported she had not reached out to either community. Additionally, recognizing and affirming other aspects and axes of identity can support and reinforce sexual and gender identity, as breaking down systems of oppression that are interlocking and reinforcing will provide a more open and accessible campus community for all. Participants' experiences were influenced by other aspects of their identities, such as undergraduate or graduate status, (dis)ability identities, religious identity, and involvement in other campus activities.

The literature shows that for undergraduate students, the perception of campus climate is based more so on the entire campus whereas for graduate students, their perception may be based more on departmental-specific engagement and professional identity (Vaccaro, 2012). This was in many ways the case for the participants of this study. While undergraduate students did discuss the role of their major or their classes in changing the climate of the campus, they also discussed having to navigate multiple areas within that environment of campus and sometimes choosing their major and/or classes due to their comfort level within them. Whereas for graduate students, the major or career was chosen in isolation to the climate surrounding it and that climate was then negotiated accordingly. One participant, Rachel, said, "This was the best program in the country for what I want to do, so I was coming here. Once I got in, this was the only option, so we [referring to herself and her wife] were coming here regardless." For graduate students, it was their cohort and departmental peers that made a greater difference in feeling support from the campus or not.

The literature states that both male and female sexual minority students found participation in arts and politics more important and were more likely to discuss sociocultural 
issues, such as human rights, multiculturalism, and politics with their peers (Carpenter, 2009; Longerbeam et al., 2007). LGB students were less likely to have a religious affiliation than their heterosexual peers, were most likely to report increased growth in critical thinking and liberal learning, or openness to broad perspectives and an appreciation of a wide range of intellectual topics (Longerbeam et al., 2007). All of these aspects of identity and involvement were expressed as important within this study as well. Oftentimes participants were involved in groups surrounding sociocultural issues and felt that their sexual identity was reinforced by this involvement rather than by direct involvement on LGBTQ issues. Additionally, several participants mentioned that being atheist or agnostic was an important aspect of their identities, which is reflective of LGB students being less likely to have a religious affiliation.

LGBTQ college students with disabilities have been relegated to a status of invisibility; little is known about the experiences of LGBT students with disabilities, those working with individuals have little training or knowledge and the identities are often dealt with as separate entities within the university (Harley et al., 2002). There was very little mention by student of physical disabilities, but several participants in this study brought up invisible mental and emotional disabilities. Some students discussed their positive experiences with seeking mental health and counseling services on campus, but these were much more positive among LGB students than they were among trans* students. For those who identified as transgender, they did not believe that the mental health and psychological services available were adequate to meet their needs and stated that they had even been told as much by the providers on campus.

Rankin (2006) shows how there will be differences in perceptions of campus policies and climate based on social group membership — for instance African Americans may rate the campus racial climate as more negative or men may not perceive sexual harassment on campus. 
While the sample size and demographics were not broad enough to make conclusive statements about the experience of campus climate based on racial group membership, white participants did believe that the campus climate was more negative based on racial group membership and discussed worrying about racism and ethnic bias on campus.

\section{Implications}

There are many implications of this study, but in order to best improve the campus climate at West Virginia University, I have chosen those, which I believe based on the research, would make the biggest impact within this context. While these are specific to this study and this specific cultural context, some of these ideas could translate to other areas and universities as well. The implications of this study are divided into three categories, that of conceptual implications, methodological implications, and practical implications.

The conceptual implications include our use of language - it is not just about what we need to do, but how we should go about doing it. Language implications affect all students, faculty and staff - not just those who identify within the LGBTQ acronym and that is, in part, the point. The language implications are especially important regarding the most marginalized of the already marginalized populations, specifically non-monosexual students identifying as bisexual, pansexual or fluid sexualities and gender non-conforming students identifying as trans*, genderfluid, genderqueer, agender, bigender, genderless or any other label not included in the LGBTQ acronym.

The methodological implications of this study included participant advertising and selection implications. While the representation of participants identifying as bisexual and pansexual was at first unexpected due to the underrepresentation of bisexual participation in research in general, this was perhaps not coincidental. The language used within advertising has 
direct implications on participations and thereby on all other aspects of the study. Additionally for this study, the last step of the methods allowed for open-ended journaling after the focus groups. Because all participants declined to participate in this, the implications surrounding this method and the lack of data drawn from it will also be discussed.

There are several practical implications of this study and outreach is among them. The need to focus specific outreach on meeting the needs of trans* and gender non-conforming students resonated very clearly in this study. The implications on how to do this are very similar to that which is set forth by the best practices of all universities, but these resonated on a very personal level calling for accountability from WVU's own students. Students stressed the positive impact of panels, but they also showed the possible negative outcomes that could come of these without appropriate institutional support and structure. This lends to the next recommendation of institutional support in the form of providing training and resources for creating the figured worlds of panels, both within classrooms and within other aspects of the university.

Finally, the last practical implication rests on the multitude of identities that each student brought with them along with their sexuality and gender identity. It was often through these identities that they either felt their sexual orientation and/or gender identity were affirmed or made invisible. In order to create a climate that is supportive to a whole-person identity, it is important to create figured worlds within all aspects of the institution that allow spaces for authoring so that we have students, faculty and staff of all identities who are able to move into and create their own identity and agency.

\section{Conceptual Implications}


The conceptual implications are drawn from the framework of the study. The conceptual framework was situated within the concepts of intersectionality and interdependence understanding The ways in which students' identities of sexuality, gender, gender identity, race, class, and other identity markers come together at societal and individual levels to reinforce privilege and oppression were highlighted within this framework. Queer theory, curriculum theory, and understandings of the hidden versus stated curriculum were also within the conceptual framework. All of this serves as a context within which students' experiences are central, specifically within which their identity and agency is constructed through self-authoring in the figured world. Many of these aspects of the conceptual framework were evident within the data and will be discussed in relation to the following five areas: (a) language implications, (b) climate influences upon whole-person identity, (c) that exclusion from curriculum is political, and (d) that dialogue may generate critical thinking.

Language implications. One major implication of this study regards the language that we use within institutions to describe identity, specifically gender identity and expression and sexual and/or romantic orientation. The reasons for the language chosen in this study were discussed in the first chapter, especially in relation to use of the LGBTQ acronym. However, the use of language in ways that are inclusive or exclusionary was something that came up frequently within this study. It was a common theme that participants felt that non-monosexual and gender non-conforming identities were marginalized. Additionally, there were multiple examples of students claiming labels that they didn't necessarily feel fit their identities and doing so out of convenience, though it should be noted that it was not their own convenience, but that of others. 
Knowing all of this, those of us who work with students may want to consider a move away from the often-limiting LGBT acronyms. There are many ways in which we can do this and some of these examples can be found within this study. One participant had especially strong feelings about not identifying as queer and seeing it as a derogatory term that did not apply to his identity. He would no longer attend the student organization's meeting when they had changed their name to Queer Student Union. Towards the end of her individual interview, Penelope began using the acronym GSRM, meaning Gender, Sexuality and Romantic Minorities. She stated this within the context of discussing her own accomplishments at the university, saying:

"I've informed people and I've educated people. I feel like on the whole, there are people now who are more educated and probably more accepting of LGBTQIAPUA, I again, P again - all those GSRM identities; I'm just gonna say GSRMs now - because of me, and that's good."

Even though I had not used the LGBTQ acronym many times within the interview, Penelope mimicked this institutionalized language, but also troubled its potential. Eventually though, that just became too much work and she chose to switch the structure of her language use altogether to better reflect her reality, as well as that of many other students. It is very important for those of us who do work with students in any capacity to recognize the ways in which we include or marginalize already-vulnerable populations. Language is a powerful tool in doing this. The use of labels can help us to recognize and include populations that may have previously been invisible, but we need to also be aware of who is being made invisible by those labels. During the second focus group, Owen discussed this phenomenon:

I would say that the problem that I see is that we can still find people who don't fit into any of them, and, for instance, if you're a guy and you like women and people who are 
asexual or you can come up with people who don't fit on everything you say. That would be the problem with labels - you can always come up with people who don't fit, or people who transcend them.

Owen's choice of the use of the word 'transcend' points out that the problem lies not in the people who do not fit within the labels, but with the labels themselves. Queer theory gives a framework from which to view this struggle with language and the inclusion of a varied and myriad spectrum of sexualities and gender identities, by disrupting the seemingly stable relationships between sex, gender and sexuality. The concept of heteroglossia is useful here for including all conflicting voices (Pinar et al., 2008). By simultaneously attempting to see all of the possible differences of voices, rather than just assimilating new knowledge into prior knowledge, there can become a new place for dialogue and a new and authentic understanding of identity. This may mean that we do not yet have the language to enter into that new space, but we need to open our language to accommodate that movement.

Climate influences a whole person identity. The identit(ies) and experiences of participants were often fragmented based on social and physical locations. They had to navigate not just the larger "cultural world" of the university, but it was also clear that cultural or figured worlds existed in nearly every aspect of their lives. Students had to learn individually and independently how to navigate each of these and this navigation included choosing which aspects of their identity to disclose and which to keep hidden within each world. The state and location in which this university is located influences the participants' experiences and understandings of their own identities. Students make meaning of this in differing ways. For instance the ways in which Natalie and Penelope navigated the campus community versus the "local community" differed, with Natalie feeling more comfortable venturing into the local 
community than onto campus and Penelope expressing that the opposite was true. However, this does not mean that it was necessarily a safer space for trans* individuals, but perhaps that more aspects of identity were at stake by going into the campus community whereas a certain level of anonymity was allowed within the general community. These findings indicate that in order for students to develop a whole person identity where they do not have to choose how to present in their everyday lives, information on sexuality and gender identity needs to be disseminated into more aspects of the campus community, as well as the broader local and even state community as a part of our role as a land grant university.

Exclusion from curriculum is political. There is an overlap between the curriculum that is distinctly in-class and that which is distinctly out-of-class, as is there an overlap between what is learned inside and outside of the classroom and students' coursework. Many elements of institutional power tie into all of these and they all have both explicit, or stated, and implicit, or hidden, aspects of curriculum. The fact that participants saw inclusion of sexual orientation and gender identity within the curriculum as inappropriate, at any point, demonstrates the ways in which there has been a historical image of the American education system as being impartial and politically neutral; much like it was portrayed in texts prior to the 1970's (Pinar et. al., 2008). While this may be a mythology of education, it is not the reality. Giroux (1989) states that in order to conceptualize the cultural politics of schooling, it is necessary to analyze "how social power organizes the basic categories of class, race, gender, and ethnicity as a set of ideologies and practices that constitute specific configurations of power and politics" (p. 147). Therefore the lack of a curriculum that includes sexuality and gender is overtly political. Additionally, the absence of a discussion on race, racism and ethnic bias, as discussed by participants, is also an overtly political act. The lack of an open discussion on politically charged issues is due to 
college and university administrators being "much more likely to be timorous and to see only the dangers and the downside of fostering genuine political debate on their campus" (Smith et al., 2008, p. 136).

Dialogue is capable of generating critical thinking. Freire (2010) stated in Pedagogy of the Oppressed, "Only dialogue, which requires critical thinking, is also capable of generating critical thinking" (p. 150). Educational panels are one way of challenging the status quo and allowing for the authentic speaking of non-dominant voices within the classroom. bell hooks (1994) stressed the need for both analytical and experiential ways of knowing, that all students come to us with the "authority of experience" (p. 89), and that teachers should welcome this knowledge and grow from it. One way of teachers across the campus welcoming this knowledge and growing from it would be to incorporate educational panels into more varied disciplines of study. This would allow for the experiential ways of knowing to be utilized within the classroom without relying on students within their academic courses to provide that experiential way of knowing. Because students within a class may be hesitant to take on the positional identity of their sexuality or gender identity when they want to be recognized primarily for their role as a student within the class, this experience may not be recognized if not from an outside source. Students within the class still gain critical thinking from the experience as they engage in dialogue with the panel. These critical thinking skills gained from being audience members were mentioned by one participant, Sophia, as the skills gained by another student were positively commented upon by a professor in her department.

\section{Methodological Implications}

The researcher's methodological approach to a study methodologically holds implications not only the format of the study, but for the questions and the outcomes. These 
include the analysis, findings and conclusions. The methodological implications that are most important for this study include participant advertising and sampling and the impact these procedures had not only on demographic selection, but also on the direction that the study took with regards to the primary analysis of individual interviews and the focus group topic selections. The second methodological implication is the use of an unstructured versus structured feedback format after the focus group interviews. Because no participants chose to utilize this feedback mechanism, it eliminated a form of data that would have been included in the study and, for that reason; the implications of the type of feedback mechanism used are discussed.

Participant advertising implications. There are both language and methodological implications for the selection and recruitment of participants for this study and for future studies. There was not a specific question within the questionnaire or interview process that asked participants how they found out about the study. This could be beneficial to include in future studies. However, there are implications that can be drawn based on how participation was solicited for this study and the type of involvement that was drawn. Because the advertisement included the language identifies as lesbian, gay, bisexual, transgender, transsexual, queer, pansexual, same-gender loving or other non-heterosexual and/or non-cisgender identity, it opened the study to a larger variety of identities than it would have had the study only be advertised to LGBTQ students. However, putting the first identities listed may have put the focus on LGBTQ students and still have limited the participation in some ways.

Structured post focus group feedback. None of the participants chose to give feedback at the end of either of the focus groups. It is highly unlikely that no one had anything additional to say about any of the topics covered in any of the individual or focus group interviews. What is more likely is that no one wanted to be the only person who stayed to give feedback. Having 
allowed an open-ended format through much of the individual and focus group interview process, it may have been worthwhile to implement a more structured feedback approach during this final solicitation of feedback. At the very least, it would have allowed participants with the opportunity to definitively write that they had no more to share rather than implying this by choosing to not journal.

Researcher identity and interaction implications. The study did not happen in a vacuum separate from the researcher's identity and experience. As is the case with qualitative research, the process was a collaborative one between researcher and participants. The researcher's identity and interaction within this process carries important implications that impact the entirety of the study. While my identity as bisexual and pansexual would seem to have some influence over the fact that so many participants identified as such, this identity was not known insofar as I am aware to the bisexual and pansexual participants. However, my own identity as pansexual influenced my decision to specifically include this identity on the participant advertisement and this most likely influenced the response rate of pansexual participants. Additionally my institutional identities, such as instructor and graduate assistant could have worked in favor or against the trust of the participants, especially trans* and gender non-conforming participants who shared negative perceptions of the campus. However, they still openly and willingly participated in the study and therefore it may have been because of my affinity identity as an activist on campus and my level of understanding of the issues that may have influenced this openness.

\section{Practical Implications}

The practical implications are arguably the most important implications to be drawn from this study, as they are what would make the most tangible difference in students' day to day lived 
experience moving forward. These practical implications include: supporting trans* and gender non-conforming students, supporting the cultural worlds of panels, providing spaces for reflection, and supporting a whole person identity.

Supporting trans* and gender-nonconforming students. Despite being unable to include everyone who identified as gender non-conforming in the focus groups of this study due to the participants' time constraints, I still wanted to ensure that these voices were centered in the analysis and findings. The implications were clear when it came to students who were trans* that their needs on campus were not being met. It was also clear that these needs were very much reflective of the broader research-based implications for campuses. This in some ways indicates that the needs of students who are transitioning or seeking hormone replacement therapy should have the easiest the needs to meet. Their needs were not ambiguous or contradictory. They were clear, concise and completely in line with the literature. In order to support trans* and gender non-conforming students, the university should ensure access to gender neutral bathrooms, create gender-neutral housing options, enable a simple process for changing one's preferred name within all university systems, and provide adequate health care that includes access to hormone replacement therapy, endocrine tests, psychological, counseling and transitioning services especially in the cases when students are mandated to pay the university for their health care coverage. These services enable a basic level of functioning for trans* students within the university setting, allowing them to participate within the academic community in a way that is safe and supported. Additionally, curriculum inclusion of gender identity that addresses transphobia and bias would serve all students on campus, not just those who identify as trans* and gender non-conforming. 
Supporting the figured worlds of panels. The participants gave many examples of the ways in which panels can be empowering for LGBTQ students, as well as allies. However, they also gave some very specific ways in which the carefully constructed cultural world of the panel can become fragmented. The effects of this on self-authoring and therefore agency and identity, not just of the LGBTQ-identified panel participants, but for all students involved, could be devastating. Enough students, faculty, and staff feel strongly enough about these panels that they will most likely continue regardless of institutional support. The level at which they will function and the benefits and potential drawbacks are that the area will suffer without institutional support. Supporting the figured worlds of panels would also support all students on the campus, not just those who identify as LGBTQ or as a gender, sexuality and/or romantic minority (GSRM). By providing outside support for those participating in the panels, the space of the educational panel would function better to allow for academic exchange for both those on the panel, but also and perhaps more importantly for furthering institutional goals, for those who are within the audience of the panel, no matter how they identify.

Providing space for reflection. It was difficult for students for carve out spaces for themselves based on identity or commonality. Often this came in the form of other common traits that were affirming of students' sexuality and gender identity. However, there were benefits to participants in engaging in reflection within an identity-based space and an actionoriented space. The focus groups gave participants an opportunity to create a dialogue with peers of similar identities as themselves. Participants used this space to ask questions, share ideas with one another, and affirm the others' experiences. This seemed to be done not for the sake of the research, but for each other. 
The focus group allowed participants to ask one another reflective questions on their experiences in panels and how to handle various situations. It also would be beneficial to have reflective spaces available for those who participate in panels and do other kinds of activism work. These spaces could be useful to students whether or not they feel that they need them, as they provide an opportunity for students to create a figured world around their activist identities and thereby provide the space for authoring that may not be open within the unpredictable context of the classroom during the panels.

Supporting a whole person identity. The identit(ies) and experiences of participants were often fragmented based on social and even physical location. They had to navigate not just the larger "cultural world" of the university, but it was also clear that cultural or figured worlds existed in nearly every aspect of their lives. Students had to learn individually and independently how to navigate each of these and this navigation included within each world choosing which aspects of their identity to disclose and which to keep hidden. These findings indicate that in order for students to develop a whole person identity where they do not have to choose how to present themselves in their everyday lives, information on sexuality and gender identity needs to be disseminated into more aspects of the campus community. It means that other areas in which students may go to seek affirmation or inclusion for their identity, such as religious groups, social groups, and academics, need to be aware of the ways in which they can be inclusive and affirming of students' range of sexualities and gender identities as well.

\section{Limitations}

A key limitation to this study is also a source of its strength - it is specifically designed to only look at the experiences of students in relation to the campus climate at West Virginia University. The analysis and implications herein give a depth of information on the experience of 
students based on their particular location within this campus climate and environment at West Virginia University. While there may be some parallels that could be drawn to similar campuses and to the broader national context, this is not certain and cannot be assumed. This study is limited to this specific context and to understanding these identities and experiences within that context. It is also limited by the self-reporting of students related to location and context. Specificity of the comfort-level experienced within various locations on campus was a difficult area for participants to address. As with any study that relies on self-reporting, this study was limited by participants' abilities to be reliable instruments in discussing their own lives. However, as this study centered student experiences within this context, their experiences were seen as the most important aspect.

It is a qualitative study using an interview format with fifteen individuals and further analyzing two themes from those interviews by conducting focus groups within the same pool of participants. This allowed for a great depth of information. It did not, however, cover a breadth of information and nor was that the study's intention. The small sample size, only looking at the experience of fifteen students, is one limitation. A larger, quantitative study could allow comparisons among and within college populations and settings and would provide a larger sample, though there are drawbacks to this as well in that there would, without the benefit of mixed methods, be no insight to the reasoning behind the responses and no changes could be made once the study began (Brown \& Gortmaker, 2009).

While this study methodologically allowed for discussion of concepts in individual interviews with follow-up in focus group interviews, there were some particular topics and concepts that would have benefitted from additional focus group discussion with more diverse participation. Specifically, it was a limitation that there were not particular identities represented 
within some of the focus group data. For instance for the focus group discussion that dealt with racism and bias on campus, only white participants were present. This conversation may have been possible because of the racial homogeneity of the group, but that homogeneity is also a limitation of this study, and indeed shaped the focus group conversation in some ways. Within the bisexual and pansexual focus group, there was some diversity of gender identity, but the discussion surrounding this topic was limited and the gendered identities of the participants remained relatively invisible within the context of sexuality. Therefore, it cannot be inferred that just because the diversity is present in a focus group that it will necessarily be easier to discuss the topic. In fact, the homogeneity could make it easier for students to discuss these difficult topics. This homogeneity of voices and perspectives is still a limitation though.

Lastly, this study was missing the voices of the students who chose not to identify themselves for the purposes of this study, as well as those who may not identify their sexual orientation and/or gender identity and expression within their everyday lives. The experiences of these students may be very different from the students who are 'out' and/or comfortable with their identities. This can include those who are questioning their identities or it could include those who are comfortable and secure in their identities but choose for other reasons to not disclose them.

\section{Future Research}

There are many aspects of this study that could be expanded upon for future research. While most any aspect of this study could be applied to the context of another university, the data, analysis, and findings are specific to the context of this institution and even the institutional context of the literature review is institution-specific. This study creates a localized lens within which to view student experiences within a larger conceptual understanding. Given this lens, it 
makes the most sense to also frame future research within the context of West Virginia University. For that reason, the areas of future research that are most applicable to this particular context were chosen for a deeper level of discussion. These include: self-authoring of allies, gender non-conforming student experiences, meeting the needs of 'invisible' identities, conceptualizing safe spaces, and a full campus climate assessment.

\section{Self-Authoring of Allies}

One aspect of this study focused on the panelists' experiences and it can be seen how they are able to self-author to create identity and agency through the figured world of the panel environment. Some anecdotal evidence of the audience members' perspectives indicated that something similar might be going on for those who are a part of the panels in a different capacity. Without talking to individuals who participated directly, this is just speculation. As these panels are done for the purpose of educating the full campus community, it would be useful to have a research-driven perspective on the impact of the panels on the audience. The mere interaction with LGB peers may influence attitude, as research found that attitudes of acceptance towards LGB peers can be cultivated when undergraduate students interact across race, interact with LGB peers, or enroll in diversity courses (Engberg et al., 2007). When these educational panels take place within a student's college career may have an impact as well, such as whether this is within their first year at school or later on, as there is some evidence that higher education level leads to an increase in tolerance and one study found that juniors and seniors had significantly more positive attitudes towards gays and lesbians than did freshmen and sophomores (Lamber et al., 2006). Additionally, early normalizing experiences in childhood, meeting LGB peers in high school or college and experiences of empathy based on LGB peers' struggles and successes have been shown to be key factors in positive attitude formation to LGB 
individuals (Stotzer, 2009). Research on the self-authoring of allies (and non-allied students), could help to best maximize the use of educational panels and to best understand the figured worlds of campus climate and curriculum.

\section{Self-Authoring Within Queer Studies}

As there is some evidence of students having difficulties with the self-authoring process within queer studies classes, this could be an area for further exploration. As with the example of Harper feeling that she was judged negatively when she came out as bisexual to her LGBTQ studies class, this is an opportunity to not only better serve a pool of students identified within various ways as gender, sexual and romantic minorities, but also as allies. Given that these academic settings may serve as one of the only sources of support for students, this is an important opportunity to both pedagogically engage with queer studies in a way that challenges heteronormativity and also in a way that supports students' identities. This is a very difficult balance to strike and the research on it is limited. The possible negative outcomes both to students and to curriculum are such that this is an important area to consider for research.

\section{Gender Non-Conforming Student Experiences}

There was a clear distinction in the experiences of gender non-conforming students and there was a silencing of discussion about these experiences when they were among cisgender students. While there are some very clear ways in which trans* students' basic needs can be met, this does not take the discussion to a deeper level to look at the various identities within this overall umbrella of gender non-conforming identities. There are many identities within the gender non-conforming label and it would be useful to understand how to best serve our students to know the differences and similarities across experiences of those who identify as gender-fluid, 
genderqueer, agender, bigender, genderless or any other label perhaps not included here. Further research on their experiences would be useful on many levels.

\section{Meeting the Needs of 'Invisible' Identities}

This study was able to recruit participants who identified within some of the marginalized categories of identities, but these were, for the most part, still recognized identities. While there were some students who chose primarily not to label their sexuality, they would still choose, under certain circumstances, to apply labels to this aspect of their identity. Behaviors differ from identities as well and so there are many ways in which the university could be missing the needs of students if the university is focusing on identity instead of actions and behaviors. Within the context of this study, the greatest disjuncture of behavior and identity rested in those who identified as pansexual or bisexual, but who had been invalidated in their identity by others for having not had experiences with others of the same gender. However, this is not the only example of an instance where identity and behavior may not "match" outside perceptions. For instance, individuals may identify as straight or heterosexual but still engage in sexual behaviors with those of the same gender. They may also identify as asexual, but may engage in sexual behaviors for the sake of their partner or partners. Sexual orientation and sexual identities are complex concepts, but even more complex are the ways in which these intersect with one's behaviors and the ways in which all of these may be invisible from an outsider's perspective. In order to best serve our students, we need to understand all of these and approach them from a multitude of perspectives depending on the goals we are trying to achieve.

\section{Conceptualizing Safe Spaces}

Students had a difficult time relying on memory and report to come up with examples of 
spaces or locations that stood out to them in terms of campus climate related to sexual orientation and gender identity. When they were asked "what is your perception of the campus climate related to sexual orientation and gender identity at WVU?" they often didn't know how to reply. This led to prompting with a follow-up of asking if various parts of campus or offcampus stood out to them as especially welcoming or comfortable. Additionally, I asked them if any parts of campus or off-campus stood out to them as especially hostile or unwelcoming. They had trouble generally recognizing spaces in which they felt comfortable and safe and those in which they felt were hostile or unwelcoming. Many people mentioned the same or similar examples, but often they said that these were based on hearsay or speculation and not necessarily their own experiences. It is possible that this methodology was not conducive to answering this particular question. Participants may not have been best able to come up with their perceptions of various spaces on campus without the visual or everyday cues and prompts to remind them of their experiences.

One area for future study would be to better understand students' relationships to the physical spaces on campus. This could mean conducting a study in which students shared the spaces and locations on and off campus that most influenced their perception of campus climate. Photovoice is one methodological option that would explore how the individuals viewed their experiences through their own photography and narratives. This method has been used to create dialogue and speak to the collective experience of queer people of color (Lee, 2009). Allowing students a photovoice method to think about this question as they go through their everyday routines may yield different results. Students could be instructed to take pictures of places on and off campus that represent different concepts to them, such as safety, affirmation, disconnection, or inclusion. Besides using photovoice, students could also journal or just otherwise notate the 
spaces that represent this. Students could discuss their visual images or their written entries with the researcher or as a part of a focus group. It would be beneficial to understand students' relationships to space on campus and there may be better methods by which to do this as a means of future research.

\section{Full Campus Climate Assessment}

The participants in the study indicated a clear need for further research on the overall campus climate related not just to gender identity and sexual orientation, but also to race, ethnicity, ability, and religious affiliation or non-affiliation. This would call for a much larger and more comprehensive study, perhaps mixed method in nature, combining quantitative to get the breadth of data needed, with qualitative to explore responses in-depth and allow for a better understanding of experiences. Incorporating qualitative into a full campus climate assessment would still allow for the "real life experiences (that) can be particularly revealing and have a strong impact on the study's audience” (Brown and Gortmaker, 2009, p. 121).

There is no one way to conduct a campus climate assessment. Hart and Fellbaum (2008) in a study of campus climate assessments found that those conducting the studies were most often institutional employees and there were no standardization of design or instrumentation. Studies do not rely on any single definition of campus climate or any best practices for assessing climate. It is however, important to look at many factors when conducting a full campus climate assessment, especially the following:

To see the "big picture" and thoroughly understand the campus environment in its entirety, student outcomes, campus climate, and institutional practice must be examined and assess in comprehensive ways, integrating evaluations of these three components of diversity into one survey or used in combination with other instruments. Only then will a 
campus be able to identify how the dynamics of diversity shapes their work and learning environment, and subsequently impacts outcomes for members of their community. (Hurtado, Griffin, Arellano, et al., 2008, p. 218)

While there is no one way to conduct a campus climate assessment, there are individuals who have established best practices. For instance Rankin and Reason (2008) created the Transformational Tapestry Model as a "comprehensive, five phase, and strategic model of assessment, planning, and intervention" (p. 262). The model is designed for assisting campus communities to conduct inclusive assessments of their institutional climate to better understand the challenges facing their respective communities. No matter the method that is chosen for assessing the climate, it is important to take a comprehensive and intersectional approach, looking not only at the experiences of students, faculty, and staff, but also at the ways in which policies and institutional practices contribute to the climate.

\section{Conclusion}

It is important for institutions of higher education to take steps to understand students' experiences on their campuses in relation to their identities. Through a qualitative method, this study used individual and focus group interviews to understand LGBTQ student experiences of campus climate. From this starting point, this study was able to uncover a greater understanding of bisexual and pansexual student experiences, the figured worlds of gender identity, and the role of panels within an academic and social context.

This study examined students' navigations of sexuality and gender within the complex figured worlds at West Virginia University. There was much to be learned from this study, in the categories of curriculum findings, figured world findings, and identity findings. This study found that the collective lens of curriculum is greater than the individual lens and the role of a single 
person in improving curricular inclusion. It also found that students self-author in figured worlds and that the figured world of gender non-conforming students is substandard. Finally, it found that non-monosexual students occupy positional identities and that agency is dependent on intersectional access. The study carries implications that are divided into three categories: that of conceptual implications, methodological implications, and practical implications. These include implications on the language that we choose to use and the ways in which climate influences whole person identit(ies). On a practical level, the implications include supporting trans* and gender non-conforming students, supporting the cultural worlds of panels, providing spaces for reflection, and supporting a whole person identity.

While there were many remarkable outcomes of this study, there were also limitations. These included the specificity to the location context of the university, the small sample size, the lack of individual follow-up data after focus groups, and the missing voices of those who chose not to identify for the study. With these given limitations, this study was not intended to be definitive understanding of students' navigations of sexuality and gender on this campus, but in fact opens up the possibility of much more research that could be completed in the future. This includes self-authoring of allies, gender non-conforming student experiences, meeting the needs of 'invisible' identities, conceptualizing safe spaces, and a full campus climate assessment.

Research shows that "getting campus leaders to attend to and act on meeting the learning and development needs of LGBT students, as illuminated in a campus climate study, particularly in a politically conservative environment, is not easy" (Brown \& Gortmaker, p. 129). Brauer (2012) described the difficulty of administrative change by saying:

That is the nature of social and institutional change: they take time, gathering energy from symbolic acts; gaining momentum from every voice, connection, and action; 
churning toward transformation with the erratic power of an ocean wave. Every campus will build that energy and momentum differently, but when they do, their collective efforts will combine in a surge of greater LGBTQ inclusion across higher education. (p.

9)

This study was just one small slice into understanding experiences within the figured world of sexuality and gender on this campus. By looking in depth and by using identity as a lens and the figured worlds tool, this study was able to present some students' understandings of gender, sexuality and romantic minority students. There is still much to learn though, not just from students, but from the entire campus at large. It is therefore highly recommended that future research be done. Namely, the first step might be a comprehensive campus climate assessment. 


\section{Works Cited}

Ahmed, S. (2006). Queer phenomenology. Durham, NC: Duke University Press.

Alexander, K. B. (2011). Teaching discomfort? Uncomfortable attachments, ambivalent identifications. Transformations: The Journal of Inclusive Scholarship and Pedagogy, 22(2), 57-69.

Anderson, K. J., \& Kanner, M. (2011). Inventing a gay agenda: Students' perceptions of lesbian and gay professors. Journal of Applied Social Psychology, 41(6), 1538-1564. doi:10.1111/j.1559-1816.2011.00757.x

Apple, M. (1989). The politics of common sense: Schooling, populism, and the new right. In H. Giroux \& P. McLaren (Eds.), Critical pedagogy, the state, and cultural struggle. Albany, NY: State of New York Press.

Basow, S., \& Johnson, K. (2000). Predictors of homophobia in female college students. Sex Roles, 42(5-6), 5-6.

Beckham, A. (2013, October). Coming out of your closet: Ash Beckham at TedxBoulder. [video file]. Retrieved from http://tedxtalks.ted.com/video/Coming-Out-of-Your-Closet-Ash-B

Beemyn, B. (2005). Making campuses more inclusive of transgender students. Journal of Gay \& Lesbian Issues in Education, 3(1), 77-87.

Beemyn, B., Curtis, B., Davis, M., \& Tubbs, N. (2005). Transgender issues on college campuses. New Directions for Student Services, 111, 49-60.

Bell, M. P., Ozbilgin, M. F., Beauregard, T. A., \& Surgevil, O. (2011). Voice, silence, and diversity in $21^{\text {st }}$ century organizations: Strategies for inclusion of gay, lesbian, bisexual, and transgender employees. Human Resource Management, 50(1), 131-146.

Bilodeau, B. L., \& Renn, K. A. (2005). Analysis of LGBT identity development models and 
implications for practice. New Directions for Student Services, 111, 25-39.

Blumenfeld, W. (2012). LGBTQ campus climate: The good and the still very bad. Diversity \& Democracy: Association of American Colleges and Universities. 15(1), 20-21.

Brauer, D. (2012). Graphing institutional change toward more inclusive environments. Diversity \& Democracy: Association of American Colleges and Universities, 15(1), 8-9.

Brewster, D. (2011, October 2). 'Enough is enough'. The Daily Athenaeum. Retrieved from http://www.thedaonline.com/opinion/guest-column-enough-is-enough-

\subsection{0\#.UZZMEkrViOI}

Brown, B. (2006). Shame resiliency theory: A grounded theory study on women and shame. Families in Society: The Journal of Contemporary Social Services, 87(1), 43-52.

Brown, B. (2010, December). Brené Brown: The power of vulnerability. [Video file]. Retrieved from http://www.ted.com/talks/brene_brown_on_vulnerability.html

Brown, R. D., Clarke, B., Gortmaker, V., \& Robinson-Keilig, R. (2004). Assessing the campus climate for gay, lesbian, bisexual, and transgender (GLBT) students using a multiple perspectives approach. Journal of College Student Development, 45(1), 8-26.

Brown, R. D., \& Gortmaker, V. J. (2009). Assessing campus climates for lesbian, gay, bisexual and transgender (LGBT) students: Methodological and political issues. Journal of LGBT Youth, 6(4), 416-435. doi:10.1080/19361650903296429

Burleson, D. A. (2010). Sexual orientation and college choice: Considering campus climate. Wiley InterScience, 1, 9-14. doi: 10.1002/abc.20003

Butler, J. (2003). Global violence, sexual politics. In Center for Lesbian and Gay Studies, CUNY (Ed.), Queer ideas: The David r. Kessler lectures in lesbian and gay studies (pp. 198214). New York: The Feminist Press at the City University of New York. 
Campus Pride (2013). Retrieved from http://campuspride.org/

Carnoy, M. (1989). Education, state, and culture in American society. In H. Giroux \& P. McLaren (Eds.), Critical pedagogy, the state, and cultural struggle (pp. 3-23). Albany: State of New York Press.

Carpenter, C. S. (2009). Sexual orientation and outcomes in college. Economics of Education Review, 28, 693-703. doi: 10.1016/j.econedurev.2007.10.010

Chesanko, M. (2011a, October 25). The importance of an open dialogue on LGBT policies. The Daily Athenaeum. Retrieved from http://www.thedaonline.com/opinion/letter-to-theeditor-the-importance-of-an-open-dialogue-on-lgbt-policies-1.2665982

Chesanko, M. (2011b, November 8). A step toward equality on campus. The Daily Athenaeum. Retrieved from http://www.thedaonline.com/opinion/column-a-step-toward-equality-oncampus-1.2689501\#.UZZCU0rViOI

Clark, J. (2011, November 2). SGA resolution supports LGBTQ student community. The Daily Athenaeum. Retrieved from http://www.thedaonline.com/news/sga-resolution-supportslgbtq-student-community-1.2681002

D'Augelli, A. (2006). Coming out, visibility, and creating change: Empowering lesbian, gay, and bisexual people in a rural university community. American Journal of Community Psychology, 37(3/4), 203-210. doi:10.1007/s10464-006-9043-6

Dilley, P. (2004). LGBTQ research in higher education: A review of journal articles, 2000-2003. Journal of Gay \& Lesbian Issues in Education, 2(2), 105-115.

Draughn, T., Elkins, B., \& Roy, R. (2002). Allies in the struggle: Eradicating homophobia and heterosexism on campus. Journal of Lesbian Studies, 6(3/4), 9.

Dugan, J. P. \& Yurman, L. (2011). Commonalities and differences among lesbian, gay, and 
bisexual college students: Considerations for research and practice. Journal of College Student Development, 52(2), 201-216.

Eberly News. (2012, October 8). WVU host LGBT civil rights advocate. Retrieved from http://eberly.wvu.edu/eberly_news/2012/10/8/wvu-hosts-lgbt-civil-rights-advocate Employment Benefit Research Institute (2009). Domestic partner benefits: Facts and background. Retrieved from: www.ebri.org/pdf/publications/facts/0209fact.pdf

Engberg, M. E., Hurtado, S., \& Smith, G. C. (2007). Developing attitudes of acceptance toward lesbian, gay, and bisexual peers: Enlightenment, contact, and the college experience. Journal of Gay \& Lesbian Issues in Education, 4(3), 49-77.

Evans, N. J., \& Herriott, T. K. (2004). Freshmen impressions: How investigating the campus climate for LGBT students affected four freshmen students. Journal of College Student Development, 45(3), 316-332.

Festival of Ideas (2013, January 23). Candace Gingrich-Jones: The accidental activist, a personal and political journey. Retrieved from http://festivalofideas.wvu.edu/archive/candace-gingrich-jones

Fine, L. E. (2011). Minimizing heterosexism and homophobia: Constructing meaning out of campus LGB life. Journal of Homosexuality, 58(4), 521-546.

Friere, P. (2010). Pedagogy of the oppressed. New York, NY: The Continuum International Publishing Group, Ltd.

Garvey, J. C., \& Inkelas, K. K. (2012). Exploring relationships between sexual orientation and satisfaction with faculty and staff interactions. Journal of Homosexuality, 59, 1167-1190.

Gay, Lesbian, and Straight Education Network. (2010). 2009 National School Climate Survey. Retrieved from: http://www.glsen.org/cgi-bin/iowa/all/library/record/2624.html 
Gee, P. J. (2001). Identity as an analytic lens for research in education. Review of Research in Education, 25, 99-125. Retrieved from http://www.jstor.org/stable/1167322

Gee, P. J. (2011). How to do discourse analysis: A toolkit. New York: Routledge.

Giroux, H. (1989). Schooling as a form of cultural politics: Toward a pedagogy of and for difference. In H. Giroux \& P. McLaren (Eds.), Critical pedagogy, the state, and cultural struggle. Albany: State of New York Press, 125-151.

Goodman, M. B., \& Moradi, B. (2008). Attitudes and behaviors toward lesbian and gay persons: Critical correlates and mediated relations. Journal of Counseling Psychology, 55(3), 371384.

Gortmaker, V. J., \& Brown, R. D. (2006). Out of the college closet: Differences in perceptions and experiences among out and closeted lesbian and gay students. College Student Journal, 40(3), 606-619.

Grant, J., Mottet, L., \& Tanis, J. (2011). Executive Summary Injustice at Every Turn: A Report of the National Transgender Discrimination Survey. Retrieved from http://www.thetaskforce.org/downloads/reports/reports/ntds_summary.pdf

Hackman, H. (2012). Teaching LGBTQI issues in higher education: An interdependent framework. Diversity \& Democracy: Association of American Colleges and Universities. $15(1), 2-4$.

Hall, D. (2009). Reading sexualities: hermeneutics and the future of queer studies. New York: Routledge.

Halperin, D. M. (2003). The normalization of queer theory. Journal of Homosexuality, 45(2), 339-343.

Harley, D. A., Nowak, T. M., Gassaway, L. J., \& Savage, T. A. (2002). Lesbian, gay, bisexual, 
and transgender college students with disabilities: A look at multiple cultural minorities. Psychology in the Schools, 39(5), 525.

Hart, J., \& Fellabaum, J. (2008). Analyzing campus climate studies: Seeking to define and understand. Journal of Diversity in Higher Education, 1(4), 222-234. doi: $10.1037 / \mathrm{a} 0013627$

Holland, D., Lachicotte, W., Skinner, D., \& Cain, C. (1998). Identity and agency in cultural worlds. Cambridge: Harvard University Press.

Holley, L. C., Larson, N. C., Adelman, M., \& Trevino, J. (2008). Attitudes among university undergraduates toward LGB and five ethnic/racial groups. Journal of LGBT Youth, 5(1), 79-101.

hooks, b. (1994). Teaching to transgress: Education as the practice of freedom. New York: Routledge.

Human Rights Campaign. (2009, June 1). State hate crime laws. Retrieved from http://www.hrc.org/files/assets/resources/hate_crime_laws(1).pdf

Human Rights Campaign. (2011, July 1). Statewide school laws \& policies. Retrieved from http://www.hrc.org/files/assets/resources/school_laws(1).pdf

Human Rights Campaign. (2011b, November 29). Statewide housing laws \& policies. Retrieved from http://www.hrc.org/files/assets/resources/Housing_Laws_and_Policies(1).pdf

Human Rights Campaign. (2012, January 6). Statewide employment laws and policies. Retrieved from http://www.hrc.org/files/assets/resources/Employment_Laws_and_Policies.pdf

Human Rights Campaign. (2012b). Benefits. Retrieved from http://preview.hrc.org/issues/workplace/benefits.asp Human Rights Campaign Foundation. (2009). The State of the Workplace for Lesbian, Gay, 
Bisexual and Transgender Americans 2007-2008. Retrieved from http://www.hrc.org/files/assets/resources/HRC_Foundation_State_of_the_Workplace_20 07-2008.pdf

Hurtado, S., Griffin, K. A., Arellano, L., \& Cuellar, M. (2008). Assessing the value of climate assessments: Progress and future directions. Journal of Diversity In Higher Education, 1(4), 204-221. doi:10.1037/a0014009

Jagose, A. (1996). Queer theory: an introduction. New York, NY: New York University Press.

Joyce, T. (2007). Lesbian, gay, bisexual, and transgender issues on campus: Making the private public. Journal of Curriculum \& Pedagogy, 4(2), 31-36.

Jurgens, J. C., Schwitzer, A. M., \& Middleton, T. (2004). Examining attitudes toward college students with minority sexual orientations: Findings and suggestions. Journal of College Student Psychotherapy, 19(1), 57-75. doi:10.1300/j035v19n01_07

Klawitter, M. (2011). Multilevel analysis of the effects of antidiscrimination policies on earnings by sexual orientation. Journal of Policy Analysis and Management, 30(2), 334-358.

Kvale, S. \& Brinkmann, S. (2009). Interviews: Learning the craft of qualitative research interviewing. Thousand Oaks, CA: Sage Publications, Inc.

Lambert, E. G., Ventura, L. A., Hall, D. E., \& Cluse-Tolar, T. (2006). College students' views on gay and lesbian issues: Does education make a difference? Journal of Homosexuality, 50(4), 1-30.

Ladne, M., \& Lips, D. (2012). Report card on American education: Ranking state K-12 performance, progress, and reform. American Legislative Exchange Council Retrieved from http://www.alec.org/docs/17thReportCard/ALECs_17th_Report_Card.pdf

Lee, W. J. E. (2009). Visualizing the margins: The experiences of queer people of colour. (Order 
No. MR61562, McGill University (Canada)). ProQuest Dissertations and Theses, 187. Retrieved from http://search.proquest.com/docview/305110980?accountid=2837. (305110980).

Longerbeam, S. D., Johnson, D. R., Inkelas, K. K., \& Lee, Z. S. (2007). Lesbian, gay, and bisexual college student experiences: An exploratory study. Journal of College Student Development, 48(2), 215-230.

Loutzenheiser, L. (2008). Ruminations on stuck places: identities, race, and queer theories. Journal of Curriculum and Pedagogy, 4(2),100-106.

Loutzenheiser, L. and MacIntosh, L. (2004). Citizenships, sexualities, and education. Theory into practice, 43(2), 151-158.

Marsh, J., \& Lammers, J. C. (2011). Figured Worlds and discourses of masculinity: Being a boy in a literacy classroom. In R. Rogers (Ed.), An introduction to critical discourse analysis in education. New York, NY: Routledge.

Mazzei, L. A. (2007). Inhabited silence in qualitative research: Putting poststructural theory to work. New York, NY: Peter Lang Publishing, Inc.

Martinez, J. M. (2003). Racism, heterosexism, and identities: A semiotic phenomenology of selfunderstanding. Journal of Homosexuality, 45(2-4), 109-127. doi:

10.1300/J082v45n02_05

Merithew, E. (2013, April 29). New student org begins equality movement. The Daily Athenaeum. Retrieved from http://www.thedaonline.com/news/new-student-org-beginsequality-movement-1.3038494\#.UZZDUUrViOI

Messinger, L. (2009). Creating LGBTQ-friendly campuses. Academe, 95(5), 39-42.

Misawa, M. (2009). The intersection of homophobic bullying and racism in adulthood: A 
graduate school experience. Journal of LGBT Youth, 6, 47-60. doi: $10.1080 / 19361650802379714$

Morgan, D. (1997). Focus groups as qualitative research. Thousands Oaks, CA: Sage.

National Education Association. (2011, December). Rankings of the states 2011 and estimates of school statistics 2012. Retrieved from http://www.nea.org/assets/docs/NEA_Rankings_And_Estimates_FINAL_20120209.pdf

Palmer, L. (2012, March 14). WVU honors LGBT community as part of National Social Work Month. The Daily Athenaeum. Retrieved from http://www.thedaonline.com/a-e/wvuhonors-lgbt-community-as-part-of-national-social-work-month-

\subsection{2\#.UZZJpErViOI}

Palmer, L. (2012, October 18). SGA approves LGBT center resolution. The Daily Athenaeum. Retrieved from http://www.thedaonline.com/news/sga-approves-lgbt-center-resolution1.2930658\#.UZY8PErViOI

PEIA (2013, March 21). West Virginia retiree health benefit trust fund and PEIA finance board meeting. Charleston, WV.

Pew Forum on Religion \& Public Life. (2009, December). How religious is your state?Retrieved from http://www.pewforum.org/How-Religious-Is-Your-State-.aspx

Pew Forum on Religion \& Public Life. (2010). U.S. religious landscape survey. Retrieved from http://religions.pewforum.org/maps

Pinar, W. (2003). Queer theory in education. Journal of Homosexuality, 45(2), 357-360.

Pinar, W., Reynolds, W., Slattery, P., \& Taubman, P. (2008). Understanding curriculum: an introduction to the study of historical and contemporary discourses. New York: Peter Lang. 
Pope, R. L., Mueller, J. A., \& Reynolds, A. L. (2009). Looking back and moving forward: Future directions for diversity research in student affairs. Journal of College Student Development, 50(6), 640-656.

Poynter, K., \& Washington, J. (2005). Multiple identities: Creating community on campus for LGBT students. New Directions for Student Services, 111, 41-47.

Prentice, P. (2012, April 19). Tea for two, but none for you: Marginalized at the Diversi-tea event. The Daily Athenaeum. Retrieved from http://www.thedaonline.com/opinion/column-tea-for-two-but-none-for-you-marginalizedat-the-diversi-tea-event-1.2853658\#.UZZAFkrViOI

Rankin, S. R. (2006). LGBTQA students on campus: Is higher education making the grade? Journal of Gay \& Lesbian Issues in Education, 3(2/3), 111-117.

Rankin, S., \& Reason, R. (2008). Transformational Tapestry Model: A comprehensive approach to transforming campus climate. Journal of Diversity In Higher Education, 1(4), 262274. doi:10.1037/a0014018

Rankin, S., Weber, G., Blumenfeld, W., \& Frazer, S. (2010). 2010 state of higher education for lesbian, gay, bisexual, \& transgender people. Charlotte, NC: Campus Pride.

Renn, K. A. (2007). LGBT student leaders and queer activists: Identities of lesbian, gay, bisexual, transgender, and queer identified college student leaders and activists. Journal of College Student Development, 48(3), 311-330.

Renn, K. A., \& Bilodeau, B. L. (2005). Leadership identity development among lesbian, gay, bisexual, and transgender student leaders. NASPA Journal, 42(3), 342-367.

Robinson, C. M., \& Spivey, S. E. (2010). Structuring injustice: Partisan politics in the making and unmaking of James Madison University’s Equal Opportunity Policy. Journal of 
Homosexuality, 58(9), 1306-1329. doi: 10.1080/00918369.2011.605742

Russell, G. M., \& Horne, S. G. (2009). Finding equilibrium: Mentoring, sexual orientation, and gender identity. Professional Psychology: Research \& Practice, 40(2), 194-200.

Russell, S. T. (2005). Beyond risk: Resilience in the lives of sexual minority youth. Journal of Gay \& Lesbian Issues in Education, 2(3), 5-18. doi: 10.1300/J367v02n03_02

Ryan, R. (2005). The evolution of an LGBT center at a public institution. New Directions for Student Services, 111, 71-74.

Saldaña, J. (2013). The coding manual for qualitative researchers. London: SAGE.

Sanlo, R. (2000). The LGBT Campus Resource Center Director: The new profession in student affairs. NASPA Journal (National Association of Student Personnel Administrators, Inc.), 37(3), 485-495.

Sanlo, R. (2006). Setting up an LGBT center on your campus. Student Affairs Leader, 34(6), 1-2.

Savin-Williams, R. C. (2005). The new gay teenager. Cambridge, MA: Harvard University Press.

Savin-Williams, R. C. \& Diamond, L. R. (2000). Sexual identity trajectories among sexual minority youth: Gender comparisons. Archives of Sexual Behavior, 29(6), 607-627.

Seelman, K. L., Walls, N. E., Hazel, C., \& Wisneski, H. (2012). Student school engagement among sexual minority students: Understanding the contributors to predicting academic outcomes. Journal of Social Sciences Research, 38, 3-17. doi:

$10.1080 / 01488376.2011 .583829$

Sheets, R. L., \& Mohr, J. J. (2009). Perceived social support from friends and family and psychological functioning in bisexual young adult college students. Journal of Counseling Psychology, 56(1), 152-163. 
Shenton, A., K. (2004). Strategies for ensuring trustworthiness in qualitative research projects. Education for Information, 22, 63-75.

Skelton, T. (1997). Issues of sexuality in the teaching space. Journal of Geography in Higher Education, 21(3), 424-431. doi:10.1080/03098269786273

Smith, B., Mayer, J., \& Fritschler, A. (2008). Closed minds? Politics and ideology in American universities. Washington, DC: The Brookings Institution.

Staff. (2012, November 14). Time to take a stand. The Daily Athenaeum. Retrieved from http://www.thedaonline.com/opinion/editorial-time-to-take-a-stand-

\subsection{0\#.UZZCtkrViOI}

Staff. (2013, February 13). Liberty and justice for all. The Daily Athenaeum. Retrieved from http://www.thedaonline.com/opinion/editorial-liberty-and-justice-for-all-

\subsection{2\#.UZZDMErViOI}

Stotzer, R. (2009). Straight allies: Supportive attitudes toward lesbians, gay men, and bisexuals in a college sample. Sex Roles, 60(1/2), 67-80.

Strauss, S. A. (2005). The legacy of Brown: Implications for equal educational opportunities for gay, lesbian, and bisexual students. Teachers College Record, 107(3), 424-452.

Sullivan, N. (2003). A critical introduction to queer theory. New York, NY: New York University Press.

Transgender Law \& Policy Institute. (2011, November 23). Colleges/universities. Retrieved from http://www.transgenderlaw.org/college/index.htm

University Relations. (4, February 2011). WVU board endorses 2020 strategic framework for the future. Retrieved from http://wvutoday.wvu.edu/n/2011/2/4/wvu-board-endorsesstrategic-plan-oks-7-5-million-in-research-trust-funds 
U.S. Census Bureau. (10, January 2013). West Virginia state and county quickfacts. Retrieved from http:/quickfacts.census.gov/qfd/states/54000.html

Vaccaro, A. (2012). Campus microclimates for LGBT faculty, staff, and students: An exploration of the intersections of social identity and campus roles. Journal of Student Affairs Research and Practice, 49(4), 429-446.

Weber, L. (2009). Understanding race, class, gender and sexuality: A conceptual framework. New York, NY: Oxford University Press.

West Virginia Department of Education. (2013). Office of healthy schools: Policy 4373 electronic manual. Retrieved from http://wvde.state.wv.us/healthyschools/ElectronicManual4373New.html

West Virginia University. (2012a, April 26). Non-discrimination statement. Retrieved from http://diversity.wvu.edu/policies/non_discrimination_statement

West Virginia University. (2012b, July 19). Syllabus statement. Retrieved from http://diversity.wvu.edu/policies/syllabus_statement

West Virginia University. (2013a, January 3). Affirmative action/equal opportunity. Retrieved from http://diversity.wvu.edu/policies/affirmative_action

West Virginia University, (2013b, May 1). Dual career. Retrieved from http://dualcareer.hr.wvu.edu/

West Virginia University. (2013c, May 8). Feedback 2020 Strategic Plan for the Future. Retrieved from http://strategicplan.wvu.edu/the_map/website_feedback

West Virginia University, (2013d, May 15). 2020 Strategic Plan for the Future. Retrieved from http://strategicplan.wvu.edu/the_map 
West Virginia University, (2014, March 15). Syllabus statement. Retrieved from http://diversity.wvu.edu/policies/syllabus_statement

Widlavsky, A. (1997). Between planning and politics: Intellect vs. interaction as analysis. In L. Goodchild, C. Lovell, E. Hines, \& J. Gill (Eds.), Public policy and higher education (pp. 26-45).

WVU College of Law. (2013, February 1). Supreme Court lawyer to address gay rights. Retrieved from http://www.thedaonline.com/opinion/column-a-step-toward-equality-oncampus-1.2689501\#.UZZCU0rViOI

Young, C. (2011, April 4). New employee benefits to include gays. The Daily Athenaeum. Retrieved from http://www.thedaonline.com/news/new-employee-benefits-to-includegays-1.2163944\#.UZTzokrViOJ

Zemsky, B., \& Sanlo, R. L. (2005). Do policies matter? New Directions for Student Services, (111), 7-15. 


\section{Appendix A: Demographic Questionnaire}

Hello! I'd like to learn a little more about you. Please answer the following questions as they best describe your experiences and/or identit(ies). Please give as much information as you feel comfortable. (Use the back of the paper if needed.)

- How do you identify your sex, gender and gender identity?

- How do you identify your sexual orientation?

- How do you identify your race and ethnicity?

- How would you describe your social class and background? Growing up? Currently?

- How would you describe any (dis)ability-related identities that you have?

- How do you identify any religious or spiritual affiliation that you have?

- What is your major, year in school, and goal after graduating?

- In what activities, extra- and co-curricular events, student organizations, or activism have you been involved while at WVU?

- What else do you feel is important in your life and related to your identity that you would like to share? 


\section{Appendix B: Interview Protocol Questions}

The following questions, with follow-ups, will be asked within the interviews.

- What identities do you feel best describe your sexual orientation and gender identity?

- When did you first identify with that identity?

- How has your way of describing yourself changed while at WVU?

- Do you see it changing in the future?

- Tell me about your experiences at West Virginia University as an LGBTQ student.

- Tell me about a time when you felt a sense of belonging or involvement based on your identity.

- Describe for me a time when you felt a sense of isolation, pain, or discomfort based on your identity.

- In what ways do you think your experiences are similar or different from other LGBTQ students at WVU?

- What is your perception of the campus climate related to sexual orientation and gender identity at WVU?

- What is your perception of various parts of campus? Such as your department? Athletic events? Student organizations?

- What is your perception of the climate in off-campus areas? Such as downtown Morgantown? Areas surrounding Morgantown? Local bars or clubs? Other areas?

○ How comfortable do you feel being "out" on campus?

- Tell me about a time at this university when you felt especially aware of specific aspects of your identity.

- Are there any aspects of your identity that seem to stand out more while you've been at WVU than they did within other contexts of your life?

- Can you tell me about an experience in which you felt that any aspect of your identity was made invisible or unacknowledged within the context of this university? 
○ Can you tell me about a time in which you felt that any aspect of your identity was validated or reinforced within the context of this university?

- How do you feel sexual orientation and gender identity have been represented within the curriculum at WVU?

- What role do you see faculty and staff playing in including sexual orientation and gender identity?

- What role do you see administration serving regarding equity and inclusion of sexual orientation and gender identity?

- What is your perception of how the policies at WVU have shaped your experiences within the university?

- How do you see policies at WVU changing in the future?

- How do you see the experiences of WVU students who are LGBTQ changing in the future?

- Has there ever been a time during which you felt silenced or repressed while at WVU?

○ Can you tell me more about what caused that feeling?

- How do you see your time at WVU as having shaped you as you move forward into the future?

- Have you altered any of your decisions based on your experiences as an LGBTQ student at WVU?

○ How do you feel you have impacted WVU during your time here as a student? 
IDENTIT(IES) \& AGENCY 203

\section{Appendix C: Focus Group General Protocol Questions}

The following questions, with follow-ups, will be asked during the focus groups. Similar questions based on the answer given during the individual interviews may be asked as needed. In addition, I may revisit any questions from the interview protocol that were not answered thoroughly through the interviews.

- How was the campus climate at WVU different from what you expected prior to coming to campus?

○ In what ways did it live up to your expectation?

- Tell me about your experiences with academic life at WVU as an LGBTQ student.

- In what ways would you include LGBTQ topics in the curriculum?

- Have you ever altered your behavior in class based on your perception of the climate of that class?

- How supported have you felt in your identity by campus events and speakers?

○ How supported have you felt in your identity by the curriculum, faculty, and classmates in WVU classes?

- Tell me about your experiences as an LGBTQ student with other students, faculty, and staff.

- Can you tell me about a situation where you witness a faculty or staff exhibiting homophobic or heterosexist behaviors? In class? Outside of class?

- Can you tell me about a situation where you witness another student exhibiting homophobic or heterosexist behaviors? In class? Outside of class?

- Tell me about your experiences with student life at WVU as an LGBTQ student.

- What impact have student organizations had on your experiences?

- What impact has your living situation had on your experience as an LGBTQ student? Dorms? Off-campus housing? Other housing situations? 
- In what ways do you think your own multiple identities influence your experience of the campus climate at WVU?

- What do you think the campus climate is like for students who are racial or ethnic minorities at WVU?

○ Students who have differing/(dis)abilities?

○ Students of differing religions?

- Where at WVU do you feel most comfortable being yourself?

Is it an on- or off-campus location? Why?

- What changes would you most like to see WVU make for LGBTQ students? 
IDENTIT(IES) \& AGENCY 205

\section{Appendix D: Focus Group A Protocol Questions}

Tell me about your experiences with panels at WVU.

- Has everyone's experiences with panels been within a WGST class? Yes/No?

- To summarize, give me a one-sentence response to "What was the most positive outcome of participating in panels at WVU?

- To summarize, give me a one-sentence response to "What was the most troubling aspect to participating panels at WVU?"

I'd like to know a little bit about your perceptions of panel audience - the students in the classes - ability to transfer and generalize the information.

- Can you give me any examples that point to transfer and generalization in another academic area? Another class? Another subject matter?

- What about non-academic transfer and generalization?

- What about instructors' discussion and follow-up? Is there any transfer and generalization?

I'd like to know if there is more that happens in the panels than just the question/answer, sort of the "unofficial parts" or the "unintended parts," if you will.

- Can you give me any examples of things that you remember noticing during any panels? Such as non-verbal communication of the students, the instructor, or other panelists?

- Are there other "unofficial" aspects to the panels that contribute to the experience?

- Is there anything that you would describe as "immeasurable" or "unspoken?"

I'd like to know about the ways in which you see within group unity and/or marginalization playing out within the panels.

- Can you give me any examples of a time in which you felt that other panelists were being exclusionary or not inclusive of other identities? How can we deal with this?

- Can you give me an example of how panels have helped to bring identities together or to form a stronger community?

- Do you think there could be a need for a campus-wide panel to address marginalization? What would that look like? 
Within the past semester, we implemented a small training session for participating in panels and began giving out these packets, both hard copy and digitally for participants. Some of your have participated during the trainings and some before. I'd like to know from all of you, what your thoughts are regarding a training.

- Can you give any examples of why a training could be useful?

- Can you give any examples of why a training could be a drawback to the purpose of the panels?

- Can you give any examples of problems, tension or drama that have arisen during panels that could have possibly been alleviated by a training?

Last, I'd like to share a little about my experiences at JMU and how that shaped me to this line of questioning.

- In what ways could you see this happening at WVU?

- What are some differences or similarities?

What else would you like to add?

Journals - I'd like to give you an opportunity to respond privately to the questions asked here through a journal. Feel free to write whatever you like or use creative expression to communicate your thoughts. 
IDENTIT(IES) \& AGENCY 207

\section{Appendix E: Focus Group B Protocol Questions \\ Bisexual, Pansexual and Fluid Sexual Identities}

\section{Identity and language}

- I chose the terms I'm using for this focus group based on the interviews. Many of you expressed reluctance or dissatisfaction by some of the terms of identity surrounding sexual orientation that are available or at least actively used. I'd like to know more about your thoughts surrounding these terms: Pansexual, Bisexual, Fluid Sexual Identity

○ What do you like about each of these terms?

- How do you feel about the language that we currently have to define sexual orientation?

○ Do you feel that it is representative of your experience(s)? Why or why not?

- What are we missing with this language?

- What is unsettling or uncomfortable about any of these terms for you?

\section{Marginalization}

- Have you experienced any within group marginalization based on sexual orientation? - Based on other aspects of identity?

\section{Academic learning}

- The other focus group I conducted was on panels and I am specifically interested in the ways in which you have brought your identit(ies) into the classroom.

- Can you give me an example of a time when you were able to discuss something related to your identity in the classroom? 
- How have you or have you not seen yourself reflected in formal academics?

- When encountered (identity in the classroom), how do you approach this both cognitively and affectively?

- Do these identities ever get voiced in the classroom?

\section{Models of Identity Development}

- Models of identity development have long been critiqued to be modeled off of gay or lesbian populations, and most specifically off of white, male populations. That said, I brought the two examples that are most widely seen as applicable to non-monosexual identities and I would like to get your feedback on it/them.

○ D'Augelli's lifespan model

○ Perhaps another model 
IDENTIT(IES) \& AGENCY 209

\section{Appendix F: IRB-Approved Advertisement}

Hello,

I am a WVU doctoral student within the Department of Curriculum \& Instruction who is conducting research that will take place on campus at West Virginia University. I am looking for lesbian, gay, bisexual, transgender, and queer (LGBTQ; or other non-cisgender/non-heterosexual identified) students to participate in a research project dedicated to understanding the experiences of LGBTQ students and campus climate at WVU.

Your participation will take approximately 60 minutes for an individual interview, with a followup focus group happening at a later time that will take approximately 75-90 minutes and allowing for additional follow-up as needed. Your involvement in this project is completely voluntary and will be kept as confidential as legally possible. You must be 18 years of age or older, have attended WVU for at least one year, and attend WVU currently or recently (within one year) to participate. West Virginia University's Institutional Review Board acknowledgement of this project is on file. This research aims to benefit the campus climate by better understanding student experiences.

\section{If you are interested in participating in this research project, please contact: Melissa Chesanko at (304)319-0112 or by e-mail at mchesanko@gmail.com.}

For the sake of confidentiality, please contact me directly and do not respond on Facebook or other social networking sites.

Please forward this information to any persons who may be interested in participating in this study and have them contact me directly. I appreciate your support for my research.

Best,

Melissa M. Chesanko

Department of Curriculum \& Instruction

P.O. Box 6122 | 602 Allen Hall

Morgantown, WV 26506 
IDENTIT(IES) \& AGENCY 210

\section{Appendix G: IRB-Approved Consent Form}

\section{W- WestVirginiaUniversity.}

Human Research Protocol Only Minimal Risk Consent Form

Without HIPAA

\begin{tabular}{|c|c|}
\hline & $\begin{array}{c}\text { Only Minimal Risk } \\
\text { Consent Information Form (without HIPAA) }\end{array}$ \\
\hline Principal Investigator & Melissa Sherfinski \\
\hline Department & Curriculum \& Instruction \\
\hline Protocol Number & 1307066339 \\
\hline Study Title & $\begin{array}{l}\text { Lesbian, Gay, Bisexual, Transgender, \& Queer (LGBTQ) Student Experiences } \\
\text { and Perception of Campus Climate }\end{array}$ \\
\hline Co-Investigator(s) & Melissa Chesanko \\
\hline Sponsor (if any) & $N / A$ \\
\hline
\end{tabular}

If you have any questions, concerns, or complaints about this research, you can contact:

Melissa Chesanko at (304) 293-9798.

For information regarding your rights as a research subject, to discuss problems, concerns, or suggestions related to the research, to obtain information or offer input about the research, contact the Office of Research Integrity \& Compliance at (304) 293-7073.

In addition if you would like to discuss problems, concerns, have suggestions related to research, or would like to offer input about the research, contact the Office of Research Integrity and Compliance at 304-293-7073.

Introduction

You, have been asked to participate in this research study, which has been explained to you by Melissa Chesanko. This study is being conducted on the campus of West Virginia University by Melissa Chesanko to satisfy doctoral dissertation degree requirements under the supervision of Dr. Melissa Sherfinski in the Department of Curriculum \& Instruction at West Virginia University, without funding or sponsorship.

Purpose(s) of the Study

The specific aims of the study include understanding the experiences of LGBTQ students related to curriculum, policy, roles on campus, and participants' identities. The study also aims to make recommendation on how to improve the experiences of LGBTQ students on campus.

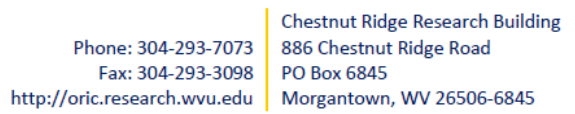

886 Chestnut Ridge Road

Morgantown, WV 26506-6845
P a g e | 1

Subject's Initials

Date 
IDENTIT(IES) \& AGENCY 211

WestVirginiaUniversity.

\author{
Description of Procedures
}

You will be asked to complete a demographic questionnaire. This will take approximately $5-10$ minutes. You do not have to answer all the questions if you do not want to disclose. You will have the opportunity to see the questionnaire before signing this consent form.

This study involves individual and focus group interviews and will take approximately $60-90$ minutes for each of these for you to complete. You may complete both an individual interview and participate in a focus group, or you may choose to just participate in one of these. You will be asked to answer questions about your experiences and perception of campus climate. You do not need to answer any questions that you do not wish to answer. After the focus group, you will have time if you so choose to write any thoughts that you were not able to state during the focus group.

\title{
Discomforts
}

There are no known or expected risks from participating in this study, except for the possible discomfort associated with answering the questions. A list of resources and counseling services will be distributed after the interview to allow students to seek assistance with any possible discomforts that this study brings up.

\section{Benefits}

You may not receive any direct benefit from this study. You may become more self-aware through the interviews and may understand your own experience better within the context of your peers' experiences in the focus groups. The knowledge gained from this study may eventually benefit others.

\section{Financial Considerations}

There are no special fees for participating in this study.

\section{Confidentiality}

Any information about you that is obtained as a result of your participation in this research will be kept as confidential as legally possible. Your research records and test results, just like hospital records, may be subpoenaed by court order or may be inspected by the study sponsor or federal regulatory authorities (including the FDA if applicable) without your additional consent.

In addition, there are certain instances where the researcher is legally required to give information to the appropriate authorities. These would include mandatory reporting of infectious diseases, mandatory reporting of information about behavior that is imminently dangerous to your child or to others, such as suicide, child abuse, etc.

Audiotapes will be kept locked up and will be destroyed as soon as possible after the research is finished. In any publications that result from this research, neither your name nor any information from which you might be identified will be published without your consent.

\begin{tabular}{|c|c|}
\hline $\begin{array}{r}\text { Whone: } 304-293-7073 \\
\text { Fax: } 304-293-3008\end{array}$ & $\begin{array}{l}\text { Chestrut Fidge hevearch Bulding } \\
386 \text { Chestrut Fidge hoad } \\
\text { po Bex } 6845\end{array}$ \\
\hline Hp://ork.reieardh.wwu.edu & Morkartown, WV $26506-6845$ \\
\hline
\end{tabular}

$P a g=12$

Subject's Intiak.

Datr. 
IDENTIT(IES) \& AGENCY 212

\section{W-WestViriniauniversity}

Human Research Protocol Only Minimal Risk Consent Form

Without HIPAA

\section{Voluntary Participation}

Participation in this study is voluntary. You are free to withdraw your consent to participate in this study at any time. Refusal to participate or withdrawal will not affect your class standing or grades, as appropriate and will involve no penalty to you. Refusal to participate or withdrawal will not affect your future care, or your student or employee status at West Virginia University.

In the event new information becomes available that may affect your willingness to participate in this study, this information will be given to you so that you can make an informed decision about whether or not to continue your participation.

You have been given the opportunity to ask questions about the research, and you have received answers concerning areas you did not understand.

Upon signing this form, you will receive a copy.

I willingly consent to participate in this research.

\section{Signatures}

Signature of Subject

$\begin{array}{lll}\text { Printed Name } & \text { Date Time }\end{array}$

The participant has had the opportunity to have questions addressed. The participant willingly agrees to be in the study.

Signature of Investigator or Co-Investigator

\begin{tabular}{lll}
\hline Printed Name & Date & Time
\end{tabular}

\begin{tabular}{r|l} 
& Chestnut Ridge Research Building \\
Phone: 304-293-7073 & 886 Chestnut Ridge Road \\
Fax: 304-293-3098 & PO Box 6845 \\
http://oric.research.wvu.edu & Morgantown, WV 26506-6845
\end{tabular}

Subject's Initials Date 


\section{Appendix H: IRB-Approved LGBTQ Resources}

\section{WVU Carruth Center for Psychological and Psychiatric Services}

Provide psychological, psychiatric, and counseling services for a wide range of student concerns. Offer individual, couples, and group services.

http://well.wvu.edu/ccpps

(304) 293-4431 during business hours (M-F, 8:15 am - 4:45 pm)

(304) 293-4431 after business hours/weekends

\section{Spectrum: WVU's LGBTQ Student Organization}

Spectrum is the official WVU student organization for gender and sexual diversity and supports lesbian, gay, bisexual, transgender, queer (LGBTQ) students and their allies by providing community, social support, education, programming, and opportunities to participate in campus and community activism.

\section{https://www.facebook.com/groups/wvu.qsu/}

Weekly meetings: date/time/location TBA

\section{The Trevor Project}

The Trevor Project is the leading national organization providing crisis intervention and suicide prevention services to lesbian, gay, bisexual, transgender, and questioning youth. Offer a chat line, a phone life line, and volunteer opportunities.

http://www.thetrevorproject.org/

Trevor Lifeline: 1-866-488-7386

\section{Campus Pride}

Campus Pride serves LGBT and ally student leaders and campus organizations in the areas of leadership development, support programs and services to create safer, more inclusive LGBTfriendly colleges and universities. It exists to develop, support and give "voice and action" in building future LGBT and ally student leaders. 
IDENTIT(IES) \& AGENCY 214

\section{Appendix I: D’Augelli's Model of Identity Development}

\section{D'Augelli's Model of Lesbian, Gay, and Bisexual Identity Development}

D'Augelli identified six interactive processes (not stages) involved in lesbian, gay, and bisexual identity development.

\section{Exiting heterosexual identity}

Recognition that one's feelings and attractions are not heterosexual as well as telling others that one is lesbian, gay, or bisexual.

\section{Developing a personal lesbian/gay/bisexual identity status}

A "sense of personal socio-affectional stability that effectively summarizes thoughts, feelings, and desires" (D'Augelli 1994). One must also challenge internalized myths about what it means to be gay, lesbian, or bisexual. Developing a personal identity status must be done in relationship with others who can confirm ideas about what it means to be nonheterosexual.

\section{Developing a lesbian/gay/bisexual social identity}

Creating a support network of people who know and accept one's sexual orientation. Determining people's true reactions can take time. Reactions may also change over time and with changing circumstances.

\section{Becoming a lesbian/gay/bisexual offspring}

Disclosing one's identity to parents and redefining one's relationship after such disclosure. D'Augelli noted that establishing a positive relationship with one's parents can take time but is possible with education and patience. This developmental process is particularly troublesome for many college students who depend on their parents for financial as well as emotional support.

\section{Developing a lesbian/gay/bisexual intimacy status}

This is a more complex process than achieving an intimate heterosexual relationship because of the invisibility of lesbian and gay couples in our society. "The lack of cultural scripts directly applicable to lesbian/gay/bisexual people leads to ambiguity and uncertainty, but it also forces the emergence of personal, couple-specific, and community norms, which should be more personally adaptive" (D'Augelli, 1994).

\section{Entering a lesbian/gay/bisexual community}

Making varying degrees of commitment to social and political action. Some individuals never take this step; others do so only at great personal risk, such as losing their jobs or housing.

D'Augell, A. R. (1994). Identity development and sexual orientation: Toward a model of lesbian, gay, and bisexual development. In E. J. Trickett, R. J. Watts, \& D. Birman (Eds.), Human diversity: Perspectives on people in context (pp. 312-333). San Francisco: Jossey-Bass.

Adapted from:

Evans, N. J., Forney, D. S., \& Guido-DiBrito, F. (1998). Student development in college: Theory, research, and practice (pp. 96-98). San Francisco: Jossey-Bass. 